University of South Florida

DIGITAL COMMONS

Digital Commons @ University of

@ UNIVERSITY OF SOUTH FLORIDA

South Florida

KIP Articles

KIP Research Publications

January 2005

\title{
Conservation of Texas spring and cave salamanders (Eurycea)
}

Paul T. Chippindale

Andrew H. Price

Follow this and additional works at: https://digitalcommons.usf.edu/kip_articles

\section{Recommended Citation}

Chippindale, Paul T. and Price, Andrew H., "Conservation of Texas spring and cave salamanders

(Eurycea)" (2005). KIP Articles. 5771.

https://digitalcommons.usf.edu/kip_articles/5771

This Article is brought to you for free and open access by the KIP Research Publications at Digital Commons @ University of South Florida. It has been accepted for inclusion in KIP Articles by an authorized administrator of Digital Commons @ University of South Florida. For more information, please contact digitalcommons@usf.edu. 


\title{
Conservation of Texas Spring and Cave Salamanders (Eurycea)
}

\author{
PAUL T. CHIPPINDALE AND ANDREW H. PRICE
}

Many species of endemic aquatic organisms inhabit the springs and water-filled caves of the Edwards Plateau region of central Texas. Most have limited distributions, and their existence is dependent upon the availability of clean water from subterranean sources (the Edwards Aquifer and associated aquifers). The Edwards Plateau is composed of uplifted karst limestone; water percolates through the limestone, recharges the underground reservoirs, and re-emerges from a large number of springs. The biggest and most well known of these springs are located along the southern and eastern margins of the Edwards Plateau (the Balcones Escarpment) and include Barton Springs in the city of Austin (Travis County); San Marcos Springs in the city of San Marcos, southwest of Austin in Hays County; and Comal Springs in the city of New Braunfels, northeast of San Antonio in Comal County. North of the Colorado River (which flows through the city of Austin), a smaller aquifer system supplies water to the springs, creeks, and caves of Travis, Williamson, and Bell counties at the northeastern edge of the plateau. Sweet (1982) provides a useful overview of the hydrogeology of the region; also see Abbott (1975), various authors in Abbott and Woodruff (1986), and Veni (1988).

Throughout the southern and eastern portions of the Edwards Plateau, numerous populations of salamanders of the genus Eurycea are known, and all are restricted to caves with water and/or the vicinity of spring outflows (Hamilton, 1973; Sweet, 1982, 1984; Chippindale, 2000; Chippindale et al., 2000). Here we include in the genus Eurycea two species formerly assigned to the genus Typhlomolgc, based on the phylogenetic work conducted by Chippindale et al. (2000) and discussed below. Nearly all populations of Eurycea in central Texas are paedomorphic (i.e., attain reproductive maturity without undergoing metamorphosis). The only known exceptions are a few transforming populations in mesic canyons of the Hill Country, in the southwestern Edwards Plateau (Bogart, 1967; Sweet, 1977b). All members of the group are aquatic, although transformed individuals may venture short distances onto land (Sweet, 1977b, 1978b).

\section{Taxonomic History}

The taxonomic history of the Texas Eurycea is somewhat complicated. Chippindale et al. (2000) provide a systematic revision that includes a detailed history and list of synonymies as well as the description of three new species, and Chippindale (2000) outlines past and current perspectives on species diversity in the group. Hillis et al. (2001) describe another new species (Austin blind salamanders /Eurycea waterlooensis $($ ) and provide further taxonomic revisions. Here we provide a brief summary of species that were recognized prior to molecular-based systematic studies of the group.

In 1895, large aquatic plethodontid salamanders that exhibited highly cave-associated morphological features (e.g., lack of pigmentation, wide, flattened skulls, vestigial eyes, elongated limbs, and reduced numbers of vertebrae) were discovered in the outflows of a 58-meter-deep artesian well drilled at San Marcos, Hays County. Stejneger (1896) described this species as Typhlomolge rathbuni (Texas blind salamanders). Decades later, the status of the genus Typhlomolge became controversial when Mitchell and Reddell (1965) and Mitchell and Smith (1972) provided evidence that $T$. rathbuni should be considered a member of the genus Eurycea. This view was contradicted by Potter and Sweet (1981), who argued for continued recognition of the genus Typhlomolge as distinct from Eurycea. However, molecular phylogenetic evidence supports synonymization of Typhlomolge under Eurycea (Chippindale, 1995, 2000; Chippindale et al., 2000; Hillis et al., 2001; see discussion below).

Bishop and Wright (1937) described the next member of the group, Eurycea neotenes (Texas salamanders; see also Bruce, 1976), from a spring at Helotes, Bexar County, north of San Antonio. Until recently, nearly all populations of spring and cave Eurycea in the Edwards Plateau region were assigned to this species; now (as discussed below) Texas salamanders are restricted in distribution to springs in the general area of the type locality (Chippindale et al., 2000). Eurycea nana (San Marcos salamanders) were described by Bishop (1941a; see also B.C. Brown, 1967b) from San Marcos Springs, Hays County. Despite confusion in the literature regarding the distribution of this species, it is clear that these animals occur only at the type locality (Chippindale et al., 1998). Smith and Potter (1946; see also B.C. Brown, 1967a) described E. latitans (Cascade Caverns salamanders) from Cascade Caverns, Kendall County (northeast of San Antonio), and Burger et al. (1950) described E. pterophila (Fern Bank salamanders) from 
Fern Bank Springs, Hays County (north of San Marcos). Baker (1957) described E. troglodytes (Valdina Farms salamanders) from Valdina Farms Sinkhole, a deep and extensive cave in Medina County in the southwestern Edwards Plateau region. Mitchell and Reddell (1965) described E. tridentifera (Comal blind salamanders, which exhibit a strongly cave-associated morphology second only to that of the members of the formerly recognized genus Typhlomolge) from Honey Creek Cave, Comal County. Sweet (1977a, 1978b, 1984) later extended the distribution of this species to include additional caves in Comal and Bexar counties, a move supported by the work of Chippindale et al. (2000).

Potter (1963), in a master's thesis, described a second species of Typhlomolge, T. robusta (Blanco blind salamanders), based on a single specimen collected in 1951 from a hole drilled in the dry bed of the Blanco River just east of San Marcos. However, this description cannot be considered valid under current rules of zoological nomenclature. Technically, Longley (1978) must be credited with an accidental description of the species. Potter and Sweet (1981) redescribed T. robusta and argued for continued recognition of the genus Typhlomolge. A description recently was published of a third species, Austin blind salamanders ( $E$. waterlooensis), most closely related to E. rathbuni and E. robusta (Hillis et al., 2001).

Wake (1966) assigned plethodontids of the genera Eurycea and Typhlomolge (plus the genera Gyrinophilus, Haideotriton, Hemidactylium, Pseudotriton, Stereochilus, and Typhlotriton) to the tribe Hemidactyliini, within the subfamily Plethodontinae. However, relationships among and within the genera and species boundaries in the Hemidactyliini remain uncertain. With respect to the central Texas hemidactyliines, most authors prior to the work of Sweet (1977a, 1978a,b, 1982, 1984) recognized at most six species of central Texas Eurycea (E. latitans, E. nana, E. neotenes, E. pterophila, E. tridentifera, and E. troglodytes) and one species of Typhlomolge ( $T$. rathbuni; the recognition of $T$. robusta did not become widespread until Potter and Sweet published their 1981 redescription). Until recently, nearly all workers have regarded E. neotenes (Texas salamanders) as widely distributed in the Edwards Plateau region and assigned the majority of known populations to this species (e.g., Bishop, 1943; B. C. Brown, 1950, 1967c; Schmidt, 1953; Conant, 1958a, 1975; Baker, 1961; Mitchell and Smith, 1972; Sweet, 1977b, 1978a,b, 1982, 1984; Behler and King, 1979; Dixon, 1987; Conant and Collins, 1991; Petranka, 1998). However, several authors suggested that additional species remained to be discovered in the group (e.g., B.C. Brown, 1950, 1967c; Baker, 1961; Bogart, 1967; Mitchell and Smith, 1972).

Sweet (1977a,b, 1978a,b, 1982, 1984) conducted comprehensive studies of geographic distribution and morphological variation in the group. He reduced the number of recognized species of central Texas Eurycea to three: E. neotenes (which he viewed as widespread in springs and caves throughout the Edwards Plateau); E. nana (which he restricted to San Marcos and perhaps Comal Springs); and E. tridentifera (from caves of the Cibolo Sinkhole Plain of Comal and Bexar counties; Sweet also believed that this species might range underground into the Southwestern Plateau region). Sweet (1978a, 1984) also suggested that the population from Barton Springs, Travis County, was a distinct species, but did not formally describe it (this population was described as E. sosorum [Barton Springs salamanders] by Chippindale et al., 1993). Sweet (1978b) considered E. pterophila conspecific with $E$. neotenes, and Sweet (1978a, 1984) viewed E. latitans and E. troglodytes as hybrids between $E$. neotenes and a subterranean taxon, most likely $E$. tridentifera. As described above, Potter and Sweet (1981) also recognized $T$. rathbuni and $T$. robusta.

\section{Current Views of Species Diversity in the Central Texas Eurycea}

Assessments of species boundaries in the central Texas Eurycea based on morphology alone have been complicated by three factors. First (as described above), nearly all members of the group are paedomorphic, retaining larval morphologies throughout their lives. Thus, adult characters that typically are used to differentiate and diagnose species of plethodontids are not available for examination (although larval morphological characters have been used successfully to distinguish some species in the group; e.g., Chippindale et al., 1993, 2000). Second, plethodontid salamanders often exhibit morphological evolutionary stasis despite long periods of isolation and evolutionary divergence. This has resulted in the existence of numerous morphologically cryptic species in the family (e.g., Wake et al., 1983; Highton et al., 1989, 1990; Larson and Chippindale, 1993; Highton, 2000), and the Texas Eurycea contain several noteworthy examples (Chippindale et al., 2000). Third, the history of the central Texas hemidactyliines is likely to have involved repeated instances of isolation in islands of aquatic habitat followed by convergent or parallel morphological evolution, especially in caves (Chippindale et al., 2000; Wiens et al., unpublished data). As has been the case for other groups of plethodontids (reviewed by Larson and Chippindale, 1993; Chippindale, 2000; Highton, 2000), reliable assessments of species boundaries in the central Texas Eurycea have required application of molecular techniques.

Chippindale $(1995,2000)$ and Chippindale et al. (1993, 1998,2000 ) used allozyme electrophoresis, sequencing of mitochondrial DNA, analysis of other molecular data, and, in some cases, external morphology and osteology to reconstruct the phylogeny of the central Texas hemidactyliines and reassess species boundaries in the group. Chippindale et al. (2000) provide a systematic revision of the central Texas Eurycea and conclude the following:

1. The central Texas hemidactyliines (Eurycea and Typhlomolge) represent a monophyletic group within the genus Eurycea. Therefore, the genus Typhlomolge must be placed in the synonymy of Eurycea because it is inappropriate for one genus to be nested within another under the Linnean system of classification.

2. Levels and patterns of divergence and phylogenetic relationships in the group are inconsistent with recognition of E. neotenes as widespread within the Edwards Plateau, and indicate the presence of numerous evolutionarily distinct lineages. Sweet's (1978a, 1984) hypothesis of a hybrid origin for $E$. latitans and $E$. troglodytes was rejected. Therefore, Chippindale et al. (2000) make the following taxonomic recommendations with respect to previously recognized species:

a. Eurycea neotenes is restricted in distribution to springs in the vicinity of the type locality in Bexar and Kendall counties.

b. Eurycea nana, E. sosorum, E. tridentifera, E. (formerly Typhlomolge) rathbuni and E. (formerly Typhlomolge) robusta are valid species and should continue to be recognized. 
c. The names E. latitans, E. troglodytes, and E. pterophila should be resurrected and applied to populations at the type localities. However, the range of each probably extends beyond the type locality. Eurycea pterophila occurs in springs and caves of the Blanco River drainage of Blanco, Hays, and Kendall counties, although evidence for its status as a distinct species should be considered relatively weak. Chippindale et al. (2000) assigned numerous populations from the southeastern Edwards Plateau to the E. latitans complex, but emphasized that species boundaries in this group remain to be investigated more thoroughly. Chippindale et al. (2000) also recognized the $E$. troglodytes complex encompassing all populations from the southwestern portion of the Edwards Plateau. This group is well supported as monophyletic and exhibits deep genetic divergences among populations.

3. There remain additional, previously unrecognized species in the group. Populations from northeast of the Colorado River (the "northern" group) are extremely divergent from all others based on a variety of nuclear and mitochondrial molecular data sets, consistent with the presumed great age of the Colorado's entrenchment. Isolation of the northern populations probably occurred millions of years ago. Within the northern group, there are at least three distinct species, which Chippindale et al. (2000) formally described as E. tonkawae (Jollyville Plateau salamanders; Travis and Williamson counties), E. naufragia (Georgetown salamanders; Williamson County), and E. chisholmensis (Salado salamanders; Bell County). Jollyville Plateau salamanders occur within the rapidly growing Austin metropolitan area; the areas northeast of Austin that are inhabited by Jollyville Plateau salamanders and Georgetown salamanders are undergoing rapid urbanization. Very recently, a blind subterranean species, E. waterlooensis (Austin blind salamanders), was discovered in the Barton Springs Aquifer beneath the southern portion of the city of Austin, and a formal description was published (Hillis et al., 2001). Based on morphological and DNA evidence, this new species is closely related to E. rathbuni (and presumably E. robusta) and is partially sympatric with E. sosorum, to which it is much more distantly related. Many undescribed species probably exist within the southwestern group (E. troglodytes complex), and Chippindale et al. (2000) identified two potential candidates within the southeastern group that probably are distinct species from Pedernales Springs (Travis County) and Comal Springs (Comal County). Molecular work on these species groups is in progress and it is likely that additional species will be described in the near future.

\section{Conservation Status of the Central Texas Eurycea}

Several Texas hemidactyliines currently enjoy protection at the state and/or federal level. Eurycea (formerly Typhlomolge) rathbuni was federally listed as endangered in 1967, prior to the final version of the Endangered Species Act (ESA) in 1973, followed by state listing in 1974. San Marcos salamanders (E. nana) were listed as a threatened species by the state of Texas in 1977, followed by federal listing under the ESA in 1980. The history of the conservation status of Barton Springs salamanders
(E. sosorum) is especially interesting, if not sobering; one popular account can be found in Stearns and Stearns (1999). Barton Springs salamanders are known only from Barton Springs, located in the Zilker Park recreation area of downtown Austin. Most of the population inhabits the outflows of Parthenia Springs that fill Barton Springs pool, an extremely popular semi-natural community swimming area for over a century (Brune, 1981). The propriety of including the Barton Springs salamander in the nascent Balcones Canyons Conservation Plan was brought to the attention of the U.S. Fish and Wildlife Service (USFWS) as early as 1990 . Concerns over increased development within the Barton Springs watershed and the concomitant decline in water quality led to the establishment of a coalition of local citizens known as the Save Our Springs Alliance (S.O.S.). This group succeeded in placing a restrictive water quality ordinance on the ballot in 1992, and following a postponement of the referendum scheduled for the preceding May by the Austin City Council, the measure passed in August by a 2:1 margin of those citizens voting ( $20 \%$ of those eligible). A petition was filed in January 1992 to list Barton Springs salamanders as an endangered species under the ESA, and this generated considerable controversy at both local and national levels. The species was described by Chippindale et al. (1993), and although they saw no conflict between human use of the pool and continued survival of the salamander, swimmers feared that listing might jeopardize the recreational use of Barton Springs. This fear was fueled by those in favor of development in the Barton Springs watershed; listing of the salamander posed a major threat to planned growth in the region because development held the potential for increased siltation and impervious cover that could threaten recharge of the Barton Springs segment of the Edwards Aquifer. While the petition for listing was being considered by the USFWS, considerable local support arose for the salamander as a totem for the collective environmental protection efforts in the Austin region. Posters, $t$-shirts, and frisbees appeared celebrating the salamander. At the same time, many of those interested in the protection of the salamander joined forces with city of Austin personnel to formulate salamander-friendly methods for pool maintenance (for many years prior to the recognition of Barton Springs salamanders as a distinct species the city had drained the pool and used chlorine and high-pressure hoses to clean algae from pool surfaces).

A proposal to list Barton Springs salamanders as a federally listed endangered species was published in February 1994 (O'Donnell, 1994). A storm of controversy ensued, leading the business community and development interests to file a lawsuit in Hays County District Court successfully challenging the legality of the S.O.S. ordinance and prompting the Texas Legislature to enact laws exempting several large developments within the Austin extraterritorial jurisdiction and Barton Springs watershed from water quality regulations. At the same time, the USFWS extended the deadline for final action on the proposed rule (normally a year following a proposal to list) to August 1995. Congress, prompted in part by the Texas delegation, enacted a moratorium on listing actions in April 1995 and eliminated funding to conduct final listings. A Federal Court upheld a lawsuit by the S.O.S. Legal Defense Fund charging the USFWS with failure to enforce the ESA in this case and issued an order at the end of November 1995 requiring that a final determination of listing status be made within 14 days. A stay was granted pending an appeal by the USFWS on the grounds that Congressional actions prevented the agency from complying with the order. The listing moratorium was lifted at the end of 
April 1995 by Presidential decree, and a new public comment period was closed in mid-July by U.S. District Court order.

At the local level, the city of Austin and the Texas Parks and Wildlife Department (TPWD) formed the Aquatic Biological Advisory Team (ABAT) in 1994, a group of five experts charged with independently reviewing the listing proposal and salamander issues. ABAT issued a final report (Bowles, 1995) recommending a regional approach to salamander conservation in the Austin area. As a result of this report, a "Barton Springs Salamander Conservation Agreement and Strategy" was drafted and signed in August 1996 by representatives of three state agencies (TPWD, Texas Natural Resource Conservation Commission, and Texas Department of Transportation) and the USFWS. The Barton Springs Salamander Conservation Team (BSSCT), consisting of staff from these agencies and other individuals with knowledge and expertise on relevant issues, was formed to draft a plan to implement the recommendations of the ABAT report, and the proposal to list Barton Springs salamanders as a federally endangered species was withdrawn by the USFWS in September (Helfert, 1996). The S.O.S. ordinance was reinstated by the Third District Court of Appeals in August 1996 as well. The activities of BSSCT were abruptly terminated by the state agencies involved when the U.S. Tenth District Court ruled that the withdrawal of the listing proposal violated the ESA and ordered a listing decision within 30 days. The Barton Springs salamander was listed as federally endangered at the end of April 1997 (O'Donnell, 1997).

In recent years, the city of Austin has exhibited great dedication to the conservation of both the Barton Springs salamanders and the newly described Jollyville Plateau salamander, and its efforts represent a model for conservation of endangered species in urban areas. Swimmers continue to coexist with Barton Springs salamanders at Barton Springs, and available evidence indicates that protection of water resources for salamanders is consistent with protection of water resources for human use (USFWS, 1998a). The city is currently engaged in a regional planning effort, including the acquisition of sensitive tracts of land within the recharge and contributing zones for Barton Springs (Barton Springs Salamander Recovery Plan, in preparation). The city recently completed a comprehensive two-year study of water quality parameters and populations of Jollyville Plateau salamanders (Davis et al., 2001). To address threats to Jollyville Plateau salamanders, the USFWS recently established a task force involving the city of Austin, several state and county agencies, and private groups (R. Hansen, personal communication). The recent, surprising discovery of another endemic species of Eurycea from the aquifer beneath southern Austin (Hillis et al., 2001) adds a new dimension to salamander conservation efforts in the region, but the city of Austin is already working with this species and establishing a group in captivity (Hillis et al., 2001; R. Hansen, D. A. Chamberlain personal communication).

One other species of central Texas hemidactyliine has been the subject of a petition for federal listing as an endangered species-Blanco blind salamanders (E. robusta); these cave dwellers have been found only in the San Marcos pool of the Edwards Aquifer (Russell, 1976; Chippindale et al., 1990). However, the petition, filed in 1995, was rejected in 1998 due to insufficient information indicating that listing of this species is warranted (O'Donnell, 1998).

Several species of central Texas Eurycea (Cascade Caverns salamanders, San Marcos salamanders, Comal blind salamanders, Barton Springs salamanders, Texas blind salamanders, and Blanco blind salamanders) are protected by the state of
Texas. A permit is required to possess or collect individuals of these species, but importantly, these measures (as do most state regulations) specifically omit any form of habitat protection. Valdina Farms salamanders may already be extirpated at the type locality, Vaidina Farms Sinkhole, due to human-induced flooding of the cave and introduction of surface predators (Veni and Associates, 1987; Chippindale et al., 2000; G. Veni, personal communication).

\section{Future Prospects}

The Edwards Plateau region of central Texas is inhabited by an ancient and diverse assemblage of hemidactyliine plethodontid salamanders of the genus Eurycea. Given the recent taxonomic revisions by Chippindale et al. (2000) and Hillis et al. (2001), re-evaluation of their conservation status is in order. Most of the recognized species have extremely restricted distributions, and many distinct species remain to be described formally. All species in the group are dependent on the maintenance of water quality and adequate water levels in the Edwards and associated aquifers, and many (Cascade Caverns salamanders, Georgetown salamanders, Fern Bank salamanders, Texas blind salamanders, Blanco blind salamanders, Austin blind salamanders, Barton Springs salamanders, Jollyville Plateau salamanders, Comal blind salamanders, and several putative, undescribed species) occur in or near the metropolitan areas of Austin and San Antonio. This part of Texas is undergoing tremendous development and urban growth (USFWS, 1995b; Rowell, 1999; Barton Springs Salamander Recovery Plan, in preparation) and the water supply for the entire city of San Antonio comes exclusively from the Edwards Aquifer. Based on recent projections for use of waters of the southern Edwards Aquifer, Comal Springs (inhabited by a probable new species of Eurycea as well as federally endangered species of fishes and invertebrates) was expected to cease flowing by 2000 if pumping continued to increase at historical rates and a drought of record were to occur (Technical Advisory Panel, 1990; Comal Springs ceased flowing from 13 June to 4 November 1956, the sixth year of a sevenyear drought). San Marcos Springs (home to San Marcos salamanders, Texas blind salamanders, and numerous endangered species of invertebrates, fishes, and plants) is expected to go dry by 2010 under similar scenarios (Klemt et al., 1979). Water quality and quantity within the Barton Springs segment of the Edwards Aquifer continues to decline (Barton Springs/Edwards Aquifer Conservation District, 1997; Mahler and Lynch, 1999; Mahler et al., 1999; Rowell, 1999), and much of the proximate recharge zone for Barton Springs is already developed (Hauwert et al., 1998).

North of the Colorado River, water supplies for springs and caves inhabited by the newly described species Jollyville Plateau salamanders, Georgetown salamanders, and Salado salamanders are derived from small, localized aquifers that are highly subject to pollution and depletion (see references in Rowell, 1999). Not surprisingly, Davis et al. (2001) found an inverse relationship between the physicochemical integrity of spring sites and abundance of Jollyville Plateau salamanders. Large quantities of foam of unknown chemical composition have been observed flowing from springs at the type locality of Jollyville Plateau salamanders, and some individuals recently collected at this locality exhibit spinal deformities. As Rowell (1999) and Chippindale et al. (2000) emphasized, development in the northern region can be expected only to increase. The human population of Travis, Williamson, and Bell counties (encompassing the entire range of 
the five species of central Texas Eurycea described since 1990) was stable at about 650,000 people for the first seven decades of the twentieth century; that number has more than doubled in the last two decades. Groundwater levels in artesian zones in this region declined by more than $30 \mathrm{~m}$ between 1975 and 1985 (see references in Rowell, 1999), and total water consumption in these three counties has doubled in these two decades and has been projected to increase 6.5 times by the year 2050 . Strategies for the protection of the northern species must be implemented quickly to ensure their survival. The city of Austin has been proactive in this respect, and has instituted an intensive monitoring program for Jollyville Plateau salamanders, with the goal of developing a protection plan whether or not federal or state listing of this species occurs.

If the diversity of central Texas Eurycea is to be preserved, it is essential that the springs and caves inhabited by these species and the aquifers that supply water to these habitats be protected. Doing so represents a major challenge. In the face of unprecedented urban growth along the southern and eastern margins of the Balcones Escarpment during the last decade and the unmitigated demand for human water consumption throughout the central Texas region, we are not optimistic. We can find no compelling reason to obviate the words of Gunnar Brune, who said, " The story of Texas' springs is largely a story of the past. In the not very distant future most of Texas' springs will exist only in a legend of a glorious past ... destroyed by pollution and overpopulation" (Brune, 1981). Our view and challenge to our fellow Texans remains closer to the final paragraph in Morowitz (1991), " As human population goes up, biological species diversity goes down. We might be able to moderate the rate of decline, but we cannot fend off the inevitable. As species number goes down, we might, of course, change our valuation system and subsequent responses; they are, after all, cultural, not metaphysical. The answer to 'How much is a species worth?' is 'What kind of a world do you want to live in?" The experiment in central Texas is well underway.

\section{Summary}

Recent studies of central Texas salamanders of the genus Eurycea have revealed extensive geographic and genetic fragmentation and have greatly increased the number of recognized species. Most species have very restricted distributions in caves and spring waters associated with the aquifers of the Edwards Plateau region, and the health of the many aquifer-dependent ecosystems is threatened by human activities. Several species of central Texas Eurycea are the focus of conservation plans at the local, state, and/or federal levels, and intensive efforts will be necessary to preserve the diversity in the group. 
Chamberlain's Dwarf Salamander (Eurycea chambertaini)

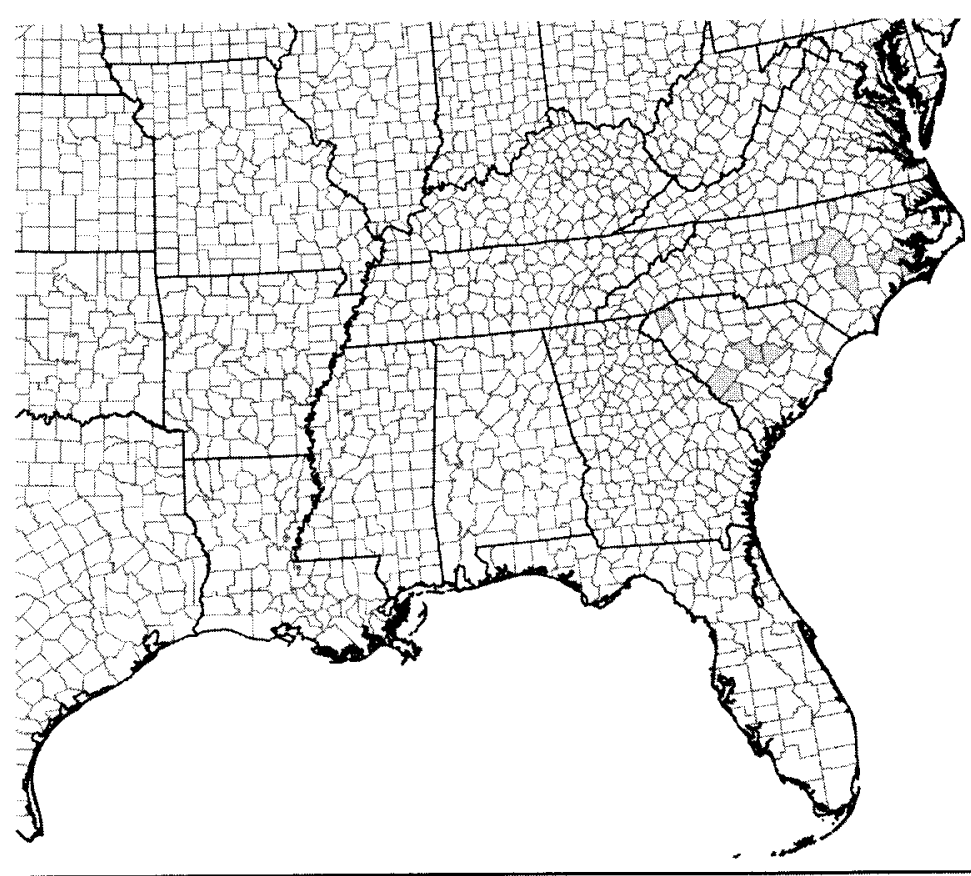

M. Longevity. Unknown.

N. Feeding Behavior. Unknown, but this is a species with a highly projectile (boletoid) tongue, and is therefore likely to be a sit-and-wait predator. Prey items eaten by adults are probably similar to those consumed by dwarf salamanders; these include earthworms, several kinds of insects, spiders, pseudoscorpions, mites, ticks, and millipedes (Carr 1940; McMillan and Semlitsch, 1980; Powders and Cate, 1980).

O.Predators. Unknown, but likely predators probably include crayfish, predaceous insects, large spiders, small snakes, and birds.

P. Anti-Predator Mechanisms. Unknown, but probably limited to immobility coupled with cryptic coloration.

Q. Diseases. Unknown.

R. Parasites. Unknown.

\section{Conservation.}

Chamberlain's dwarf salamanders have no legal protection but, with the possible and likely exception of some local populations, are probably not in any immediate jeopardy. Protection of larval and adult habitats (springs, seepage areas, and small streams in forested areas) is important for the species' survival.

\section{Larvae/Metamorphosis.}

i. Length of larval stage. According to Brimley (1923), most hatching occurs in March with metamorphosis occurring 2-3 mo later.

ii. Larval requirements.

a. Food. Unknown but presumably similar to that of congeneric dwarf salamanders (Carr, 1940; Taylor et al., 1988), their putative relative; items consumed include amphipods, ostracods, cladocerans, and chironomid larvae.

b. Cover. As reported by Brimley (1923) for populations in North Carolina, leaf-choked seepage areas and spring runs presumably provide adequate cover for larvae.

iii. Larval polymorphisms. Hatchling larvae of Chamberlain's dwarf salamanders have an average of 4.5 (1-7) dorsal spots; the number of spots declines over the larval period (Harrison and Guttman, 2003). Spots are absent in hatchling dwarf salamander larvae.

iv. Features of metamorphosis. Unknown.

v. Post-metamorphic migrations. Unknown, but probably limited to immediately adjacent upland habitats.

D. Juvenile Habitat Requirements. Similar to those of adults.

E. Adult Habitat Requirements. Chamberlain's dwarf salamanders are a semi-terrestrial species. Information from 33 records in the files of the North Carolina State Museum of Natural History (A. Braswell, personal communication) indicates that they normally occupy the mar- gins of streams or seepages $(70 \%)$ or floodplain or pond sites $(30 \%)$.

F. Home Range Size. Unknown.

G. Territories. Unknown.

H. Aestivation/Avoiding Desiccation. Unknown. However, in North Carolina, Brimley (1923) apparently did not find Chamberlain's dwarf salamanders during the period from late spring to early autumn. Presumably, the salamanders were in underground retreats, but whether or not they were aestivating remains to be determined.

I. Seasonal Migrations. Unknown, but probably do not occur.

J. Torpor (Hibernation). Unknown. However, Brimley (1923) reported that he often found Chamberlain's dwarf salamanders from mid-October to late April, most frequently during the winter breeding season.

K. Interspecific Associations/Exclusions. Chamberlain's dwarf salamanders co-occur with congeneric dwarf salamanders at two locations: the Savannah River site in Barnwell County and a site in Allendale County, both in South Carolina (Harrison and Guttman, 2003).

L. Age/Size at Reproductive Maturity. The smallest mature adult measured by Harrison and Guttman (2003) is $22 \mathrm{~mm}$ SVL. Folkerts (1971) studied specimens of Chamberlain's dwarf salamanders (identified as E. quadridigitata) from the upper Piedmont of South Carolina and measured adults or subadults from 20.5-28.7 SVI.
Eurycea chisholmensis Chippindale, Price, Wiens, and Hillis, 2000

SALADO SALAMANDER

Paul T. Chippindale

\section{Historical versus Current Distribution.}

Salado salamanders (Eurycea chisholmensis) were described by Chippindale, Price, Wiens, and Hillis (2000) from springs at Salado, Bell County, Texas. Prior to the work of Chippindale (1995) and Chippindale et al. (2000), this population was known from a single juvenile specimen and was considered a peripheral isolate of Texas salamanders (E. neotenes; Sweet, 1978a, 1982). Salado salamanders are members of the "northern group" of Chippindale $(1995,2000)$ and Chippindale et al. (2000); this monophyletic group occurs northeast of the Colorado River in the Edwards Plateau region of central Texas. Based on molecular markers, this and other northern species are extremely divergent from $E$. neotenes and other Eurycea from the southern Edwards Plateau region (Chippindale et al., 2000).

\section{Historical versus Current Abundance.}

Almost nothing is known of the historical abundance of this species. Chippindale et al. (2000) collected most specimens in 1989-91, when several could sometimes be found on a single visit. Between 1991 and 1998 , no additional animals could be located despite more than 20 visits to the type locality; one specimen was found in August 1998. 


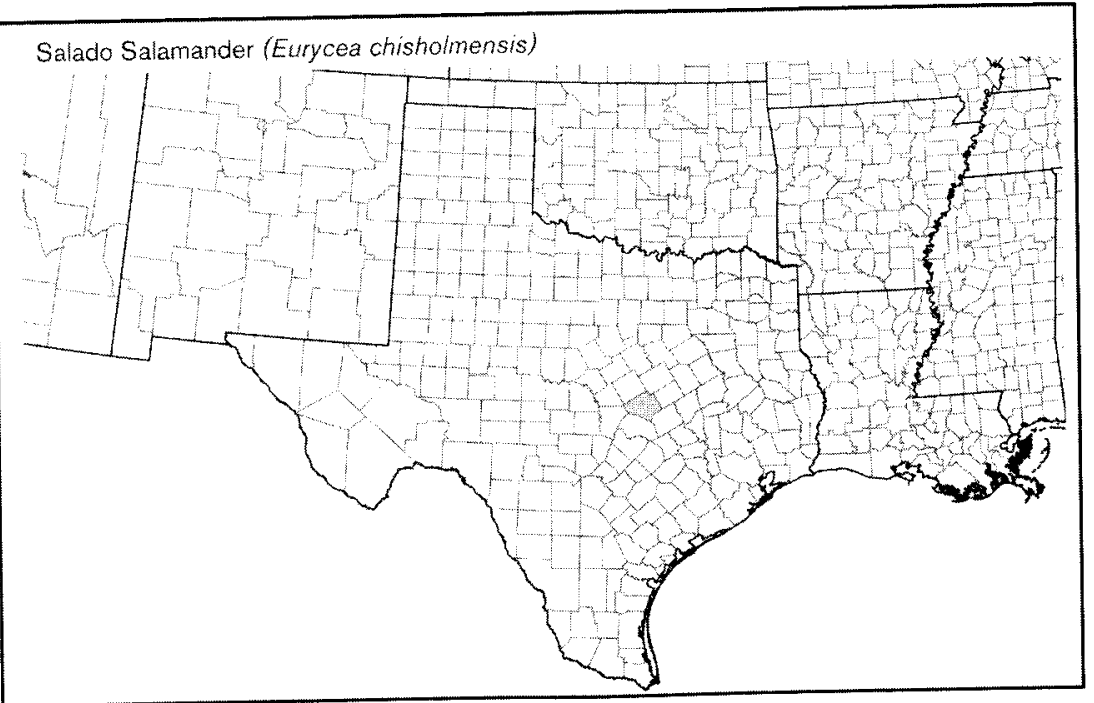

3. Life History Features.

A. Breeding. Reproduction is aquatic.

i. Breeding migrations. Unlikely to occur.

ii. Breeding habitat. The aquatic habitats of adults.

\section{B. Eggs.}

i. Egg deposition sites. Unknown; some other spring-dwelling species of central Texas Eurycea are thought to deposit eggs in gravel substrates.

ii. Clutch size. Unknown.

C. Larvae/Metamorphosis. Salado salamanders are paedomorphic and natural metamorphosis is unknown.

D. Juvenile Habitat. Probably similar to adult habitat.

E. Adult Habitat. Completely aquatic. Salado salamanders are known only from the immediate vicinity of spring outflows, under rocks, and in gravel substrate. Water temperature in springs of the Edwards Plateau is relatively constant throughout the year and typically ranges from $18-20^{\circ} \mathrm{C}$, or slightly warmer near the fault zone at the Plateau's edge (Sweet, 1982). Sweet (1982) provided a comprehensive distributional analysis of the central Texas Eurycea and discussed hydrogeology of the region in relation to salamander distribution.

F. Home Range Size. Unknown.

G. Territories. Unknown.

H. Aestivation/Avoiding Desiccation. Unknown.

I. Seasonal Migrations. Unlikely to occur, although there may be seasonal variation in surface versus subsurface habitat use.

J. Torpor (Hibernation). Probably active throughout the year.

K. Interspecific Associations/Exclusions. Unknown

L. Age/Size at Reproductive Maturity. Unknown. The average SVL of Salado salamanders measured by Chippindale et al. (2000) was $32.9 \mathrm{~mm}$; all specimens measured were thought to be sexually mature, but this was verified for only some of the specimens. several groundwater contamination incidents have occurred in the recent past. The potential remains for more incidents. The type locality for this species is located in a municipal park. Salado salamanders are listed as a Candidate species for federal listing (http://ecos.fws.gov).

\section{Eurycea cirrigera (Green, 1830)}

SOUTHERN TWO-LINED SALAMANDER

\section{Thomas K. Pauley, Mark B. Watson}

1. Historical versus Current Distribution.

The range of southern two-lined salamanders (Eurycea cirrigera) extends from Illinois and Indiana southeast through southern Ohio, southern West Virginia and Virginia, and south through Kentucky, Tennessee, North Carolina, and South Carolina to Georgia, Alabama, Mississippi, and Louisiana (E. E. Brown, 1992; Sever, 1999b). Southern two-lined salamanders have contact zones with northern two-lined salamanders (E. bislineata) in Ohio (Guttman and Karlin, 1986), Virginia (Mitchell and Reay, 1999), and West Virginia (Montani and Pauley, 1992; Brophy, 1995). Southern two-lined salamanders are absent in eastern Ohio and northern West Virginia where northern two-lined salamanders are found, and from the southern Blue Ridge Mountains where Blue Ridge two-lined salamanders (E. wilderae) occur (Sever, 1999b). There has been some debate among systematists on the validity of assigning full species status to members of the E. bislineata complex. For a summary of the taxonomic status of this group see Guttman and Karlin (1986), Jacobs (1987), Guttman (1989), Petranka (1998), Sever (1999b), Camp et al. (2000), and Highton (2000).

Thurow (1997) reports a successful translocation and subsequent establishment of southern two-lined salamanders from western Indiana to west-central Illinois.

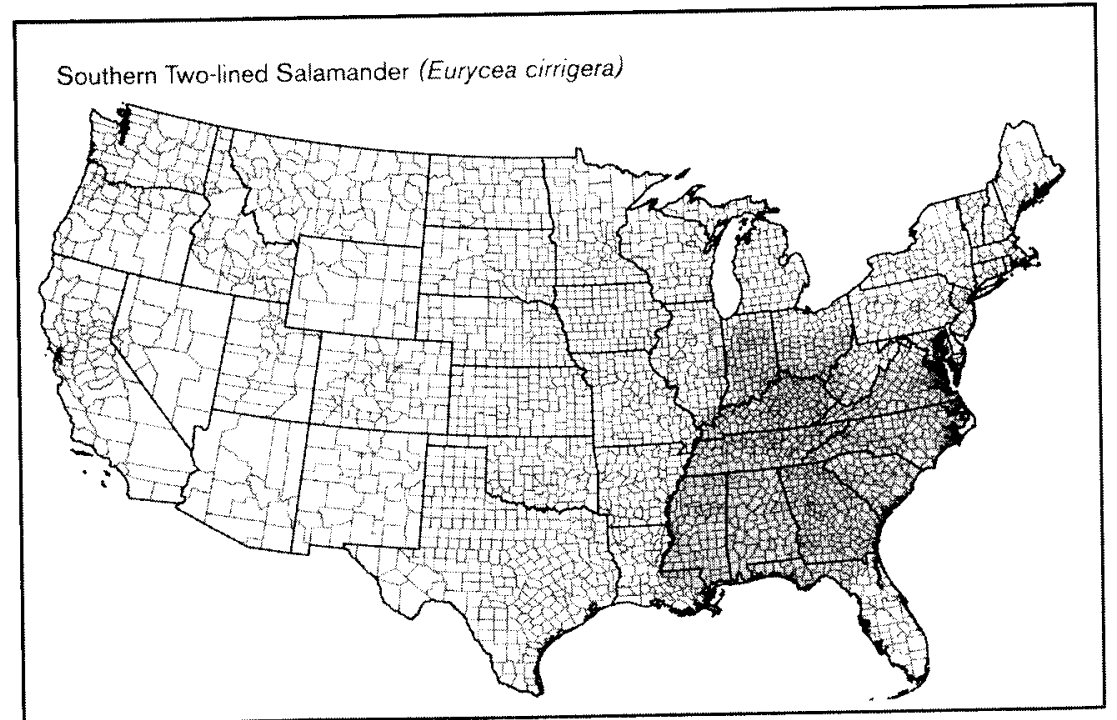


2. Historical versus Current Abundance. Southern two-lined salamanders appear to remain common throughout most of their range. There are no known reports of declines in abundance. Disjunct populations on the periphery of their range in northeastern Illinois apparently are the same as in the 1930s (Mierzwa, 1998). Numbers of specimens in museums from Hamilton County, Ohio, from pre-1940-95 show the number of southern two-lined salamanders to be about the same (Davis et al., 1998). While museum records cannot identify populations trend (but see Boundy, this volume), they can illustrate the occurrence of species. In Indiana, Minton (1998) compared historical and present abundance of amphibians and reptiles at eight sites. Southern two-lined salamanders initially were found at two sites in 1948, and their abundance was basically the same when Minton checked again in 1991 and 1993.

\section{Life History Features.}

A. Breeding. Reproduction is aquatic.

i. Breeding migrations. Weichert (1945) reported that during the spring breeding season, adult salamanders were found in water, but at all other times of the year, two-lined salamanders in the Cincinnati, Ohio, area were found away from water. In West Virginia during the summer, they can either be associated with aquatic habitats or found great distances from visible water sources. Individuals in upland, nonbreeding habitats migrate to first-, second-, and third-order streams in the autumn where they remain through the winter (T.K.P., personal observations).

ii. Breeding habitat. Breeding and egg deposition occur in aquatic habitats, especially in streams. Courtship activity of southern two-lined salamanders in a laboratory setting was described by Noble and Brady (1930). They also reported that southern two-lined salamanders from North Carolina would readily mate with northern two-lined salamanders from New York. Weichert (1945) found the breeding season for southern Ohio was limited to the end of March to the first two weeks of April. Courtship occurs in the fall in North and South Carolina and Virginia (Martof et al., 1980). Brophy (1995) located a mature male and gravid female together at the end of March in southwestern West Virginia, and the female had a spermatophore visible in her cloaca, suggesting the breeding season is early spring for this region.

\section{B. Eggs.}

i. Egg deposition sites. Eggs may be deposited under rocks or leaves, attached to logs and sticks adjacent to streams (Richmond, 1945; Wood, 1953a; Baumann and Huels, 1982; Green and Pauley, 1987), or broadcast underwater among rocks and gravel in stream beds (T.K.P., personal observations). Females usually brood egg clusters (Green and Pauley, 1987; Marshall,
1996). Marshall (1996) found seven clusters of eggs in a single stream in Mississippi; three clutches were attached to the underside of logs and four were unattached and buried in the substrate. In Georgia, Martof (1955) found females in January-February to be distended with eggs and suggested that eggs were laid in February. Wood (1953a) reported that eggs were deposited over a 10 -wk period from late January to mid-April on the Virginia Coastal Plain. Baumann and Huels (1982) found 1-3 egg masses of two-lined salamanders in Pine Creek in southeastern Ohio attached to the undersides of rocks. Brophy (1995) found egg masses in early development between 21 March-8 April in southwestern West Virginia. Masses were ovular in shape and attached to the underside of rocks in streams. Eggs are deposited in streams under rocks and other objects in winter and spring in North and South Carolina and Virginia (Martof et al., 1980) and in May in Illinois (Smith, 1961).

ii. Clutch sizes. Baumann and Huels (1982) reported that egg masses of southem two-lined salamanders averaged $16 \mathrm{~cm}^{2}$ in total area. The number of eggs/nest reported in the literature varies greatly. The number of eggs in a clutch ranges from 12-110 and averages from 18-50 (Noble and Richards, 1932; Richmond, 1945; Wood and Duellman, 1951; Wood and McCutcheon, 1954; Smith, 1961 Mount, 1975). Differences in the number of ova reported are likely due to differences in the body size of females (Wood and McCutcheon, 1954). Barbour (1971) reported 30 eggs/clutch in Kentucky, and Brophy (1995) found clutch sizes from 36-59 eggs in southwestern West Virginia. Clutches were commonly made up of around 40 eggs. Large counts of 200 or more eggs in a nest may be the result of communal nests (Baumann and Huels, 1982)

In Illinois, eggs hatch about 1 mo after deposition (Smith, 1961). In northern Georgia, hatching occurs in early March (Martof, 1955). Duellman and Wood (1954) found that eggs hatch in late June in southwestern Ohio, where hatchlings are $<9 \mathrm{~mm}$ SVL. Reports of newly hatched larvae vary from $10.5 \mathrm{~mm}$ (TL) in Louisiana (Dundee and Rossman, 1989) to $13 \mathrm{~mm}$ in Kentucky (Barbour, 1971).

\section{Larvae/Metamorphosis}

i. Length of larval stage. The larval period of southern two-lined salamanders lasts from 1-3 yr. Lengths of the larval stage range from 2 yr (Petranka, 1984b) to 2-3 yr in Kentucky (Barbour, 1971); 1-3 yr in Alabama (Mount, 1975); 1-2 yr in Louisiana (Dundee and Rossman, 1989); 2 yr in Illinois (Phillips et al., 1999) and Ohio (Duellman and Wood, 1954); and possibly $3 \mathrm{yr}$ in West Virginia (Pollio, 2000). A small number of larvae transform during the third year in Ohio (Duellman and Wood, 1954). Brophy (1995) found two size classes of larvae from southern and southwestern West Virginia. First-year larvae from a pond-dwelling population grew significantly faster than a streamdwelling population, but the streamdwelling population grew significantly faster in the second year. Larvae from both populations grew little during cooler months (Brophy, 1995). Some larvae can reach the same size as sexually mature adults.

ii. Larval requirements.

a. Food. Larval southern two-lined salamanders are euryphagous feeders. Prey items usually are invertebrates and include ostracods, copepods, and insects such as dipterans (chironomids), ephemeropterans, and coleopterans (dytiscid beetle larvae; Caldwell and Houtcooper, 1973; Petranka, 1998). In a comparison of prey items between pond- and stream-dwelling larval populations in southern West Virginia, Brophy and Pauley (in press) found that pond larvae consumed 9 prey taxa, while stream larvae consumed 15 . Primary prey for pond larvae included ostracods and chironomid larvae; stream larvae fed on copepods, isopods, and chironomids.

Southern two-lined salamander larvae also prey on vertebrates. Petranka (1984b) observed that large larvae will prey heavily on streamside salamander (Ambystoma barbouri) larvae.

b. Cover. Petranka (1984b) found that larvae showed diurnal movements to and from cover objects, and that larvae feed along streambeds during darkness. Smith and Grossman (2003) show that microhabitat use is correlated with habitat heterogeneity and the availability of cover

iii. Larval polymorphisms. Unknown and unlikely.

iv. Features of metamorphosis. Size of larvae at transformation has been reported at $52 \mathrm{~mm}$ (TL) in Kentucky (Petranka, 1984b); $52 \mathrm{~mm}$ TL for males and $50.9 \mathrm{~mm}$ TL for females in southwestern Ohio (Duellman and Wood, 1954); $72 \mathrm{~mm}$ TL in Georgia (Martof, 1955); and 34-40.2 mm SVL in Ohio and Indiana populations (Sever, 1972).

v. Post-metamorphic migrations. Migrations occur from pond and stream habitats to adjacent uplands. Martof (1955) found transforming larvae in September in Georgia. Duellman and Wood (1954) discovered transformed individuals in southwestern Ohio during the summer. Transformation occurs in May to midJune in Kentucky (Petranka, 1984b). Early metamorphic animals from a southern West Virginia pond in August were composed of two size classes, suggesting that these individuals had metamorphosed from 1-2-yr larvae (Brophy, 1995).

vi. Neoteny. Mount (1975) reported that neotenic individuals are not uncommon in Alabama. This condition has not been reported in other areas of the range of 
southern two-lined salamanders, but needs further study.

D. Juvenile Habitat. Juveniles are found under stones and other cover objects at the edges of aquatic habitats (Hudson, 1955; Petranka, 1998) and in surrounding forests (Petranka, 1998).

E. Adult Habitat. Southern two-lined salamanders are a semi-aquatic species and can be found in a variety of habitats throughout its range such as streams, pools, seeps, ditches, and damp woods (Smith, 1961; Barbour, 1971; Minton, 1972, 2001; Mount, 1975; Martof et al., 1980; Green and Pauley, 1987; Dundee and Rossman, 1989; Guttman, 1989; Bartlett and Bartlett, 1999a; Phillips et al., 1999). Ashton and Ashton (1978) reported that two-lined salamanders frequently used stream habitats with coarse sand and gravel, as well as broken limestone rock, leaf litter, and crayfish burrows. Brophy (1995) found southern two-lined salamanders mostly within the stream banks of two southwestern West Virginia streams. Martof (1955) suggested southern two-lined salamanders are abundant around springs and small streams in north-central Georgia. Grover (2000) reported that southern two-lined salamanders found along streams with black-bellied salamanders (Desmognathus quadramaculatus) were captured farther from streams than in an area without black-bellied salamanders. Means (2000) found southern two-lined salamanders most often around the heads of ravines in the coastal plain.

F. Home Range Size. In laboratory experiments, two-lined salamanders demonstrated a home range size that extended for a 5-6 inch radius from a central shelter site (Grant, 1955). In natural habitats, home range size is probably much larger. A mark-recapture study by Brophy (1995) suggested that the home range size of southern two-lined salamanders from southwestern West Virginia was around $14 \mathrm{~m}^{2}$.

G. Territories. Grant (1955) showed in laboratory experiments that two-lined salamanders defend territories from conspecifics by advancing toward an intruder and placing their snout in contact with it. In other cases, the salamander defending a territory would bite the snout or tail, often resulting in autotomy of the antagonist's tail.

H. Aestivation/Avoiding Desiccation. Aestivation studies have not been reported in the literature, but southern two-lined salamanders, as with other plethodontids, probably remain in refugia underground during drought conditions.

Brooks and Sassaman (1965) measured the critical thermal maximum (CTM) of larval and adult Eurycea from the coastal plain of Virginia. The average CTM of larvae was $33.3^{\circ} \mathrm{C}$ and $34.6^{\circ} \mathrm{C}$ for adults.
Grover (2000) measured the dehydration and rehydration rates of $E$. cirrigera. The rehydration rate of $E$. cirrigera was intermediate to that of Plethodon glutinosus (northern slimy salamanders) and D. monticola (seal salamanders).

1. Seasonal Migrations. Ashton and Ashton (1978) reported that when stream temperatures fell below $7^{\circ} \mathrm{C}$, southern two-lined salamanders moved upstream to winter refugia but remained within close proximity to the stream. Brophy (1995) found no cyclic movements of southern two-lined salamanders in two populations from southwestern West Virginia.

J. Torpor (Hibernation). In an experimental hibernation study, Vernberg (1953) observed that southern two-lined salamanders, in response to an artificial temperature gradient, burrowed into smooth-walled hibernacula $25-30 \mathrm{~cm}$ into soil. Weichert (1945) found active southern two-lined salamanders on warm days during the winter in southern Ohio. Similarly, Ashton and Ashton (1978) observed movement during winter in refugia with moderate conditions.

K. Interspecific Associations/Exclusions. Southern two-lined salamanders are associated with other stream-dwelling salamanders including black-bellied salamanders, northern dusky salamanders (D. fuscus), seal salamanders, and spring salamanders (Gyrinophilus porphyriticus). Means (2000) described an assemblage of plethodontid salamanders that inhabit the steephead ravines of the coastal plain that included southern two-lined salamanders, red salamanders (Pseudotriton ruber), and either Apalachicola dusky salamanders ( $D$. apalachicolae) or spotted dusky salamanders (D. conanti).

Northern two-lined salamanders and southern two-lined salamanders will hybridize (Noble and Brady, 1930), and broad regions of intergradation exist between these forms of two-lined salamanders (Howell and Switzer, 1953; Mittleman, 1966).

L. Age/Size at Reproductive Maturity. In Ohio, sexual maturity is reached in $2-4 \mathrm{yr}$ (Guttman, 1989). Age and size at sexual maturity vary according to the length of the larval period and season when transformation of larvae occurs.

\section{Longevity. Unknown.}

N. Feeding Behavior. Weichert (1945) reported the stomach contents of southern two-lined salamanders from southern Ohio included small wood roaches, spiders, ticks, earthworms, beetles, isopods, millipedes, small snails, grubs, springtails, and dipteran and hymenopteran insects. Food was found in stomachs from every month of the year.

O. Predators. Wood (1953a) suggested that mosquitofish (Gambusia affinis holbrookii) ate two-lined salamander eggs.

Resetarits (1991) showed that brook trout (Salvelinus fontinalis) and crayfish (Cambarus bartonii) were predators of
Eurycea larvae in a Virginia stream, and the presence or absence of trout could alter the salamander assemblages in the stream. Gustafson (1994) showed that spring salamander larvae preyed upon southern two-lined salamander larvae during laboratory experiments, and the efficiency of spring salamanders as predators of southern two-lined salamanders increased with the size of spring salamander larvae. Petranka (1984b) reported that larvae were palatable to sunfish and darters in streams.

Grover (2000) found that the presence of black-bellied salamanders in streams caused a shift of southern two-lined salamanders to drier sites farther from streams, suggesting that black-bellied salamanders were predators of southern two-lined salamanders. Other predators of two-lined salamanders (including other members of the E. bislineata complex) include screech owls, common garter snakes (Thamnophis sirtalis), ring-necked snakes (Diadophis punctatus), and rainbow trout (Oncorhynchus mykiss; Huheey and Stupka, 1967; Rising and Schueler, 1980; Beachy, 1993b).

P. Anti-Predator Mechanisms. Eggs of southern two-lined salamanders are deposited in cryptic sites under logs, leaves, and rocks. Females often are seen tending the eggs as a defense against predators (Baumann and Huels, 1982).

Petranka (1984b) suggested that diurnal behavior might be an anti-predator mechanism in larvae. Larvae may also use chemical cues from predatory fish to increase use of refugia (Petranka et al., 1987; Kats et al., 1988).

Several anti-predator mechanisms of northern two-lined salamander adults have been reported. The behavior of southern two-lined salamanders is probably similar to that of northern two-lined salamanders. In a laboratory setting, northern two-lined salamanders responded to common garter snakes with a protean, flipping escape rather than posturing or undulating the tail (Ducey and Brodie, 1983). Salamanders with tails could autotomize the tail during an encounter with a snake and were more successful in escaping capture than salamanders without tails. Dowdey and Brodie (1989) showed that different densities of predators can affect the response of two-lined salamanders to those predators. Salamanders in a high density of northwestern garter snakes (T. ordinoides) ran away more than salamanders from other areas. Salamanders that ran had a survival advantage. Whiteman and Wissinger (1991) reported that tail autotomy during predation experiments with common garter snakes as predators was nearly twice as frequent in northern two-lined salamanders as in northern dusky salamanders or Allegheny Mountain dusky salamanders $(D$. ochrophaeus). They found that two-lined salamanders with tails were more likely to escape a predator than those without 
tails. Two-lined salamanders were less aggressive during encounters and bit garter snakes less frequently than dusky salamanders.

Q. Diseases. Not known.

R. Parasites. Rankin (1937) lists the protozoan Prowazekella longifilis, the trematode Brachycoelium hospitale, and proteocephalid cestode cysts from southern two-lined salamanders.

\section{Conservation.}

Southern two-lined salamanders are abundant throughout most of the range. They are found in water polluted with sewage and other organic matter. As with most forest salamanders, major concerns are habitat destruction through activities such as clearcutting and habitat degradation, including acid mine drainage and acid deposition.

Eurycea guttolineata (Holbrook, 1838)

THREE-LINED SALAMANDER

Travis J. Ryan, Brooke A. Douthitt

1. Historical versus Current Distribution.

Three-lined salamanders (Eurycea guttolineata) are distributed throughout much of the southeastern United States. From west to east, the range of three-lined salamanders begins along the eastern bank of the Mississippi from Louisiana, north through all of Mississippi and Tennessee and into Kentucky. Eastward, they are distributed throughout Mississippi (except for the northeastern corner) and Alabama (except for the northern portion), all but the northwestern and southeastern extremes of Georgia, all of South Carolina, most of western and central North Carolina, and eastern Virginia. The absence of the threelined salamanders from the bulk of North Carolina's Coastal Plain is particularly curious. Populations rarely are found above $800 \mathrm{~m}$ and almost always below $1,000 \mathrm{~m}$ (Fisher, 1887; Ireland, 1979; lireeman and Bruce, 200())
There is no evidence to support a difference between the current and historical distributions, but Petranka (1998) points out that the loss of bottomland hardwood forests throughout the Southeast has undoubtedly resulted in the extirpation of many populations. However, links between habitat loss and any putative population declines have not been empirically demonstrated.

\section{Historical versus Current Abundance.}

Three-lined salamanders are fairly abundant throughout their range. While there have been a fair number of population studies of their sister species, E. longicauda (long-tailed salamanders), the population ecology of three-lined salamanders has not been studied nearly as well. Anecdotally, some of the populations first studied two and three decades ago (Bruce, 1970, 1982) apparently are still stable.

\section{Life History Features.}

A. Breeding. Courtship has not been described for three-lined salamanders, and relatively little is known of their reproductive activities.

i. Breeding migrations. Three-lined salamanders rarely stray far from aquatic habitats, but are found more frequently at the terrestrial/aquatic interface and in the water during the late fall, winter, and early spring. If there is a migration per se from terrestrial sites to aquatic ones, it occurs in the fall, probably coincident with the onset of the breeding season. Marshall (1999) suggested an extended breeding season (July-December).

ii. Breeding habitat. Breeding occurs in lentic and slow-moving lotic systems, such as sluggish streams and seeps, bogs, and cypress bays (Petranka, 1998).

B. Eggs. Oviposition occurs in the winter, but varies considerably in published reports and is likely a consequence of both spatial (geographic) and temporal

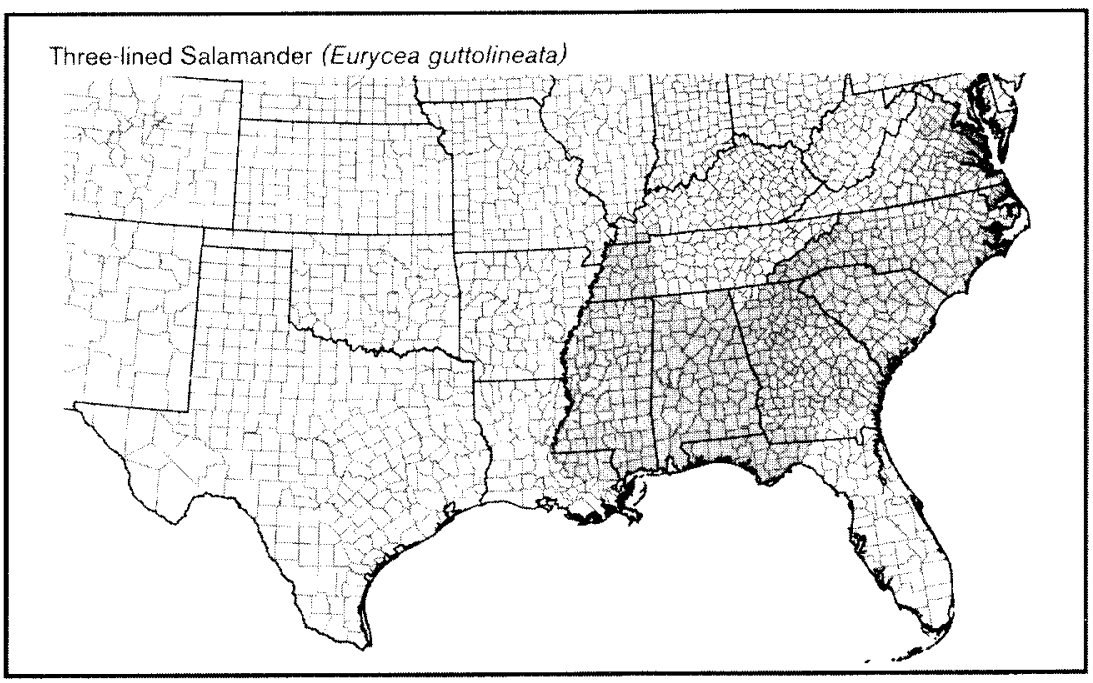

(year-to-year) variation. Gordon (1953) reports December oviposition. In North Carolina-South Carolina populations, a February oviposition date seems more likely, based on the appearance of hatchlings (Bruce, 1970, 1982; Freeman and Bruce, 2000). Marshall (1999) suggested that oviposition could occur as early as November in some populations.

i. Egg deposition sites. Few egg clutches have been observed. Mature ova are $2.5-3.0 \mathrm{~mm}$ in diameter. Bruce (1970) found hatchlings and advanced embryos scattered on the bottom of a cistern in mid-March. The eggs were not attached to any cover object, which is unusual for eastern Eurycea. Given the unconventional location of the embryos and the fact that no female was in attendance, Bruce (1970) speculated that eggs had washed into the cistern rather than having been oviposited there.

ii. Clutch size. Mount (1975) found groups of 8-14 eggs associated with several adults in a covered concrete reservoir associated with a shallow spring. Beyond this, we are aware of no reliable data regarding fecundity (Ryan and Bruce, 2000).

C. Larvae/Metamorphosis. The larval life history of three-lined salamanders is one of the best studied aspects of the species with at least five comprehensive studies.

i. Length of larval stage. In North Carolina, hatchlings emerge at $10-13 \mathrm{~mm}$ and undergo metamorphosis when they are 22-27 mm SVL after a 4-6 mo larval period (Bruce, 1970, 1982). Larvae in montane populations occasionally will overwinter and transform during the early summer, 16 mo after hatching and at between 30 and $32 \mathrm{~mm}$ SVL. The effect of elevation on larval periods was studied in a more comprehensive manner by Freeman and Bruce $(2000)$. They investigated changes in timing of and size at metamorphosis over an elevational gradient within a single watershed. At the low-elevation populations (in Georgia and South Carolina), metamorphosis came 5-6 mo posthatching. Larvae overwintered and delayed metamorphosis until 14-15 mo post-hatching in the high-elevation populations in North Carolina. There were no differences between size at hatching or growth rate between the high- and lowelevation populations. Freeman and Bruce (2000) posited that differences in hydrological stability (which is greater in the high-elevation populations) likely accounts for these differences. Marshall (1999) also found metamorphosis occurring at 5-6 mo post-hatching. However, his analysis of variation in size and age at metamorphosis led him to conclude that three-lined salamander larvae are adapted to warm, stable aquatic environments and found no support for their adaptation to variable habitats. 
ii. Larval requirements. Larvae are found in the same slow-moving streams, bogs, and marshes as the adults.

a. Food. Larval three-lined salamanders most likely feed on small invertebrates (Petranka, 1998), but there are no detailed studies of foraging behavior or gut content analyses.

b. Cover. It is difficult to quantify or even accurately describe the cover objects of three-lined salamander larvae, as they most frequently inhabit waters that make direct observation extremely difficult. Larvae are captured most easily by thrusting a dipnet (e.g., Freeman and Bruce, 2000) rather blindly through the shallow water near the land-water interface or in deeper waters along the substrate. Larvae most likely seek refuge in decaying vegetation along the $s$ ream/pond/bog/marsh bottom (Bruce, 1982).

iii. Larval polymorphisms. Unknown.

iv. Features of metamorphosis. Metamorphosis occurs fairly early in three-lined salamanders (see "Length of larval stage" above). The first sign of metamorphosis is the adoption of an adult pigment pattern that frequently far precedes other signs of metamorphosis (such as the resorption of the tail fin and external gills; Bruce, 1970).

v. Neoteny. Paedomorphosis is not known in three-lined salamanders.

vi. Post-metamorphic migrations. Recently metamorphosed three-lined salamander juveniles are encountered most frequently at the land-water interface, but it is not altogether unlikely to find juveniles in the surrounding forest among adults. Coordinated migrations (in the manner of various Ambystoma, which may frequently be members of the same guild) per se are unknown and unlikely.

D. Juvenile Habitat. Same as adult habitat, see below.

E. Adult Habitat. Mainly terrestrial as adults, however, they rarely are found considerable distances from wetlands. Most abundant in river-bottom wetlands and in the vicinity of springs and streams (sometimes ditches, vernal ponds, and bogs) where seepage keeps the ground moist. Animals occasionally are found some distance from water, but are good swimmers and at home in the water. Like most other plethodontids, three-lined salamanders are primarily nocturnal, but may be found during the day under cover objects. Surface activity is closely tied with surface moisture; adults are likely to be encountered foraging on humid or rainy nights shortly after sunset (Petranka, 1998).

F. Home Range Size. Unknown. Because three-lined salamander adults do not defend territories (see below), the definition of individual home ranges is problematic. Furthermore, detailed autecology studies have not been published to date.

G. Territories. According to Jaeger (1988) three-lined salamanders are one of the few plethodontid salamanders that are not territorial.

H. Aestivation/Avoiding Desiccation. Aestivation is unknown and unlikely.

I. Seasonal Migrations. Seasonal habiat shifts in response to temperature occur(toward the water in fall and winter as temperatures descend and away from aquatic habitats in the spring when air, ground, and water temperatures rise) but highly synchronized movements have not been described.

J. Torpor (Hibernation). Unknown and unlikely.

K. Interspecific Associations/Exclusions. Three-lined salamanders often are associated with southern two-lined salamanders (E. cirrigera) or Blue Ridge two-lined salamanders (E. wilderae). Little is known about how (Petranka, 1998) or whether these species compete. Bruce (1982) found three-lined salamanders and Blue Ridge two-lined salamanders inhabiting the same creeks in western North Carolina with no noticeable adverse effects on either; for example both species demonstrated life history patterns consistent with isolated populations (Bruce, 1970, 1988). The differences in larval life history (see Ryan and Bruce, 2000) may be sufficient to reduce competition prior to metamorphosis. As adults, three-lined salamanders tend to stay closer to aquatic habitats than do Blue Ridge two-lined salamanders or southern two-lined salamanders, particularly in the summer (T.J.R., personal observations); this may reduce competition in the post-metamorphic phase. At the higher elevation extreme, other streamdwelling plethodontids may be encountered, such as Ocoee salamanders (Desmognathus ocoee) and more rarely seal salamanders (D. monticola), red salamanders (Pseudotriton ruber) and mud salamanders ( $P$. montanus; Freeman and Bruce, 2000). However, because three-lined salamanders also inhabit more lentic waters, they also may be syntopic with members of the local pond-dwelling guilds (e.g., eastern newts /Notophthalmus viridescens and spotted salamanders /Ambystoma maculatum ]; Freeman and Bruce, 2000). Competitive interactions among these species, in either lentic or lotic environments, have not been evaluated.

Until relatively recently, three-lined salamanders were considered a subspecies of long-tailed salamanders, with which they were believed to hybridize (Bailey, 1937; Martof and Humphries, 1955; Valentine, 1962; Ireland, 1979). Carlin (1998) used morphological and genetic data to elevate $E$. guttolineata to full species. Furthermore, Carlin's analysis was capable of unambiguously identifying individuals from the putative zone of intergradation (located in northern Alabama and Georgia), making uncertain the status of hybrids that previously had been de scribed based solely on morphological characters. There are also reports of zones of sympatry along Blue Ridge escarpment that lack apparent intergradation (Ireland, 1979; T.J.R. and R.C. Bruce, personal observations)

L. Age/Size at Reproductive Maturity. Maturation is synchronous between the sexes, coming at about 2 yr post-hatching (Marshall, 1999; Ryan and Bruce, 2000). Females are slightly larger than males on average (Gordon, 1953).

M. Longevity. Unknown. Because of substantial differences in the size at maturation and average (not to mention maximum) adult sizes (Ryan and Bruce, 2000), it is reasonable to believe that there is the potential for substantial post-maturation growth. Marshall (1999) was able to measure post-metamorphic growth in a population of three-lined salamanders and found that following maturation, growth slowed considerably (from $1.7 \mathrm{~mm}$ SVL/ mo to $0.11 \mathrm{~mm} \mathrm{SVL} / \mathrm{mo}$ ). If this is consistent across populations, then it is likely that some adult three-lined salamanders must survive for upwards of a decade or more.

N. Feeding Behavior. Three-lined salamanders feed on a variety of invertebrate prey including snails, snail eggs, arachnids, millipedes, annelids, nematodes, and insects including hymenopterans (especially ants), dipterans, coleopterans, orthopterans, hemipterans, homopterans, lepidopterans, neuropterans, odonates, collembolans, and trichopterans (Tinkle, 1952; Petranka, 1998).

o. Predators. Unknown. It is easy to speculate that inhabitants of water edges and forest floors (e.g., semi-aquatic and/or semi-fossorial snakes and small mammals such as voles and shrews) and larger salamanders are likely important predators.

P. Anti-Predator Mechanisms. Threeined salamanders assume a classic urodelean defensive posture that includes coiling their body, tucking their head beneath their tail, and raising and undulating their tail (Brodie, 1977).

a. Diseases. Unknown.

R. Parasites. Rankin (1937) lists the following parasites from three-lined salamanders: Protozoa-Cryptobia borreli, Cytamoeba bacterifera, Eutrichomastix batrachorum, Haptophyra michiganensis, Hexamastix batrachorum, Hexamitus batrachorum, Prowazekella longifilis, and Tritrichomonas augusta; Trematoda-Brachycoelium hospitale and Gorgoderina tenua; Nematoda-Oxyuris magnavulvaris and spirurid cysts; Cestoda-proteocephalid cysts; AcarinaHannemania dunni.

4. Conservation. 'Three-lined salamanders remain abundant throughout much of their range, and there is no evidence to support a difference between the current and historical distributions. While the loss of bottomland hardwood forests throughout the Southeast has undoubtedly resulted in the extirpation of many 
populations (Petranka, 1998), direct links between habitat loss and population declines have not been demonstrated.

Eurycea junaluska Sever, Dundee, and Sullivan, 1976

JUNALUSKA SALAMANDER

Travis I. Ryan, David M. Sever

1. Historical versus Current Distribution. When described in 1976, Junaluska salamanders (Eurycea junaluska) were known "officially" from only three creeks, all located within Graham County, North Carolina. However, Junaluska salamanders had been collected in the Great Smoky Mountains National Park (GSMNP) as early as 1937. At that time, King (1939) recognized a unique form as $E$. bislineata $\mathrm{x}$ cirrigera, an intermediate between the northern (bislineata) and southern (cirrigera) subspecies of the widely distributed two-lined salamander. King was certain that the form he found in the GSMNP was distinct from the common Blue Ridge two-lined salamander (E. bislineata wilderae; the three subspecies of $E$. bislineata later were all elevated to species level by Jacobs, 1987). After describing E. junaluska, Sever (1976) examined a portion of King's collection and determined that they were in fact the earliest collected forms of the new species. This post hoc discovery expanded the range of Junaluska salamanders to two additional counties in Tennessee-Blount and Sever. Subsequent surveys resulted in new records from Monroe County, Tennessee (Sever, 1983a). An additional site in Graham County was later reported, but extensive surveys in the three North Carolina counties surrounding Graham County proved fruitless (Ryan, 1997). More recent fieldwork in Tennessee has resulted in new records from within the GSMNP and in Polk County (W. H. M. Gutzke, personal communication).

\section{Historical versus Current Abundance.}

Most of the other members of the E. bislineata complex (E. bislineata, E. cirrigera, and $E$. wilderae) are locally abundant throughout their ranges (Sever, 1989); but in our experience, Junaluska salamanders are an exception to this rule. Sever (1984) gives a particularly lucid and entertaining account of the difficulties that can be associated with studying this species. In the earliest account, King (1939) speculated that Junaluska salamanders were "a relic of a much older population" but did not mention their abundance. The type series of 23 individuals had to be assembled from collections made over a 3-yr period (Sever, 1984). A decade after the first members of the type series had been collected, Sever (1983a) commented on having "collected fewer than 50 metamorphosed individuals." Ryan (1998a) suggested that larvae are preferred indicators of population size because larvae are locally concentrated (i.e., confined to streams) whereas the more uncommon metamorphosed individuals may be spread out over a substantially larger area. Bruce (1982b) and Ryan (1997, 1998a) studied larval populations of Junaluska salamanders and Blue Ridge two-lined salamanders; in both cases, larvae of the latter were far more abundant than that of the former. Ryan (1998a) determined that in North Carolina, Junaluska salamanders accounted for fewer than $20 \%$ of the larval Eurycea assemblage at Santeetlah Creek (perhaps the most stable and best studied population). Junaluska salamanders represented $\leq 30 \%$ of the assemblage at Snowbird Creek in August 1994, but have not been collected at that site since later that year (Ryan, 1998a; T. J.R., unpublished data). Essentially, Junaluska salamanders were rare to begin with (perhaps contributing to their relatively late discovery), and remain so in North Carolina.

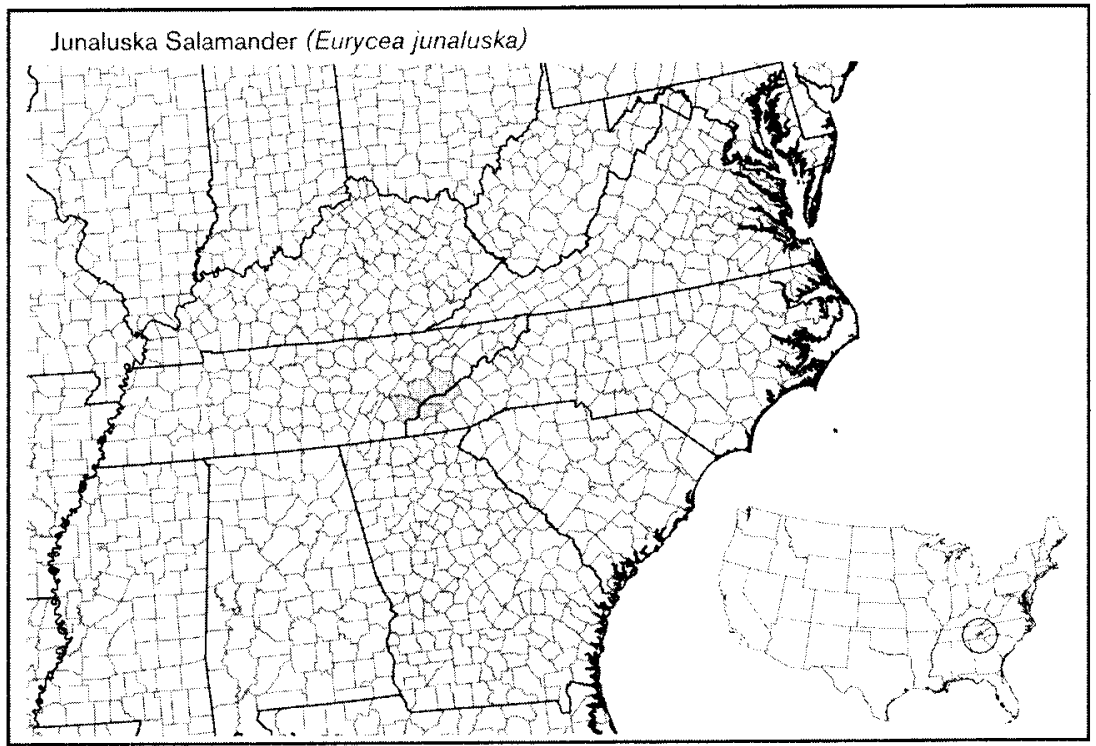

Recent collecting efforts at the type locality on the Cheoah River have been in vain (T. J.R., unpublished data; W.H.N. Gutzke, personal communication), and this population is feared to be extirpated due to anthropogenic activities upstream. Tennessee populations appear stable and quite possibly larger than those in North Carolina

\section{Life History Features.}

The life history of Junaluska salamanders is perhaps the best-known aspect of this otherwise enigmatic species. While many of Sever's Junaluska salamander papers (e.g., Sever et al., 1976; Sever, 1979, 1983a) contain valuable life history data, studies by Bruce (1982b) and Ryan (1998a) of the Santeetlah Creek population have resulted in the clearest picture of this species' life history. The life histories of Junaluska salamanders, as well as all other Eurycea, are summarized in Ryan and Bruce (2000).

A. Breeding. Reproduction is aquatic.

i. Breeding migrations. We are unaware of anything approaching a true breeding migration in Junaluska salamanders. However, the majority of adults that we have collected have come either in the fall, prior to when courtship and breeding occur in members of the E. bislineata complex, or in the spring, near the time of oviposition (e.g., Sever, 1983a; Ryan, 1998a; D.M.S. and T. J.R., unpublished data).

ii. Breeding habitat. Courtship of Junaluska salamanders has not been observed, but we believe that it likely occurs along streams where adults are found during the putative breeding season and also where eggs are deposited.

\section{B. Eggs.}

i. Egg deposition sites. Salamanders attend clutches of eggs around mid-May. Eggs typically are found attached to the underside of a large rock in water $<0.5 \mathrm{~m}$ deep, with moderate stream flow, and between 1-12 $\mathrm{m}$ from the streambank. The location of the nests does not differ appreciably from where larvae have most frequently been collected.

ii. Clutch size. Clutch sizes observed in the field range from $30-49$ (mean $=38, n=5$ ). Sever (1983a) reported gravid females contained between 41-68 (mean $=51, \mathrm{n}=10$ ) mature ovarian follicles. About $1 \mathrm{mo}$ is required for embryonic development, and hatchlings are about 7-8 $\mathrm{mm}$ TL (Bruce, $1982 b$ ). As a point of interest, each time Junaluska salamander nests have been discovered in the field, Blue Ridge two-lined salamander nests have been located syntopically, with as little as 1-2 m separating the two species.

c. Larvae/Metamorphosis. The larvae of Junaluska salamanders are superficially similar to those of Blue Ridge two-lined salamanders with regard to morphology, ecology, and life history. A photograph of 
a larva appears in Sever (1983a), and Ryan (1997) offers a description of the larvae and illustrations of larval Junaluska salamanders and Blue Ridge two-lined salamanders.

i. Length of larval stage. In North Carolina, the larval period appears to be $2 \mathrm{yr}$, possibly 3 (Bruce, 1982b; Ryan, 1998a); Ryan (1998a) estimated the age at metamorphosis to be 25.5 mo at Santeetlah Creek. Larvae grow at a faster rate in the first year of larval development than they do in the subsequent year(s) (Ryan, 1998a). Metamorphic individuals may be as small as $34 \mathrm{~mm} \mathrm{SVL}$, but most are closer to $40 \mathrm{~mm}$ SVL (Bruce, 1982b; Ryan, 1998a) making them the largest naturally metamorphosing larvae in the E. bislineata complex (Ryan and Bruce, 2000).

ii. Larval requirements.

a. Food. No data on the diet of larval Junaluska salamanders have been reported. The most commonly encountered macroinvertebrates in the streams where larvae are abundant are stonefly and caddisfly larvae. In the laboratory, we have observed that larvae feed readily on white worms (Enchytraeus sp.).

b. Cover. The ideal cover objects for Junaluska salamander larvae are large flatbottomed rocks that come in close contact with the stream substrate. Most frequently these rocks are located in regions of relatively large (i.e., higher-order) streams where there is moderate water flow and low sedimentation. We also often find larvae in quiet pools on the margins of streams. Larvae are located by carefully displacing rocks. Less frequently, we have collected larvae in riffle areas of streams. In November, when the bulk of a stream's allochthonous input has been received, we have collected larvae using dipnets and searching through the leaf mats.

iii. Larval polymorphisms. Unknown.

iv. Features of metamorphosis. Based on the few field studies, it appears that metamorphosis is more or less synchronous within a population, occurring mostly in May-August, corresponding roughly to the time of hatching of a new cohort (Bruce, 1982b; Ryan, 1998a). The length of time to complete metamorphosis once it has been initiated (e.g., once gill resorption has begun) has not been studied rigorously, but Bruce (1982b) showed that while metamorphic individuals were common (approximately 1 in 4 ) during a July collection, none were found in the preceding (May) or following (September) collections.

v. Post-metamorphic migrations. Just as there appears to be no marked breeding migration, neither is there a record of recently metamorphosed juvenile migrations.

vi. Neoteny. Paedomorphosis is not known in Junaluska salamanders.

D. Juvenile Habitat. Juveniles are poorly recorded in the literature. The minimum size of adult Junaluska salamanders is not appreciably different from the size of metamorphic larvae; thus, the transition from juvenile to adult is likely minor, with the two classes overlapping to a wide degree. Unfortunately, little is known regarding the habitat characteristics of adults, as well (see below).

E. Adult Habitat. Little is known regarding the habitats of adults. Most adults have been collected on roads near creeks during warm, rainy nights (Sever, 1984) or on streambanks and in streams during early spring (Bruce, 1982b; Sever, 1983a, 1984; Ryan, 1998a). Most likely, adult Junaluska salamanders have seasonal activity patterns similar to Blue Ridge twolined salamanders. In colder months, adults are most commonly found within streams, as this habitat is more thermally stable than the surrounding terrestrial habitat; in warmer months, adults are found predominantly in the forests surrounding the streams. Within the streams, adults have been collected within the same habitat as larvae, that is., beneath large flat rocks in regions of shallow water and moderate stream flow.

F. Home Range Size. Unknown.

G. Territories. Unknown.

H. Aestivation/Avoiding Desiccation. Aestivating behavior is unknown.

I. Seasonal Migrations. See "Breeding migrations" above.

J. Torpor (Hibernation). Unknown.

K. Interspecific Associations/Exclusions. The range of Junaluska salamanders is sympatric with that of Blue Ridge twolined salamanders, with the latter being far more common. Nonetheless, the two species are frequently syntopic, with larvae and adults of both species utilizing identical habitats (Ryan, 1997, 1998a). We frequently have found larvae of both species beneath the same rock, and, as noted above, the nesting sites of both species are, for all intents and purposes, identical. It is unclear whether the presence of one species impacts the other. At one larval Junaluska salamander site along the Cheoah River (the type locality), eastern newts (Notophthalmus viridescens) were abundant (Ryan, 1998a). Other salamanders frequently encountered while collecting Junaluska salamanders include hellbenders (Cryptobranchus alleganionsis), red salamanders (Pseudotriton ruber), spring salamanders (Gyrinophilus porphyriti(us), various dusky salamanders including shovel-nosed salamanders (Desmognathus marmoratus), seal salamanders (D. monticola), Ocoee salamanders (D. ocoee), and black-bellied salamanders (D. quadramaculatus; Bruce, 1982b; Sever, 1983a; Ryan, 1998a).

L. Age/Size at Reproductive Maturity. The age at first reproduction is unknown (Ryan and Bruce, 2000). The smallest mature female recorded in the literature $(37$ $\mathrm{mm}$ SVL; Sever, 1983a) falls well within the size range of metamorphic larvae (34-44 mm SVL; Ryan and Bruce, 2000), leading us to speculate that reproduction likely shortly follows metamorphosis. Thus, if most individuals metamorphose in their third summer, they likely breed initially at the end of the third year. The average size of females is approximately $43 \mathrm{~mm} \mathrm{SVL}$ (Sever, 1983a) with maximum sizes of 47 and $49 \mathrm{~mm}$ SVL for females and males, respectively (Sever, 1983b).

M. Longevity. We are unaware of any reliable information regarding the age of Junaluska salamanders.

N. Feeding Behavior. Both the diet and feeding behavior of metamorphosed larval Junaluska salamanders are unknown. We speculate that they feed on a wide variety of invertebrates, as with other members of the E. bislineata complex (e.g., Burton, 1976).

o. Predators. There are no reports of predation specifically on larval Junaluska salamanders. They likely face threats similar to those experienced by other members of the E. bislineata complex: fish, birds, small mammals, snakes, and other salamanders (Petranka, 1998).

P. Anti-Predator Mechanisms. Unknown.

Q. Diseases. We are not aware of any reports of diseases of larval Junaluska salamanders. However, Ryan (1998b) described scoliosis (lateral spinal malformations) in two larvae from the Cheoah River. The cause of the condition is unknown and could be due to either exogenous (e.g., disease or parasites) or endogenous (e.g., genetic) causes.

R. Parasites. See "Diseases" above.

\section{Conservation.}

Tennessee populations of Junaluska salamanders appear stable. In North Carolina, however, they were rare to begin with and remain so. For example, they have not been collected at Snowbird Creek since late in 1994, and recent collecting efforts at the type locality on the Cheoah River have been in vain. This population is feared to be extirpated, due to anthropogenic activities upstream. In North Carolina, Junaluska salamanders are listed as a Species of Special Concern and has been proposed for Threatened status.

Eurycea latitans Smith and Potter, 1946 CASCADE CAVERNS SALAMANDER

Paul T. Chippindale

\section{Historical versus Current Distribution.} Cascade Caverns salamanders (Eurycea latitans) were first described by Smith and Potter (1946) from Cascade Caverns, Kendall County, Texas. Brown (B.C., 1967a) provided a review of what was known about this species at that time. Sweet (1978a, 1984) demonstrated that this population includes individuals with a 


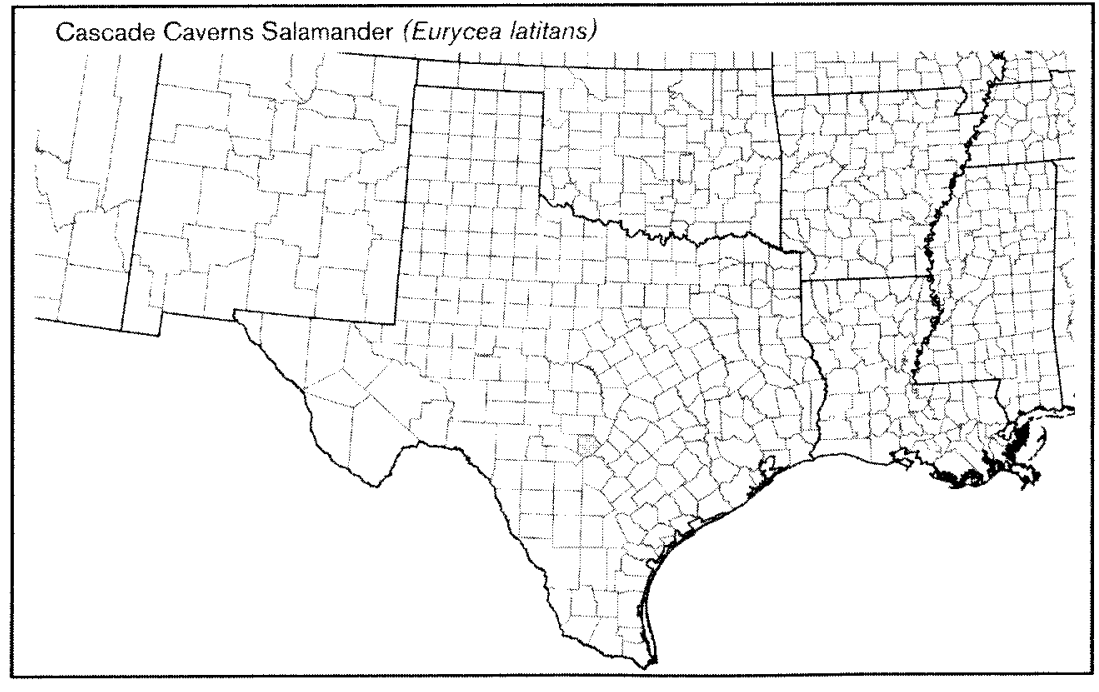

spectrum of morphological features, ranging from highly cave-associated morphologies most similar to those of Comal blind salamanders (E. tridentifera), to surface-like morphologies most similar to those of what he considered Texas salamanders ( $E$. neotenes). He hypothesized that this was the result of hybridization between a surface population of Texas salamanders and a population of the cavedwelling Comal blind salamanders. Most recent authors have not recognized Cascade Caverns salamanders as a distinct species. Chippindale et al. (2000) found no evidence that salamanders from the Cascade Caverns system are hybrids. Based on molecular data, the Cascade Caverns salamander population appears most closely related to many other cave and spring populations in the southeastern Edwards Plateau region that do not include the type localities of either Texas salamanders or Comal blind salamanders. Chippindale (2000) and Chippindale et al. $(2000)$ provisionally recognized the E. latitans complex, in which they included the population at the type locality, plus many others from Comal, Kendall, and eastem Kerr counties. Relationships among members of this group, and their relationships to other southeastern Edwards Plateau Eurycea, remain to be studied in more detail.

\section{Historical versus Current Abundance.}

As with many cave-dwelling populations of lexas Eurycea, it is difficult to assess population sizes. The most recent collection of topotypes of this species of which I am aware was in 1992, when P. Chippindale, A. Grubbs, and J. Hunter obtained five specimens from Pfeiffer's Water Cave, a subterranean extension of Cascade Caverns. Sweet (1978a, 1984) documented an apparent shift in phenotypes at the type locality, from predominance of individuals with cave-associated morphologies to predominance of individuals with surface- associated morphologies, over a period of several decades. Members of the E. latitans complex (as broadly recognized by Chippindale et al., 2000) often are common at spring outflows, but their distribution appears to be limited and patchy.

\section{Life History Features.}

A. Breeding. Reproduction is aquatic.

i. Breeding migrations. Unlikely to occur.

ii. Breeding habitat. Unknown within their cave ecosystem.

\section{B. Eggs.}

i. Egg deposition sites. Unknown; closely related species are thought to deposit eggs in gravel substrate.

\section{ii. Clutch size. Unknown.}

C. Larvae/Metamorphosis. Cascade Caverns salamanders are paedomorphic, and natural metamorphosis is unknown. Features of larval life are also unknown.

D. Juvenile Habitat. Probably similar to adult habitat.

E. Adult Habitat. Completely aquatic. Known only from caves that contain water and the immediate vicinity of spring outflows; individuals in caves are often seen in the open on submerged rock or mud substrate, whereas individuals from spring populations are found under rocks and leaves and in gravel substrate. Water temperature in springs and caves of the Edwards Plateau is relatively constant throughout the year and typically ranges from $18-20{ }^{\circ} \mathrm{C}$ or slightly warmer near the fault zone at the Plateau's edge (Sweet, 1982). Sweet (1982) provided a comprehensive distributional analysis of the central Texas Eurycea and discussed hydrogeology of the region in relation to salamander distribution.

F. Home Range Size. Unknown.

G. Territories. Unknown.

H. Aestivation/Avoiding Desiccation. Aestivation is unknown.

I. Seasonal Migrations. Unlikely.

J. Torpor (Hibernation). Probably active throughout the year.
K. Interspecific Associations/Exclusions. As described in "Historical versus Current Abundance" above, Sweet (1978a, 1984) considered the population at the type locality to be hybrids between $E$. neotenes and E. tridentifera. Chippindale (1995) and Chippindale et al. (2000) regarded this as unlikely based on molecular data and continued to recognize E. latitans as a distinct species. Sweet $(1978 a, 1984)$ noted that members of this species complex (most of which he considered E. neotenes) are usually absent from caves in which fishes occur.

L. Age/Size at Reproductive Maturity. In a morphometric analysis of some Edwards Plateau Eurycea (Chippindale et al., 1993), average SVL of the Cibolo Creek Spring population (which Chippindale et al. [2000] later included in the E. latitans complex) that were presumed to be adult was 33.8 $\mathrm{mm}$. However, Chippindale et al. (2000) probably did not include the smallest reproductively mature specimens in their analysis, and no rigorous studies of reproductive biology have been conducted for this species. Barden and Kezer (1944) described eggs and egg deposition by a captive individual from a population that is likely (based on geographic location) to be part of this species complex.

M. Longevity. Unknown.

N. Feeding Behavior. Prey probably consists mainly of small aquatic invertebrates, but no detailed feeding studies of this species have been conducted.

\section{O. Predators. Unknown.}

P. Anti-Predator Mechanisms. Individuals from spring populations are secretive. Sweet (1978a, 1984) noted that individuals from the type locality (Cascade Caverns) show escape behaviors similar to those of animals from surface springs (i.e., movement toward substrate and cover items).

\section{Q. Diseases. Unknown.}

R. Parasites. Unknown.

\section{Conservation.}

As with many cave-dwelling populations of Texas Eurycea, it is difficult to assess population sizes of Cascade Caverns salamanders. Cascade Caverns salamanders can be common at spring outflows, but their distribution appears to be limited and patchy. They are listed as Threatened in Texas, but have no special recognition by the Federal Government.

Eurycea longicauda (Green, 1818) LONG-TAILED SALAMANDER

\section{Travis J. Ryan, Christopher Conner}

1. Historical versus Current Distribution.

Long-tailed salamanders (Eurycea longicauda) are distributed throughout the Ozark Highlands, the Appalachian Highlands, and the Ohio River Valley. There is a narrow connection between the Ozarks 
and the rest of their range through southern Illinois and western Kentucky. Two subspecies, dark-sided salamanders (E. $I$. melanopleura) and long-tailed salamanders (E. l. longicauda), are recognized. Darksided salamanders are associated with the Ozark Highlands and are distributed from eastern Oklahoma and extreme southeastern Nebraska into central and eastern Missouri. Long-tailed salamanders range in a narrow band from southeastern Missouri through extreme southern Illinois, throughout most of Kentucky, central and western Tennessee, extreme northeastern Mississippi, northern Alabama, northern Georgia, extreme southwestern and northwestern North Carolina, western Virginia, West Virginia, Maryland, Pennsylvania, southern New York, and in the north from extreme eastern Illinois, west through southern Indiana, and into southern and eastern Ohio. Locally, distribution is somewhat dependant on the availability of suitable habitats. term population studies (c.f., Semlitsch et al., 1988) have been published, obfuscating any differences between historical and current local population sizes.

\section{Life History Features.}

The main aspects of the life history of long-tailed salamanders are typical of the lineage (i.e., subfamily Plethodontinae, tribe Hemidactyinii; Ryan and Bruce, 2000 ), and given the fairly broad distribution, there is relatively little variation in the pattern between subspecies or otherwise across the range.

A. Breeding. Oviposition is aquatic, as in all other Eurycea, and presumably courtship is aquatic as well. There are no published accounts of complete courtship encounters. One field observation (Cooper, 1960) mentions head-rubbing behavior, typical of plethodontids. There is only anecdotal evidence that females brood their clutches (Franz, 1964). Petranka (1998) speculated that the lone observation of

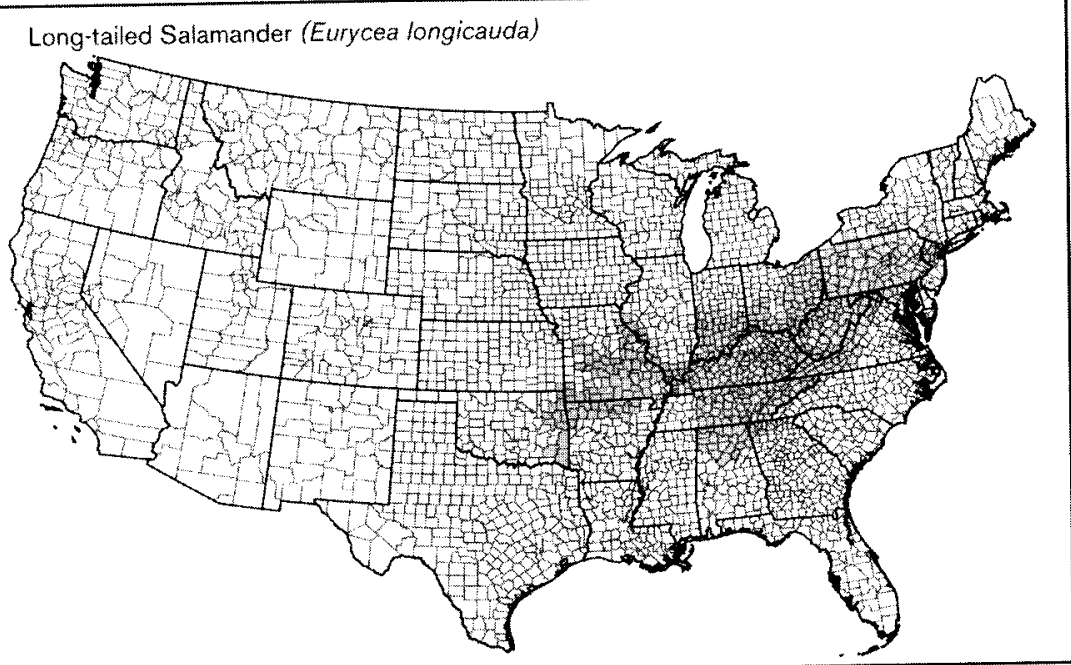

Long-tailed salamanders frequently are associated with caves, mines, and shale and limestone creek beds. They have a bi-phasic life cycle; aquatic habitats are necessary for breeding and embryonic/larval development, while terrestrial habitats, especially forests surrounding these aquatic habitats, support post-metamorphic individuals. Populations undoubtedly have been lost due to factors such as habitat loss, acid drainage from coal mining, and clearcutting. However, as with most other wide-ranging, stream-dwelling plethodontids, there are no robust distributional studies that document changes in gross distribution.

2. Historical versus Current Abundance.

Long-tailed salamanders can be locally abundant, with densities exceeding 10 adults $/ \mathrm{m}^{2}$ (Mohr, 1944; Guttman, 1989; T. J.R., unpublished data). No clear long- tino, 1966; Minton, 1972, 2001; Guttman, 1989) and also on temporal availability of suitable aquatic habitats. Eggs have been found in mid-autumn (November; Franz, 1964), late winter (March; Ireland, 1974), and in-between (January; Mohr, 1943).

B. Eggs. Egg size is typical for the genus, about $3 \mathrm{~mm}$ in diameter (Ryan and Bruce, 2000).

i. Egg deposition sites. Eggs generally are deposited in aquatic environments. Petranka (1998) notes that the discovery of eggs in the field is rare, but a trend is that oviposition is not only aquatic, but frequently subterranean as well (e.g., in caves, mine shafts, and cisterns). Nonaquatic eggs most likely are encountered in areas of high and constant humidity. For example, Franz (1964) found eggs suspended from the roof of a cave near a subterranean stream. Eggs have been found attached to undersides of stones in running water (Mohr, 1943), a pattern more typical for the lineage.

ii. Clutch sizes. Females produce between 61-106 eggs (Hutchison, 1956; Minton, 2001), apparently on an annual basis (Ireland, 1976). The incubation period ranges from 4-12 wk (Mohr, 1943; Ireland, 1974). Hatchlings are about 10 mm SVL (Hutchison, 1956; Anderson and Martino, 1966; Ireland, 1974). There is some discrepancy between the number of mature follicles in oviducal egg counts (Hutchison, 1956) and the number of eggs encountered in the field, indicating that a female may split her ovarian compliment among several clutches. This would be consistent with the apparent absence of brooding (see above).

\section{Larvae/Metamorphosis.}

i. Length of larval stage. The larval period of long-tailed salamanders is about $6 \mathrm{mo}$, but overwintering (with metamorphosis occurring at 12 mo post-hatching) occurs in some populations. In New Jersey populations, metamorphosis occurs after a 2-2.5 mo larval period and at a size of about $20 \mathrm{~mm} \mathrm{SVL}$ (Anderson and Martino, 1966). Larvae taken in February in Arkansas measure $10 \mathrm{~mm} \mathrm{SVL}$ and grow rapidly, up to $6 \mathrm{~mm} / \mathrm{mo}$ during spring and summer, arriving at metamorphosis in 5-7 mo and at $23-28 \mathrm{~mm}$ SVL (Ireland, 1976). A similar pattern was recorded by Rudolph (1978) in Oklahoma populations-hatching at about $10 \mathrm{~mm}$ SVL, metamorphosis at 25-32 mm SVL after 4-7 mo. In Rudolph's populations, however, some portion of each cohort was observed to overwinter and metamorphose the following spring. He argues that overwintering is a response to lower invertebrate densities, and thus lower growth potentials, at the mouths of caves. There are reports of some populations requiring 2 yr for larval development (Smith, 1961, cited in Johnson, 1992).

$$
\text { ii. Larval requirements. }
$$


a. Food. Larvae ingest a variety of aquatic invertebrates, including ostracods, copepods, snails, and isopods, as well as insects such as dipteran and ephemeropteran larvae, and coleopterans (Rudolph, 1978).

b. Cover. Larvae most frequently are found beneath stones, limbs, and vegetation (rotting and emergent) in streams and ponds (Anderson and Martino, 1966; Petranka, 1998). Larvae may be active above cover objects and in the open at night (Petranka, 1998) and occasionally even in the middle of the day (T. J.R. and C. C., personal observations).

iii. Larval polymorphisms. None.

iv. Features of metamorphosis. Populations frequently breed in temporally variable aquatic habitats, such as classic Ambystomatype temporary ponds (Anderson and Martino, 1966) and spring-fed intermittent streams in the Ozarks (Rudolph, 1978) and central Missouri (T. J.R., personal observations), and thus are subject to the pressure of completing metamorphosis prior to the completion of pond (or stream) drying. Obviously, overwintering is dependent on the persistence of suitable aquatic habitat throughout the year and is not possible in these ephemeral habitats.

v. Post-metamorphic migrations. Migrations of post-metamorphic juveniles are typically diffuse, with individuals gradually moving farther from the water's edge as time passes, but Franz and Harris (1965) report a mass migration of post-metamorphic animals from a Maryland population.

vi. Neoteny. Perennibranchism is not known in long-tailed salamanders; the species is sympatric with a pair of perennibranchiate congeners, Oklahoma salamanders (E. tynerensis) and many-ribbed salamanders (E. multiplicata; being perennibranchiate in some populations). The coincidence of their ranges indicates that long-tailed salamanders (at least members of the subspecies E. l. melanopleura) live in habitats that may favor perennibranchism, but long-tailed salamanders apparently lack the phenotypic plasticity in the timing of metamorphosis and maturation to adopt a neotenic life history pattern.

D. Juvenile Habitat. In New Jersey, postmetamorphic juveniles can be abundant near pond edges immediately following metamorphosis, taking refuge under rocks, fallen tree trunks, and even beneath tree bark (Anderson and Martino, 1966); this seems to be a standard pattern (Petranka, 1998). In general, juveniles are found closer to the water than are adults.

E. Adult Habitat. Adults are mainly terrestrial, found in and beneath old rotting logs and under stones. They are commonly found in crevices of shale and beneath stones and rock fragments near the margins of streams. Adults freely enter water and swim with ease. As with some other members of the genus Eurycea, they will enter caves. Adults emerge to feed on humid and rainy nights, where they are most active during the first few hours after dark (Hutchison, 1958; Smith, 1961; see also Petranka, 1998). Anderson and Martino (1966) found reduced densities surrounding permanent streams compared with populations surrounding temporary wetlands.

F. Home Range Size. Unknown. Adults can cover a considerable distance over the course of the year ( $\geq 100 \mathrm{~m}$ to and from the breeding habitat), but how much of this is considered "home range" is not clear, and it is made even less clear by the suggestion that many juveniles and adults spend a great deal of time underground.

G. Territories. Adults frequently are found in large aggregations. For example, Mohr (1944) found over 300 adults near the rear of a mine shaft, and Guttman (1989) found 80 animals underneath a limestone slab and 23 adults under a 4-mlong log (see also Petranka, 1998). No territorial behavior was evident (S. A. Perrill, personal communication) when Indiana long-tailed salamanders were tested under protocols that have demonstrated territoriality in numerous other plethodontids (Jaeger and Marks, 1993). Also, territoriality is absent in three-lined salamanders ( $E$. guttolineata; Jaeger, 1988), the sister species to long-tailed salamanders

H. Aestivation/Avoiding Desiccation. Aestivation is unknown.

I. Seasonal Migrations. Adults exhibit marked seasonal patterns in habitat use. During periods of heavy rains, adults will migrate uphill to slopes. Adults are known to migrate into and out of caves and mineshafts. Mohr (1944) found that large numbers of $(300+)$ adults aggregate in a mineshaft for about 8 mo of the year, beginning in August-September and emerging again in April-May. Because hatchling larvae were detected in the ponds prior to notable surface activity, Anderson and Martino (1966) speculated that the breeding migrations may be subterranean, or that eggs are deposited in subsurface waters. This notwithstanding, they found surface activity begins in April, and by May most adults were within $6 \mathrm{~m}(20 \mathrm{ft})$ of the breeding ponds.

J. Torpor (Hibernation). Juveniles and adults migrate to underground retreats in forests in October and emerge to breed in April to early May. Whether or not this subterranean period is marked by inactivity is unclear.

K. Interspecific Associations/Exclusions. Long-tailed salamanders are rarely the only plethodontid salamanders at a particular site. For example, they are known to exist in close association with cave salamanders (E. lucifuga) in the Ridge and Valley province in western Virginia and eastern Tennessee and Kentucky (Hutchison, 1956, 1958); in eastern Oklahoma they are also found with congeneric many-ribbed salamanders and Oklahoma salamanders, but also grotto salamanders
(Typhlotriton /Eurycea/ spelaeus, Rudolph, 1978); and in Indiana they are found syntopically with southern two-lined salamanders (E. cirrigera; T. J.R. and C.C., unpublished data). Furthermore, when breeding in temporary ponds, larvae may interact with members of this ponddwelling salamander guild, such as marbled salamanders (Ambystoma opacum), Jefferson salamanders (A. jeffersonianum), spotted salamanders (A. maculatum), and eastern newts (Notophthalmus viridescens; Anderson and Martino, 1966). Some of these potential interactions appear to be ecologically important, others appear benign.

As larvae in ephemeral ponds, longtailed salamanders and marbled salamanders are the first to appear (Anderson and Martino, 1966). Marbled salamanders are fall breeders and are likely well established by the time long-tailed salamander hatchlings become active in the spring. Furthermore, marbled salamander larvae can be important predators on and/or competitors with other larval salamanders (e.g., Boone et al., 2002). Perhaps the lower density of long-tailed salamanders near streams as opposed to ponds (see above) is a response to avoiding competition from stream-dwelling plethodontids in the region (e.g., northern two-lined salamanders /E. bislineata/, northern dusky salamanders /Desmognathus fuscus/, and red salamanders (Pseudotriton ruber). However, the larvae of long-tailed salamanders and southern two-lined salamanders are found syntopically in some limestone creeks in southern Indiana (T.J.R. and C.C., unpublished data) in a manner analogous to their respective southern Appalachian sister species, three-lined salamanders and Blue Ridge two-lined salamanders ( $E$. wilderae). The nature of potential competitive interactions has not been resolved.

Long-tailed salamander larvae appear to be competitive equals with larval cave salamanders (Wooley, 1971; Rudolph, 1978; see also Hutchison, 1956, 1958). Rudolph's (1978) study of larval plethodontid community ecology indicates that long-tailed salamanders are not equal to other species, however. Both long-tailed salamanders and cave salamanders inhabit waters at the mouths of streams with subterranean origins and as far downstream as the stream's hydrological stability permits (the likelihood of stream failure increases with distance from the stream origin). However, both species are displaced downstream when the caveadapted grotto salamanders are present. Also, the diets of long-tailed salamanders and cave salamanders were more similar to each other than to other species (e.g., Oklahoma salamanders and three-lined salamanders) in field enclosures.

L. Age/Size at Reproductive Maturity. Long-tailed salamanders mature about 1-2 yr after metamorphosis (Ladd, 1947; 
Anderson and Martino, 1966; Ireland, 1974). In New Jersey, males mature when they reach about $43 \mathrm{~mm} \mathrm{SVL}$ and females at $46 \mathrm{~mm} \mathrm{SVL}$, almost uniformly at $2 \mathrm{yr}$ post-hatching. Dark-sided salamanders in Arkansas mature at smaller sizes (31-43 $\mathrm{mm}$ SVL for males, 33-43 $\mathrm{mm}$ SVL for females) and as much as a year earlier than New Jersey populations (Ireland, 1974).

M. Longevity. Unknown.

N. Feeding Behavior. Adults feed on a wide variety of invertebrate prey. Specifically, Anderson and Martino (1966) documented annelids, isopods, diplopodans, chilipodans, arachnids (pseudoscorpions, spiders, phalangids, mites, and ticks), and various insects such as homopterans, coleopterans, dipterans, hymenopterans, lepidopterans, thysanurans, and orthopterans in the diet in their New Jersey populations. Hutchison (1958) found long-tailed salamanders in Virginia caves eat primarily dipterans, orthopterans, and coleopterans. A diet analysis of an Indiana population included $>20$ types of invertebrates, with isopods, areneans, dipterans, coleopoterans, and collembolans being most numerous. Collectively, these reports indicate that long-tailed salamanders are invertebrate generalists; variations across aduit habitats (e.g., caves versus forests) and within habitats across seasons produce different opportunities for feeding.

O. Predators. Larvae are preyed upon by sculpins (Cottus sp.) and sunfishes (Lepomis sp.; Rudolph, 1978).

P. Anti-Predator Mechanisms. This aspect of the long-tailed salamanders' biology has not been studied rigorously, but individuals discovered in the field have displayed the classic defensive posture with an elevated tail (T. J.R., personal observations). The tail autotomizes readily when handled; additionally, long-tailed salamanders are quick, bolting for cover when disturbed (Johnson, 1992).

a. Diseases. Unknown.

R. Parasites. Unknown.

\section{Conservation.}

Long-tailed salamanders can be locally abundant, but populations have undoubtedly been lost due to habitat loss, effects of coal mining, and clearcutting. However, as with most other wide-ranging, stream-dwelling plethodontids, there are no robust distributional studies that document changes in gross distribution. Long-tailed salamanders are listed as Threatened in Kansas and New Jersey (Levell, 1997), and a Species of Special Concern in North Carolina.

Eurycea lucifuga Rafinesque, $1822 a ̊$ CAVE SALAMANDER

\section{J. Eric Juterbock}

1. Historical versus Current Distribution. Cave salamanders (Eurycea lucifuga) range from the southern half of Indiana and extreme southwestern Ohio in the North, to the northern third of Alabama plus extreme northeastern Mississippi and northwestern Georgia in the South. They extend from northern Virginia in the East, to northeastern Oklahoma and extreme southeastern Kansas in the West. However, they are not always uniformly distributed within this range, due to their general (but not absolute) reliance on limestone caves and springs (see "Adult Habitat" below). Hutchison (1966) and Petranka (1998) contain additional information. respectively, were reasonable at the sites, as well as $30-35,5-10$, and $25-30$ post-larval immatures, respectively. Densities in the inhabited portion of each of these three habitats varied by a factor of 5 . It is interesting that given the localized nature of their occurrence (and not knowing their population or metapopulation genetics), the sizes of all these localized groups are well within an order of magnitude. That said, none of these studies was long term, and none has been repeated. A further caution is evidenced by a removal

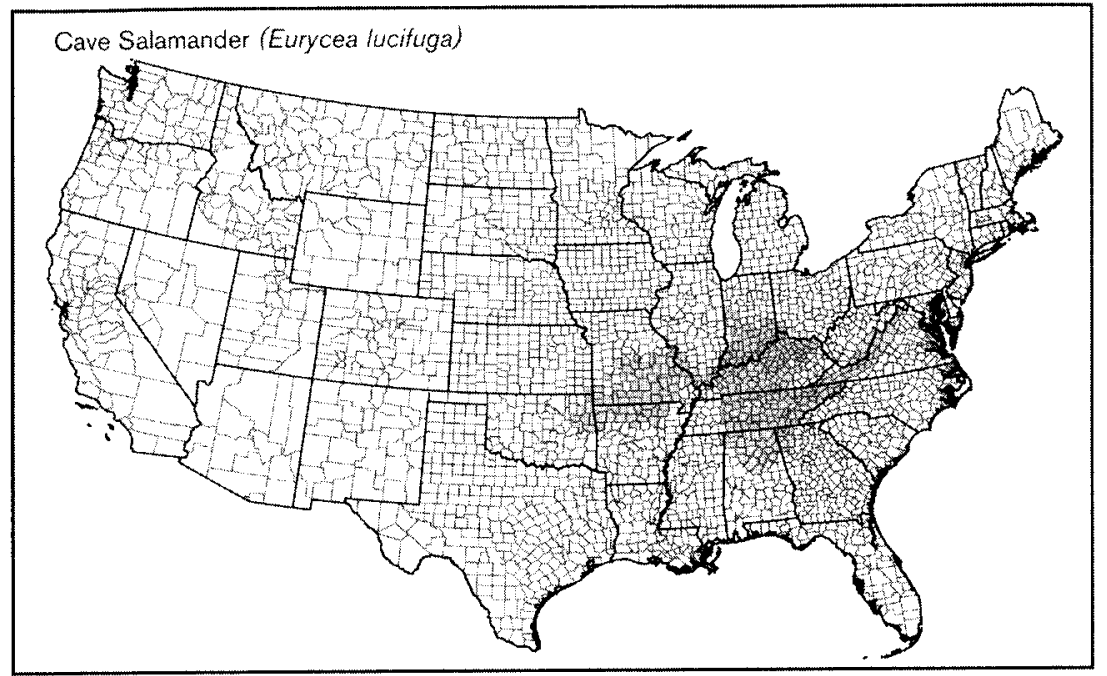

2. Historical versus Current Abundance.

It is impossible to determine accurately the general abundance of cave salamanders from available data. Although numerous accounts give some indication of the number of individuals collected, and some even indicate the number of individuals seen, only three accounts give any indication of population size/density. Hutchison (1958), after a mark-releaserecapture study, presented what he suggested were "rough estimate|s|" that he thought "to be rather close" to actual population sizes in four Virginia caves: 36,60 , 62 , and 63 . He gave no estimate of density nor indication of cave size; there has been no subsequent study of these populations. Williams (1980), who collected and preserved the specimens he observed in a 1968 Illinois study, concluded that the investigator has an effect on the size of the visible population and compared his results with those of Hutchison. Whether or not such an effect exists, it seems likely that the removal of at least 68 adults from one cave, as he apparently did during his study, would have at least as great an effect upon the population as would disturbance through visitation.

Juterbock (1998) studied three ravine sites in Ohio and, after $3 \mathrm{yr}$ of recapturing marked individuals, concluded that estimates of $30-35,20-25$, and 5-10 adults, study of salamanders in an Appalachian streamside community by Petranka and Murray (2001). They estimated that between 8 and 32 consecutive nights of sampling were required to remove $70 \%$ of the population for the six studied species. Thus, studies utilizing occasional sighting or capture-release-recapture techniques would probably underestimate population size, possibly substantially so.

To the degree that cave salamanders are dependent upon, or associated with, caves and similar limestone features, there is some reason for concern about their populations. Although the biggest threat to cave faunas may be their extremely localized occurrence, there are three recognized sources of vulnerability for cave organisms (Culver et al., 2000): (1) actions that directly degrade subsurface habitat; (2) actions that degrade surface terrestrial habitat and lead to degradation of subsurface habitat; and (3) actions that degrade surface aquatic habitat and lead to degradation of subsurface habitat. Minton (1998) contains one descriptive account of decline in cave salamander numbers, based upon his observations of Indiana sites from 1948-93. At a spring on a steep slope of exposed siltstone in Floyd County, cave salamanders, once "regularly found," ceased to be observed as the habitat was degraded over the years. 


\section{Life History Features}

For information beyond that in the following sections, Petranka (1998) is a good recent starting point. Hutchison's (1956, $1958,1966)$ reports contain much original material and review previous work.

A. Breeding. Reproduction is aquatic.

i. Breeding migrations. Breeding migrations of the type typical of pond-breeding frogs and salamanders are unknown. Neither are such migrations suspected, given the life history of cave salamanders. However, that is not to say that such seasonal movements as occur (see "Seasonal Migrations" below) may not also be related to reproduction.

ii. Breeding habitat. There are few records for this species of naturally occurring egg clutches. The sparse evidence is summarized by Petranka (1998) and would indicate sites deep within surface or cave springs or cave streams. Minton (1972, 2001) reported finding large larvae in an Indiana cave approximately $1 \mathrm{~km}$ from the entrance.

\section{B. Eggs.}

i. Egg deposition sites. Myers (1958, p. 126) reported that eggs found in early January in a Missouri cave were "attached singly to the bottoms and sides of submerged rocks." The site in the stream was approximately $245 \mathrm{~m}$ from the entrance to the cave and about $1 \mathrm{~m}$ from where the stream flowed from the cave wall. Green et al. (1967) found eggs in three West Virginia caves attached to the sides of rimstone pools on the floor or sides of the caves, as well as unattached in the silt of the pools.

Banta and McAtee (1906) proposed, on the basis of finding $18 \mathrm{~mm}$ TL larvae in early February in Indiana, that oviposition had occurred around the end of December to early January. They also found "small larvae" as late as 20 March. Myers (1958, p. 126) found eggs "in various stages of development, from early cleavage to advanced embryos" in Missouri on 2 January. At the same time, he also found newly hatched larvae, measuring $11 \mathrm{~mm}$ TL (approximately 80\% of which was SVL). Perhaps Hutchison's (1956) report of a $17 \mathrm{~mm}$ (TL or SVL not indicated) larva in Virginia during July could indicate a slow growth rate rather than a later time of oviposition. Myers (1958) "tentatively" interpreted the available data as indicating that the period from oviposition to hatching lasted from as early as October to as late as May. Green et al. (1967) slightly increased that range, reporting eggs in West Virginia caves from 24 September-5 November. The data do not exist to evaluate inter- and intrapopulation variation for this trait.

ii. Clutch size. Hutchison (1956) counted ovarian eggs in 17 adults collected during July and August in Virginia. They averaged 68.3 (median $=67$, range $=49-87)$. Trauth et al. (1990) counted ovarian eggs in 11 adults collected in Arkansas; these averaged 77.7 (range $=60-120)$. Clutch size in all likelihood varies with female body size, but insufficient data exist to evaluate such a hypothesis.

\section{Larvae/Metamorphosis.}

i. Length of larval stage. Banta and McAtee (1906) estimated a 12-15 mo larval period as typical for cave salamanders in Indiana. They suggested that some larvae undergo metamorphosis in autumn, when they collected larvae ranging between 31-56.5 mm TL. They concluded that most larvae transformed in March, when they collected an individual metamorphosing. Green et al. (1967) believed that a $30 \mathrm{~mm}$ TL larva in one of their West Virginia caves and a $41 \mathrm{~mm}$ TL larva reported by Myers (1958) from Tennessee, collected during late February to March, were $1 \mathrm{yr}$ old. Sinclair's (1950) observation of three larvae measuring $22.5 \mathrm{~mm}, 31.5 \mathrm{~mm}$, and $51.5 \mathrm{~mm}$ TL in mid March more clearly demonstrates overlapping generations.

ii. Larval requirements.

a. Food. Rudolph (1978) studied larval food habits of cave salamanders in northeastern Oklahoma and compared them to the larvae of four related salamander species. Of 370 cave salamander food items, $71.6 \%$ were ostracods and $12.2 \%$ were dipteran larvae; other food items, in order of abundance, included pulmonate snails, ephemeropteran nymphs, isopods, dipteran adults, trichopteran nymphs, adult coleopterans, larval coleopterans, plecopteran nymphs, copepods, and Araneae. As expected, most of these food items are aquatic. The food items of larvae of four syntopic species showed some overlap with larval cave salamanders. Most similar in their feeding habits were long-tailed salamander (E. longicauda) larvae, although Rudolph concluded that food competition was probably secondary to competition over space. The other species' food habits probably allow rejection of a hypothesis that cave salamander larvae were only eating things in the proportion in which they occurred in the habitat. Although ostracods were abundant in the diets of all 5 species, they were not the most numerous item for two species. Additionally, certain food items were considerably more abundant in the diets of one or more of the other species than in the diet of cave salamanders (e.g., copepods, amphipods, and isopods for grotto salamanders /Typhlotriton (Eurycea) speleaus/; copepods for long-tailed salamanders; and, isopods for Oklahoma salamanders (E. tynerensis/). Still, it is possible that microhabitat segregation may be at least partially responsible for the observed dietary differences.

b. Cover. Banta and McAtee (1906), working in Indiana, indicated that oviposition was in the deepest parts of caves and felt that larvae found at cave mouths and in outside streams were carried there by currents. Sinclair (1950) reported counting hundreds of larvae, at all hours of the day, crawling about the bottom of a surface spring with no cover. He further indicates that he could not find larvae in caves, and that they seemed to prefer cover when they approached metamorphosis. Although the numbers of larvae sound impressive, it is worth noting that, with clutch sizes over 50 (probably averaging 70-75), "hundreds" of larvae, especially if young, might only represent a few clutches. Green et al. (1967) stated that larvae move out of the rimstone pools in which they hatch as those pools overflow in the winter and early spring. Larvae were found in the small, temporary overflow streams and the permanent main stream in the cave; no cover was mentioned. These authors note that larvae were always observed to move downstream, both under their own power and by the action of currents. This alone could explain the appearance of larvae in surface springs and streams, although more needs to be learned about oviposition sites and larval life history. In northeastern Oklahoma (Rudolph, 1978), larvae were found in some surface streams $\leq 45 \mathrm{~m}$ from the source spring under unspecified cover. In southwestern Ohio ravines, larvae were rarely seen and presumed to remain underground (unpublished data).

iii. Larval polymorphisms. None known.

iv. Features of metamorphosis. In southwestern Ohio, the smallest metamorphic animals appear in the surface-active population in late summer, at approximately 35-40 mm SVL and probably 18-21 mo old. Metamorphosis in Ohio does not appear to be at all synchronous. Of individuals captured while undergoing metamorphosis, 10 individuals were captured at two sites between May and September, with six of these in August (unpublished data). The smallest two metamorphosing salamanders were $27 \mathrm{~mm} \mathrm{SVL}$ (captured in July and September); the largest one was $41 \mathrm{~mm}$ SVL in May (the second smallest of its age/size class $[\mathrm{n}=8$, SVL range $=38-50$ ) in a collection containing a $23 \mathrm{~mm} \mathrm{SVL}$, larva); the median size was $32 \mathrm{~mm}$ SVL. Only three larvae were captured at these sites, with SVLs of $15 \mathrm{~mm}$ (2 May), $23 \mathrm{~mm}$ (24 May), and $24 \mathrm{~mm}$ (13 June). I am aware of no other data on the timing of metamorphosis that is this complete (although individuals at these sites could only be found on the surface from AprilSeptember).

The smallest metamorphosed specimen reported by Williams (1980) was a 31 $\mathrm{mm}$ SVL female, and the largest larva was $33 \mathrm{~mm} \mathrm{SVL}$; TLs were $68 \mathrm{~mm}$ and $70 \mathrm{~mm}$, respectively. He concluded that metamorphosis usually occurred between 25-35 mm SVL. He reported 26 larval specimens, but indicated that this was too small a sample to determine age classes; no data beyond those of the previous sentence were presented. Green et al. (1967) stated 
that metamorphosis occurred between 50-56 mm TL. Sinclair (1950) found two recently metamorphosed animals (59 and $60.5 \mathrm{~mm}$ TL) in a Tennessee cave on 2 June.

Rudolph (1978) studied northeastern Oklahoma populations found in surface springs, as well as caves, and stated that metamorphic size for cave salamanders in these populations was approximately $25 \mathrm{~mm}$ SVL. He indicated that recently hatched larvae appeared in springs during winter and early spring, and their spring and summer growth usually allowed them to metamorphose between July-October of the same year. Metamorphosis at this time was also supported by the observation of recently metamorphosed animals in the nearby terrestrial habitat. However, he adds that during winter one can usually find a few large larvae, because some individuals overwinter and metamorphose during their second spring. This implies that metamorphosis could occur as early as about $6 \mathrm{mo}$ or as late as perhaps $18 \mathrm{mo}$.

Apparently, the only indication of growth in larval cave salamanders is contained in the two samples Rudolph (1978) collected from the same surface stream in northeastern Oklahoma. In those, there was a median size (SVL) difference of 10.5 mm (8 June 1976 collection: $n=17$, median=14 mm, range $10-22 \mathrm{~mm}$; 1 August 1976 collection: $n=26$, median $=24.5$, range $19-29 \mathrm{~mm}$ ).

v. Post-metamorphic migrations. None known.

vi. Neoteny. Unknown, although some larvae will overwinter and metamorphose the following year (Minton, 1972; Rudolph, 1978; see also Petranka, 1998).

D. Juvenile Habitat. There is no evidence that juvenile habitats differ from those of adults. One possible exception involves the timing of habitat use. In southwestern Ohio, I found that adults were much more likely to be active on the surface in late spring as compared to juveniles, whereas juveniles were much more likely to be active on the surface in late summer. For example, at one site over three years, 27 individual adults were captured in May, but only two in August or September; for juveniles, the numbers were 19 and 22, respectively (chi-squared $=16.7, \mathrm{p}<0.001$ ). The surface habitat at these sites generally is drier in late summer.

E. Adult Habitat. Adults are essentially terrestrial and/or associated with caves in limestone regions (e.g., Peters, 1946). Although most records are from, and the species appears to be most abundant in, the twilight regions of caves, where they climb over walls and ledges, they are also found outside of caves, under stones, logs, and other surface matter, as well as deeper in caves. Hutchison (1958) reported one locality where the species is associated with a non-calcareous cave. Banta and McAtee (1906) indicated that cave salamanders were found on the walls of the caves and rarely on the cave floor or in the water. Green et al. (1967) agree with this assessment, but Williams (1980) collected $16 \%$ of his adult specimens from the stream; most were under rocks. Petranka (1998) summarizes the variety of relevant reports, as well as cautioning that the species' restriction to cave habitats is overemphasized. Certainly there are no caves in Hamilton County, Ohio, where terrestrial stage individuals are infrequent to common in at least six county and one city park units. Here the habitat consists of forested limestone ravines, at least some of which appear to have subsurface water flow (Davis et al., 1998; Juterbock, 1998). In these situations, adults seldom are seen free of cover, regardless of whether or not it was during the day or night (personal observations). Metamorphosed individuals of all ages are found in the stream bed, but rarely in the water; they are under rocks (mostly), logs, and debris. They only are present on the surface when there is water present or when the soil is muddy (unpublished data). Smith (1961) reported that spring-fed cypress swamps, located "well away from" rock bluffs, were the Illinois sites where cave salamanders were most abundant. Adults and larvae were commonly found there under leaves and logs. I have also seen numerous individuals of various sizes active on the surface of a roadcut on a hillside above a stream in Kentucky (personal observations).

F. Home Range Size. In one southwestern Ohio ravine, over the course of three surface-active seasons, 31 adults were recaptured at least once. Of these, 22 (71\%) had maximum ranges along the ravine (at least $50 \mathrm{~m}$ of habitat) of $\leq 10 \mathrm{~m}$, and mean distances between captures of $\leq 10 \mathrm{~m}$ (unpublished data). Thirteen of the $22(42 \%$ of the total 31) were recaptured after overwintering below the surface at least once (and thus at least seasonally shifting the area in which they were active).

G. Territories. Territoriality has not been reported and seems unlikely. Smith (1961), for example, reported that a single large rock might contain "a number" of individuals.

H. Aestivation/Avoiding Desiccation. Aestivation has not been reported and seems unlikely, especially given the cave/spring habitat of this species. However, it is not clear what effects drought may have on the species. Hutchison (1958) found at least one individual in at least one of his four Virginia study caves each month except January.

I. Seasonal Migrations. Hutchison (1958) measured the distance from the mouth of one of his Virginia study caves to the site of each salamander's capture during the year. The salamanders were closest to the mouth in June-July and farthest from the mouth in February-March. He concluded that these data were evidence that migration from the cave did not occur. They do, however, clearly indicate seasonal movements within the cave ecosystem, from a June mean of $4.7 \mathrm{~m}$ from the mouth to a March mean of 26.6 $m$ from the mouth. Hutchison (1958) also found that the visible population in all caves that he studied increased from late February to March (in different caves) to a peak in June and then declined dramatically by September. These data mirror the distance data and support a hypothesis of seasonal movements within the habitat. Williams (1980) collected almost 4-5 times as many individuals in MayJune as he had in March-April, after which the July and August numbers returned to the level he had seen before the peak. As noted above (see "Historical versus Current Abundance" above), removing 60 or more individuals from the population during the spring should have affected summer counts. Juterbock (unpublished data) found a May-June peak in the surface-active population in southwestern Ohio limestone ravines, with a lesser, secondary peak (comprised primarily of juveniles) in late August to September. Although surface activity is unlikely in the winter in these ravine habitats, the overall pattern is similar to that described for caves and indicates at least seasonal movements from surface (active) to subsurface (inactive?) habitat.

J. Torpor (Hibernation). Considered unlikely by Hutchison (1958), who saw salamanders that were active during the winter while deep in the caves.

K. Interspecific Associations/Exclusions. Hutchison studied cave salamanders and long-tailed salamanders from four caves in Virginia. He found that the two species often shared the twilight zones of caves, with cave salamanders usually more abundant. However, because he found long-tailed salamanders in "comparatively larger numbers" in areas where cave salamanders did not occur (Hutchison, 1958 , p. 11), he concluded that interspecific competition between the two species may occur. The similarities of diet (see "Larval requirements" above and "Feeding Behavior" below) may offer a hint as to the mechanism involved.

L. Age/Size at Reproductive Maturity. Hutchison (1958) reported that Virginia males were mature at $>46 \mathrm{~mm} \mathrm{SVL}$, and females at $>48 \mathrm{~mm}$ SVL. In southern Illinois, Williams (1980) reported that females $>49 \mathrm{~mm}$ SVL were mature. Juterbock (1998), sexing recaptured individuals by means of externally visible characteristics, found the smallest mature males in Ohio to be $54 \mathrm{~mm}$ SVL and the smallest mature females to be $56 \mathrm{~mm} \mathrm{SVL}$. One of the smallest individuals was $53 \mathrm{~mm}$ and could not be sexed on 3 May, but was clearly a male when recaptured on 31 May of the same year. Although not nearly as dramatic, many of the smallest mature 
individuals he recorded were previously observed as unsexable immatures. The differences in size indicated by these three accounts may be real variation or an artifact of using different techniques.

Mostly because of the uncertainty surrounding larval age classes, age at maturity is problematic. The recapture data from southwestern Ohio (unpublished data) leave little doubt that at least 2 yr are required before maturity is attained after the summer of metamorphosis. This would be either the third or fourth summer after the winter of hatching (or approximately 2.5 or $3.5 \mathrm{yr}$ of age), depending upon the length of the larval period. As noted above, it is likely that the duration of the larval period varies, probably both within and between populations. From a conservation perspective, this is one of the more glaring gaps in our knowledge of the species.

Hutchison (1958) observed an overall male:female sex ratio of 1.51:1 in his four Virginia caves. Three of those caves, with total sample sizes of 38,54 , and 59 , had individual ratios of $0.65,1.6$, and 1.1 , respectively (so the largest sample was the closest to $1: 1)$. Williams (1980) reported a ratio of 1.125:1 $(n=70)$ with males dominant. In contrast, Juterbock (unpublished) found that (based upon externally detectable characteristics of marked salamanders) mature females insignificantly outnumbered males 39:26 (chi-squared $=2.6$, $\mathrm{p}=0.11$ ) in southwestern Ohio. Only at the site with the most adults captured $(52 \%)$ was the difference significant (11 males, 23 females; chi squared $=4.24$, $p=0.04$ ). It is not known whether these differences represent a real result of interspecific variation in life history or an artifact of what are actually rather small samples.

M. Longevity. Not known.

N. Feeding Behavior. Peck (1974) surveyed for food in the guts of 112 cave salamanders ( 11 were empty) from nine (mostly southeastern) states and found a minimum of 73 prey species. These included annelid worms, snails, crustaceans, millipedes, various arachnids, and 14 orders of insects ( 14 families of beetles, 12 families of flies, and 4 families of hymenopterans). Spiders, crickets, and at least four families of flies were found in at least $10 \%$ of those guts containing food items. Peck and Richardson (1976) studied the diets of an additional 213 cave salamanders from four southeastern states, primarily to elucidate any differences in feeding ecology with respect to location within the cave. They found that the salamanders were best fed within the twilight zone of the cave and least well-fed in the zone of permanent darkness. The major dietary difference discovered was the importance of trichopteran insects, but these were an ephemeral resource at only a few of the studied caves. They identified at least 101 taxa of prey in the study. Hutchison (1958) compared the food items in guts of 13 cave salamanders and 10 longtailed salamanders. He found seven orders of insects (more fly taxa and individuals), three orders of arachnids (but no spiders), and isopods. The frequency of occurrence of most taxa was slightly greater for cave salamanders than for long-tailed salamanders, but their diets overlapped greatly.

O. Predators. There appear to be no records of specific predators attacking or consuming cave salamanders, but their responses to disturbance (see "Anti-Predator Mechanisms" below) presumably evolved for a reason. Numerous authors have suggested potential predators (e.g., Hutchison, 1958).

P. Anti-Predator Mechanisms. As do most plethodontid salamanders, cave salamanders possess skin glands that secrete noxious substances. Cave salamanders and their relatives raise and undulate the tail over the head, which, because the body is coiled, rests near the vent (Brodie, 1977). Brodie (1977) has witnessed congeneric species use this posture when attacked by short-tailed shrews (Blarina brevicauda) and blue jays (Cyanocitta cristata). In tests with shrews, he noted that 12 of 13 attacks resulted in bites to the tail, with the shrew briefly retreating and wiping its mouth; this should allow the salamander a brief opportunity to escape.

Under this scenario, one would expect that one explanation of broken tails would be failed predation attempts. The percentage of individuals with broken or obviously regenerating tails varies widely in different populations: approximately $4 \%$ in Virginia (Hutchison, 1956); 28.3\% in Illinois (Williams, 1980 ); and $59.5 \%$ of 74 adults, $16.4 \%$ of 61 immatures in Ohio (unpubished data). This difference between tail damage rates of adults and immatures is significant (chi squared $=24.5$, $\mathrm{p}<0.001$ ) and presumably relates to the accumulation of time spent in the terrestrial environment. It is worth noting that the Ohio populations occur in ravines, not caves, in a generally urban area. Whatever else may be harassing cave salamanders at these sites (and I have observed children turning rocks at these places), there also are urban population levels of raccoons, and all the Ohio sites studied did occasionally exhibit signs of raccoon foraging.

\section{Q. Diseases. No records.}

R. Parasites. McAllister et al. (1995d), in a study of another species of Eurycea in Arkansas, noted the first record of the nematode Desmognathinema nantahalaensis in cave salamanders.

\section{Conservation}

It is impossible to accurately determine from available data the general abundance, and therefore the conservation status, of cave salamanders. Because cave salamanders are dependent upon, or associated with, caves and similar limestone features, there is some reason for concern. Although the biggest threat to cave faunas may be their extremely localized occurrence, actions that directly degrade subsurface habitat or surface terrestrial and/or aquatic habitats negatively affect populations. Cave salamanders are listed as Endangered in Ohio, Mississippi, and Kansas (Levell, 1997), and considered Rare in West Virginia.

\section{Eurycea multiplicata (Cope, 1869)} MANY-RIBBED SALAMANDER

Stanlcy E. Trauth, Harold A. Dundee

\section{Historical versus Current Distribution.} Many-ribbed salamanders (Eurycea multiplicata) occur in the Ozark Plateaus and the Boston and Ouachita mountains and associated lowland rocky formations in southwestern Missouri, eastern Oklahoma, and northwestern Arkansas, at elevations of 107-763 m (Dundee, 1965a; but see Bonett and Chippendale, 2004). Two subspecies are recognized: many-ribbed salamanders (E. $m$. multiplicata) occur in southeastern Oklahoma and west central Arkansas, while gray-bellied (or graybelly) salamanders ( $E$. m. griseogaster) occur in northeastern Oklahoma, southwestern Missouri, and northwestern Arkansas. The type locality of $E . m$. multiplicato is in question (Dundee, 1950), but the type locality of E. m. griseogaster is clearly stated (Moore and Hughes, 1941). Cope (1889) reported many-ribbed salamanders from Kansas, but this record apparently is not backed by a voucher specimen (Dundee, 1965). If Cope was correct, a range contraction for this species has occurred. Besides this mention, no evidence supports declines or shifts in distributions.

\section{Historical versus Current Abundance.} Generally unknown, but Dundee (1947) reports finding gray-bellied salamanders "in abundance" and "in large numbers" at certain sites and certain times of the year in Oklahoma, particularly in winter and early spring.

\section{Life History Features.}

A. Breeding. Reproduction is aquatic.

i. Breeding migrations. Long-distance migrations are unlikely.

ii. Breeding habitat. The mating season varies among populations of gray-bellied salamanders. Populations that inhabit thermally stable springs have a prolonged mating season compared with populations inhabiting surface streams with more variable temperatures. Based on the times when females contained spermatozoa in their reproductive tracts, mating activity could be from July-May (Ireland, 1976). Ireland (personal communication) agrees that he meant spermatheca for the term reproductive tracts. 


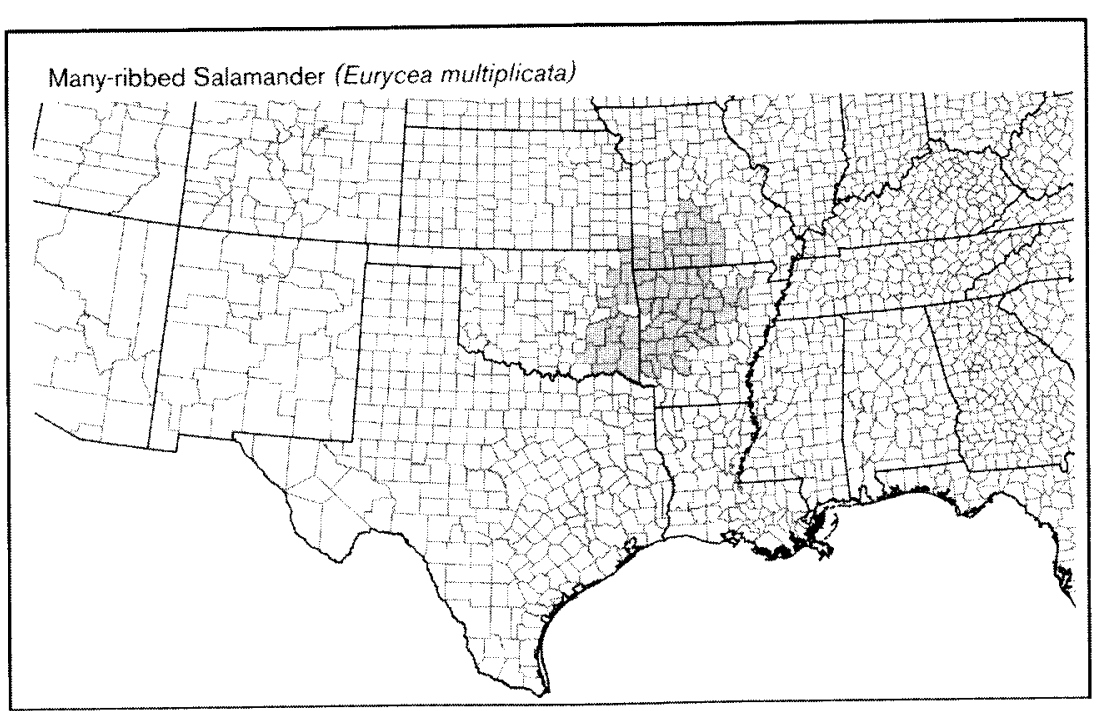

B. Eggs.

i. Egg deposition sites. Females lay their eggs in springs, spring-fed pools, and spring-fed ponds from autumn to early spring (Spotila and Ireland, 1970; Ireland, 1976). Eggs usually are laid on the undersides of submerged stones or beneath several layers of smaller stones (Trauth et al., 1990).

ii. Clutch size. Egg counts range from 2-21, but average 10-13 (Ireland, 1976; Trauth et al., 1990). Eggs range from $2.0-2.6 \mathrm{~mm}$ in diameter. Females do not brood. Hatchlings average about $10 \mathrm{~mm}$ SVL (Petranka, 1998), but Petranka does not document this size.

C. Larvae/Metamorphosis.

i. Length of larval stage. Larvae grow quickly, range in size from 23-85 mm TL, and metamorphose between $33-48 \mathrm{~mm}$ SVL, 5-8 mo after hatching.

ii. Larval requirements.

a. Food. Larvae feed most actively at night. Although larvae are described as benthic feeders and will eat isopods, ostracods, and zooplankton, aquatic insects usually are consumed (Rudolph, 1978; see also Petranka, 1998).

b. Cover. During daylight, many-ribbed salamanders are usually found under stones in slow-moving streams. Larvae will inhabit more ephemeral portions of streams than will adults (Loomis and Webb, 1951). Bragg (1955b) observed that small $(<18 \mathrm{~mm})$ gray-bellied salamanders can be found in shallow water, in the open, both day and night. Larger larvae spend more time burrowed in gravel.

c. Temperature. Gray-bellied salamander larvae have been found in water as warm as $22^{\circ} \mathrm{C}$ in summer (August) and as cold as $9.5^{\circ} \mathrm{C}$ in winter (Dundee, 1958).

iii. Larval polymorphisms. Undescribed and unlikely.

iv. Features of metamorphosis. At metamorphosis, animals are approaching sexual maturity. Ireland (1976) found that
$16 \%$ of males in the process of metamorphosing contained spermatozoa.

v. Post-metamorphic migrations. Bragg (1955b) observed that when gray-bellied salamanders begin to metamorphose, they leave the stream and complete their development along the streambank in moist leaves or under stones.

vi. Neoteny. At metamorphosis, animals are approaching sexual maturity. Gilled adults are common in gray-bellied salamander populations that inhabit caves or streams draining caves, especially on the Salem Plateau (Dundee, 1965; Trauth et al., 2004; see also Dundee, 1947, for manyribbed salamanders, and Petranka, 1998). Neotenic animals that inhabit caves often are pale and lack components of the normal pigment pattern, whereas neotenic animals in the vicinity of caves retain normal larval pigment patterns.

D. Juvenile Habitat. Similar to that of adults (cool, moist habitats near water under stones, logs, and other large materials in streams and springs, both in the open and in the twilight zone of caves; see "Adult Habitat" below), or if neotenic, similar to that of larvae (see "Neoteny" above).

E. Adult Habitat. Adults are essentially aquatic but occasionally are found on land. Many-ribbed salamanders are found in cool, moist habitats near water under stones, logs, and other large materials in streams and springs, both in the open and in the twilight zone of caves (Moore and Loomis and Webb, 1951; Ireland, 1976; see also Petranka, 1998). Large numbers of gray-bellied salamanders were found under cover objects when the adjacent water had a thin film of ice after overnight subfreezing temperatures (H. A. D., field notes). found in caves (Dundee, 1965a). At a study site in Cherokee County, Oklahoma, gray-bellied salamanders were common where water flowed over shallow soils and exposed solid limestone in cool months, Hughes, 1941; Dundee, 1947, 1958, 1965a;

In the Ozark highlands, adults are but which were dry during summer and early autumn (Dundee, 1958). Bragg (1955b) noted habitat differences between many-ribbed and gray-bellied salamanders:

Both [subspecies] occur in Cherokee County [Oklahoma] but apparently they tend to occupy different habitats. Wherever very small streams traverse solid limestone rock or soil, [many-ribbed salamanders are] very likely to be present. If a similar stream cuts through chert, flint, or granite, [gray-bellied salamanders are] the form to be expected, if either form occurs. My experience is not wide enough to say that there never are exceptions, but I can say that so far I have found none in Oklahoma.

One exception is known,-one of Dundee's (1958) study sites for gray-bellied salamanders was over solid limestone rock with grassy hummocks on it.

F. Home Range Size. Unknown but likely to be small. In the first collections of gray-bellied salamanders (Moore and Hughes, 1941), adults and larvae were collected together.

G. Territories. Unknown but unlikely. Loomis and Webb (1951) reported that frequently two or three, and up to four, many-ribbed salamander adults were found under a single rock. Much higher numbers of gray-bellied salamanders have been found under single cover objects (H. A. D., field notes).

H. Aestivation/Avoiding Desiccation. Adult gray-bellied salamanders tend to be found in association with springs and permanent streams and within the wetter portions of such streams during drier periods (Loomis and Webb, 1951). Animals may aestivate, as suggested from at least one site in Oklahoma that would dry in the summer when no salamanders could be found (Dundee, 1958). Bragg (1955b) noted terrarium observations on many-ribbed salamanders that support the possibility of aestivation.

I. Seasonal Migrations. Individuals do not disperse far from their natal streams.

J. Torpor (Hibernation). Animals apparently stay active near the surface, being found under rocks, logs, and moss in or near the edges of streams, except during periods of extreme winter weather (Dundee, 1947).

K. Interspecific Associations/Exclusions. Many-ribbed salamanders are found in association with Ouachita dusky salamanders (Desmognathus brimleyorum) in Arkansas (Strecker, 1908a). Gray-bellied salamanders are found with grotto salamanders (Typhlotriton [Eurycea] spelaeus) in Missouri (Noble, 1927b). Loomis and Webb (1951) noted that oftentimes stones that held many-ribbed salamanders provided a substrate for small- to mediumsized tarantulas (Aphonopelma hentzii), but tarantulas preferred the drier area under the stone. 
Spring-fed headwaters in eastern $\mathrm{Ok}$ lahoma often contain assemblages of 3-5 species of salamander larvae, including long-tailed salamanders (E. longicauda), cave salamanders (E. lucifuga), manyribbed salamanders, Oklahoma salamanders (E. tynerensis), and grotto salamanders that segregate by distance from the spring head. This habitat segregation may be due to competitive factors (Rudolph, 1978; see also Petranka, 1998).

L. Age/Size at Reproductive Maturity. Reproductive maturity is reached at metamorphosis, or shortly thereafter (Ireland, 1976), although gilled adults are common in some populations (Dundee, 1947; see also Petranka, 1998). Ireland (1976) found that all metamorphosed males have spermatozoa in their seminiferous tubules; $16 \%$ of males in the process of metamorphosing also contained spermatozoa. Size varies across populations, with transformed animals averaging 28-45 mm SVL (Moore and Hughes, 1941; Loomis and Webb, 1951; Dundee, 1965). Males and females vary little in size, form, or color (Moore and Hughes, 1941). Little growth occurs after metamorphosis (Dundee, 1965a). Neotenic animals can exceed metamorphosed animals in size, reaching $54 \mathrm{~mm}$ SVL and $160 \mathrm{~mm}$ TL (Dundee, 1965a).

M. Longevity. Unknown.

N. Feeding Behavior. Undescribed, but adults likely feed on a variety of aquatic and semi-aquatic vertebrates associated with springs and permanent streams. The diet of neotenic adults likely resembles that of larvae (see "Larval requirements" above), although adults, being larger, may take larger prey. Terrestrial adult gray-bellied salamanders consume some aquatic arthropods but primarily eat terrestrial arthropods, snails, and oligochaetes (Dundee, 1958).

O. Predators. According to Petranka (1998), few data are available on natural predators, but they undoubtedly include crayfish and raccoons. Terrestrial stages probably are preyed upon by large beetles, other salamanders, and frogs. Fishes will feed on larvae and appear to exclude them in downstream sections of streams (Petranka, 1998).

P. Anti-Predator Mechanisms. In daylight, both larvae and adults seek cover under stones in slowly moving water. If their stone is removed and animals feel threatened, they will seek cover under a nearby stone (Moore and Hughes, 1941).

a. Diseases. Undescribed.

R. Parasites. McAllister et al. (1995d) described the metazoan parasites of 50 larval and adult gray-bellied salamanders from seven Arkansas counties. In general, these parasites are typical of parasites reported from other plethodontid salamanders and exhibit little or no host specificity. Seven (14\%) animals were infected with $\geq 1$ parasite as follows: a seuratoid nematode (Desmognathinema nantahalaensis; three animals), an ancanthocephalan (Fessisentis vancleavei; two animals [this species also reported by Malewitz (1956) from Oklahoma specimens and from Madison and Benton counties, Arkansas, by Saltarelli (1977) and Buckner and Nickol (1978)]), larval intradermal mites (Hannemania sp.; two animals), a plagiorchid nematode, a trematode (Brachycoelium salamandrae; one animal). Ectoparasitic flukes (Sphyranra euryceae) occur in larval and neotenic gray-bellied salamanders (Dundee, 1958; McAllister et al., 1991) and nematodes in the larvae (Dundee, 1958). In terrestrial gray-bellied salamanders, cysts, probably of nematodes and flukes, are found in the skins of terrestrial individuals, and cestodes occur in the gut (Dundee, 1958).

\section{Conservation.}

Many-ribbed salamanders inhabit a fairly large region of rugged, hilly, and mountainous terrain, most of which is not amenable to agticulture or developing urban settings. Despite considerable logging over much of the terrain and use of flatter areas for cattle grazing, substantial populations of this salamander are found in many settings, even within properties that people have developed. The only threats to the species are an increasing number of recreational homes scattered throughout the region and some improvements to caves that they inhabit being turned into commercial caves. Some of the stream areas that the species inhabits might become polluted if improper sanitary facilities are constructed. Overall, we do not visualize much impact on the species.

\section{Eurycea nana Bishop, 1941(a)}

SAN MARCOS SALAMANDER

Paul T. Chippindale, Joe N. Fries

1. Historical versus Current Distribution.

San Marcos salamanders (Eurycea nana) were described from outflows of San Mar- cos Springs in the city of San Marcos, Hays County, Texas, by Bishop (1941a) Some authors (Sweet, 1978a; Dixon, 1987) also have considered the population of Eurycea at Comal Springs, Comal County, to be this species, but morphological and molecular evidence strongly reject this hypothesis (Chippindale, 2000; Chippindale et al., 1998, 2000). Their historical distribution probably is similar to their current distribution, although San Marcos Springs has been heavily modified by humans in the past century to form a small lake. Salamanders occur throughout much of this lake and extend about $150 \mathrm{~m}$ into the most upstream portion of the San Marcos River (Nelson, 1993). Based on phylogenetic analyses, E. nana appears to be the sister taxon to the southeastern Edwards Plateau subgroup of Texas Eurycea (Chippindale, 1995, 2000; Chippindale et al., 2000). Although Schmidt (1953) regarded this taxon as a subspecies of Texas salamanders ( $E$. neotenes), few others (and no recent authors) have followed this approach. Molecular and morphological data strongly support their recognition as a distinct species (Chippindale, 1995, 2000; Chippindale et al., 1998, 2000).

\section{Historical versus Current Abundance.}

Extremely abundant within their severely limited range. Population densities are estimated to be about 116-129 individuals $/ \mathrm{m}^{2}$ in vegetation mats (Tupa and Davis, 1976; Nelson, 1993). The entire population has been estimated to be about 53,200 individuals in vegetation mats and suitable rocky substrates (USFWS, 1996b).

\section{Life History Features}

A. Breeding. Reproduction is aquatic. i. Breeding migrations. Unlikely to occur. ii. Breeding habitat. A subset of adult habitat.

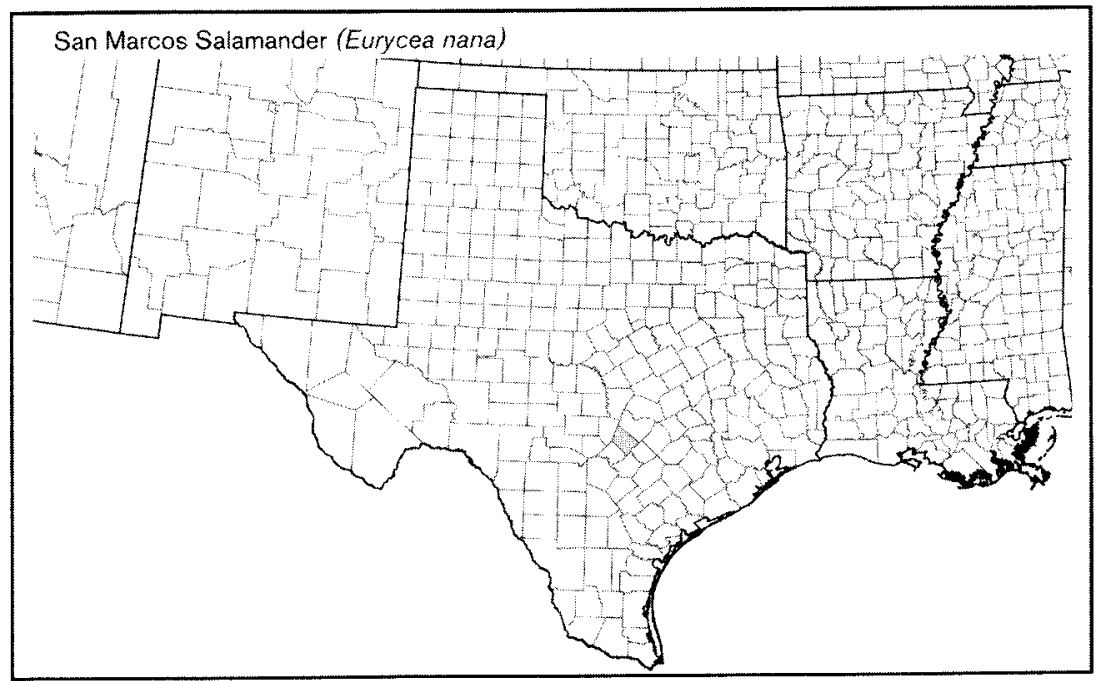




\section{B. Eggs.}

i. Egg deposition sites. Eggs have never been observed in the wild. In captivity, ovipositioning has occurred on aquatic moss, filamentous algae, rocks, and glass marbles.

ii. Clutch size. In captivity, an average of $33 \mathrm{eggs} / \mathrm{female}$ has been oviposited during a single egg-laying event. Egg size is about 1.5-2.0 mm (Tupa and Davis, 1976). Eggs hatched at $16-35 \mathrm{~d}$ postoviposition; total lengths of larvae were 9-12 $\mathrm{mm}$

C. Larvae/Metamorphosis. This species is paedomorphic, and natural metamorphosis is unknown. Transformation has been induced artificially through use of thyroid hormone (Potter and Rabb, 1960).

D. Juvenile Habitat. Probably similar to adult habitat.

E. Adult Habitat. Completely aquatic. Found in mats of blue-green algae (Lyngbya sp.), under rocks, and in gravel substrate at water depths of $<1 \mathrm{~m}$ to several meters. Water temperature is relatively constant at approximately $22^{\circ} \mathrm{C}$ throughout the year; experimental studies show a critical thermal maximum of $36-37^{\circ} \mathrm{C}$ (Berkhouse and Fries, 1995).

F. Home Range Size. Unknown.

G. Territories. Unknown.

H. Aestivation/Avoiding Desiccation. Aestivation is unknown.

1. Seasonal Migrations. Unlikely to occur.

J. Torpor (Hibernation). Active throughout the year.

K. Interspecific Associations/Exclusions. Little known; fountain darters (Etheostoma fonticola) are common in the same habitats in which this species is found.

L. Age/Size at Reproductive Maturity. Tupa and Davis (1976) noted size at sexual maturity as $19-23.5 \mathrm{~mm}$ SVL for males and $21 \mathrm{~mm}$ SVL for females. In captivity, eggs were first observed in females at $250 \mathrm{~d}$ of age.

M. Longevity. At least $3.7 \mathrm{yr}$ in captivity.

N. Feeding Behavior. Prey consists primarily of invertebrates, particularly chironomids and amphipods (Tupa and Davis, 1976). Oligochaete worms, snails, and zooplankton also are fed in captivity.

o. Predators. Suspected predators include cattishes, centrarchid fishes, and crayfishes (Tupa and Davis, 1976).

P. Anti-Predator Mechanisms. Secretive. Although tails do not autotomize, individuals sometimes exhibit partially missing or partially regrown tails and limbs.

a. Diseases. Unknown.

R. Parasites. Unknown.

\section{Conservation.}

The entire population of San Marcos salamanders has been estimated to be about 53,200 (USFWS, 1996b). They are listed as Threatened both by the State of Texas (www.tpwd.state.tx.us) and the federal government.

Eurycea naufragia Chippindale, Price, Wiens, and Hillis, 2000 GEORGETOWN SALAMANDER

Paul T. Chippindale

1. Historical versus Current Distribution. Georgetown salamanders (Eurycea naufragia) were described by Chippindale, Price, Wiens, and Hillis (2000) from springs of the San Gabriel River drainage in the vicinity of Georgetown, Williamson County, Texas; they also provisionally included one spring and one cave population from further north in Williamson County in this species. A cave population that probably represents this species was recently discovered west of Georgetown (J. Reddell, personal communication). Most of the known populations were discovered recently; the few populations known prior to the work of Chippindale (1995) and Chippindale et al. (2000) had been considered peripheral isolates of Texas salamanders (E. neotenes; Sweet, 1978a, 1982). Georgetown salamanders are members of the "northern group" of Chippindale $(1995,2000)$ and Chippindale et al. (2000); this monophyletic group occurs (2000); this mono Colorado River in the Edwards Plateau region of central Texas. wards Patecular markers, this and other northern species are extremely divergent from E. neotenes and other Eurycea from the southern Edwards Plateau region (Chippindale et al., 2000).

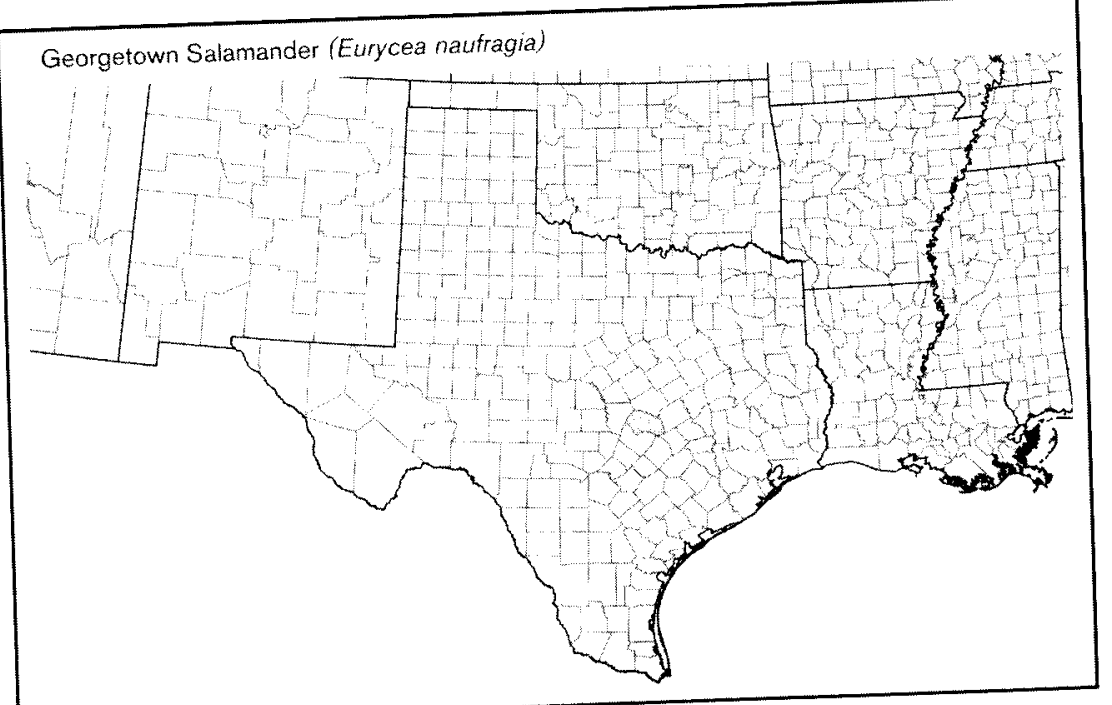

2. Historical versus Current Abundance. Little is known of the historical abundance of Georgetown salamanders. Several of the spring populations occur adjacent to Lake Georgetown, and it is likely that others were submerged when this manmade lake was created. Springs in Georgetown's San Gabriel Park, a historical locality for this species (Sweet, 1978a, 1982) have been heavily modified. One juvenile specimen was discovered at this site in 1991 (Chippindale et al., 2000), but existence of this species at these springs appears precarious. Chippindale et al. (2000) briefly addressed some aspects of the conservation biology of this species; see Price et al. (1995) for a more detailed discussion.

\section{Life History Features.}

A. Breeding. Reproduction is aquatic.

i. Breeding migrations. Unlikely to occur. ii. Breeding habitat. Same as adult habitat.

\section{B. Eggs.}

Egg deposition sites. Unknown; some other spring-dwelling species of central Texas Eurycea are thought to deposit eggs in gravel substrates.

ii. Clutch size. Unknown.

c. Larvae/Metamorphosis. Georgetown salamanders are paedomorphic, and natural metamorphosis is unknown.

D. Juvenile Habitat. Probably similar to adult habitat.

E. Adult Habitat. Completely aquatic. Georgetown salamanders are known only from the immediate vicinity of spring outflows, under rocks and leaves and in gravel substrate, and from two watercontaining caves. Water temperatures in springs of the Edwards Plateau are relatively constant throughout the year and typically range from $18-20^{\circ} \mathrm{C}$ or slightly warmer near the fault zone at the Plateau's edge (Sweet, 1982). Sweet (1982) provicled a comprehensive distributional analysis of the central Texas Eurycea and discussed 
J. Torpor (Hibernation). Probably active throughout the year.

K. Interspecific Associations/Exclusions. Unknown.

L. Age/Size at Reproductive Maturity. Unknown. Average SVL of specimens measured by Chippindale et al. (2000) was $29.0 \mathrm{~mm}$; all measured were thought to be sexually mature, but this was only verified for some of the specimens.

M. Longevity. Unknown.

N. Feeding Behavior. Prey probably consists mainly of small aquatic invertebrates, but no detailed feeding studies of this species have been conducted.

o. Predators. Unknown.

P. Anti-Predator Mechanisms. Secretive.

Q. Diseases. Unknown.

R. Parasites. Unknown.

\section{Conservation.}

Georgetown salamanders were described only recently (Chippindale et al,, 2000) and most known populations were discovered within the past decade. Little is known of their historical abundance, although several populations occurred adjacent to Lake Georgetown, and it is likely that they were submerged when this manmade lake was created. Springs in Georgetown's San Gabriel Park have been heavily modified, and the existence of Georgetown salamanders at these springs appears precarious. They currently are considered as a Candidate species for federal listing (http://ecos.fws.gov), but they have not been protected by the state of 'Texas (www.tpwd.state.tx.us).

Eurycea neotenes Bishop and Wright, 1937 TEXAS SALAMANDER

Paul T. Chippindale

1. Historical versus Current Distribution.

Texas salamanders (Eurycea neotenes) were described by Bishop and Wright (1937) from a spring at Helotes, Bexar County, north of the city of San Antonio. In subsequent years, many spring and cave populations from throughout the Edwards Plateau region of central Texas were assigned to this species (e.g., B.C. Brown, 1942, 1950, 1967a; Schmidt, 1953; Conant, 1958a, 1975; Baker, 1961; Mitchell and Smith, 1972; Sweet, 1977a, 1978a,b, 1982, 1984; Dixon, 1987; Conant and Collins, 1991; Behler and King, 1998; Petranka, 1998). These identifications were based primarily on the high degree of morphological similarity among individuals from many populations, especially those inhabiting springs.

Chippindale $(1995,2000)$ and Chippindale et al. $(1993,1998,2000)$ used molecular and morphological data to assess species boundaries in the central Texas Eurycea. Allozymes and mitochondrial sequences revealed extensive genetic subdivision within what had been considered $E$. neotenes, and Chippindale et al. (2000) restricted the dis-

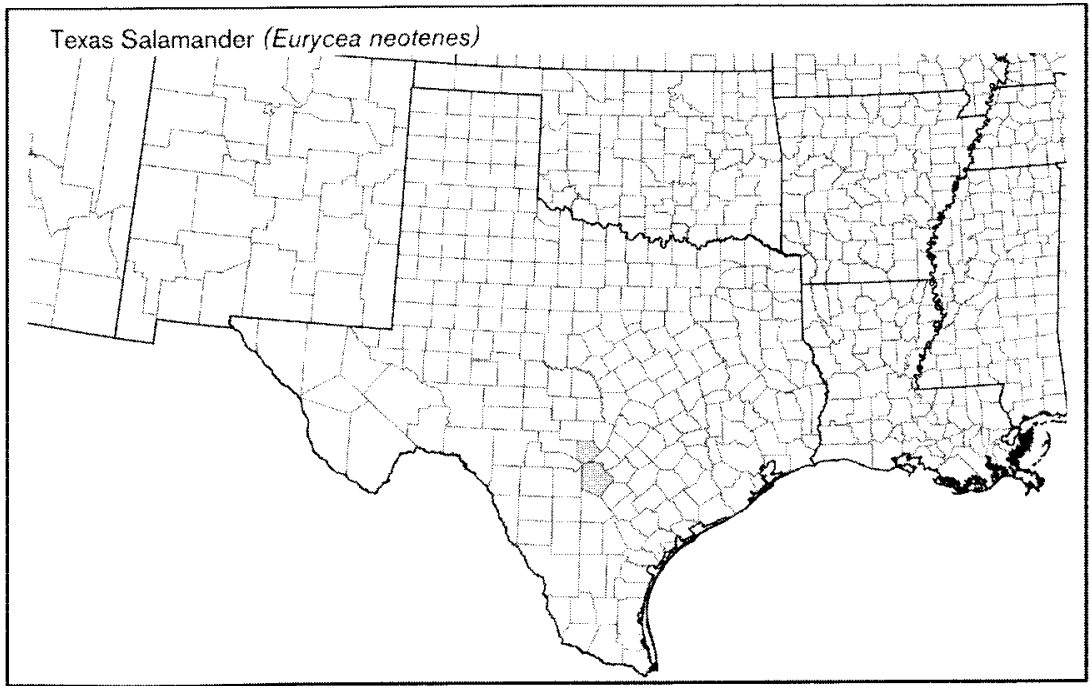

tribution of this species to several springs at and near the type locality. Most references to $E$. neotenes in the literature involve populations that Chippindale et al. (2000) considered Fern Bank salamanders (E. pterophila) or members of the E. latitans or $E$. troglodytes species complexes. Other species that formerly were considered $E$. neotenes are Barton Springs salamanders (E. sosonum), E. sp. 1 (Comal Springs), Jollyville Plateau salamanders (E. tonkawae), Georgetown salamanders ( $E$. naufragia), and Salado salamanders (E. chisholmensis). Based on phylogenetic analyses, E. neotenes is a member of the southeastern Edwards Plateau subgroup of Texas Eurycea (Chippindale, 1995, 2000; Chippindale et al., 2000), and appears to be restricted to several springs in Bexar and Kendall counties.

\section{Historical versus Current Abundance.}

Texas salamanders may be common at spring outflows, but their distribution appears to be limited and patchy.

\section{Life History Features.}

A. Breeding. Reproduction is aquatic.

i. Breeding migrations. Unlikely to occur.

ii. Breeding habitat. Unknown; closely related species are thought to deposit eggs in gravel substrates. Bogart (1967) described courtship and oviposition in Texas salamanders; in the laboratory, eggs were deposited on a variety of substrates.

\section{B. Eggs.}

i. Egg deposition sites. In the laboratory, eggs from an individual that might represent this species (see "Clutch size" below) were either free or attached to twigs and glass surfaces (Barden and Kezer, 1952).

ii. Clutch size. Barden and Kezer (1952) artificially induced egg laying in an individual that may represent this species; 12 eggs were produced in a 10 -d period.

C. Larvae/Metamorphosis. Texas salamanders are paedomorphic, and natural metamorphosis is unknown. Kezer (1952a) sis in individuals from a locality in Bexar County, which he considered to be Texas salamanders. It is likely that the populations with which he worked actually belong to the E. latitans complex, based on their geographic location. Barden and Kezer (1944) described eggs and egg-laying by a captive individual from one of these populations. Bogart (1967) described oviposition and egg development.

D. Juvenile Habitat. Probably similar to adult habitat.

E. Adult Habitat. Completely aquatic. Known only from the immediate vicinity of spring outflows, under rocks and leaves and in gravel substrate. Water temperatures in springs of the Edwards Plateau are relatively constant throughout the year and typically range from $18-20^{\circ} \mathrm{C}$ or slightly warmer near the fault zone at the Plateau's edge (Sweet, 1982). Sweet (1982) provided a comprehensive distributional analysis of the central Texas Eurycea and discussed hydrogeology of the region in relation to salamander distribution.

F. Home Range Size. Unknown.

G. Territories. Unknown.

H. Aestivation/Avoiding Desiccation. In 1990, P. Chippindale, D. Hillis, A. Price, and $D$. Bell visited the type locality of this species, a spring at the headwaters of Helotes Creek, Bexar County. The landowner informed us that the spring had been dry for approximately $2 \mathrm{yr}$ and had only started to flow again days earlier. We found dozens of extremely thin salamandying); presumably they had retreated into subterranean habitat while the spring was dry. Although this may not constitute true aestivation, it indicates that this species can survive temporary drying of surface springs.

I. Seasonal Migrations. Unlikely to occur.

J. Torpor (Hibernation). Probably active throughout the year. described thyroxin-induced metamorphoders in the spring pool (some dead and 
K. Interspecific Associations/Exclusions. Unknown.

L. Age/Size at Reproductive Maturity. In a morphometric analysis of some Edwards Plateau Eurycea (Chippindale et al., 1993), average SVL of topotypical Texas salamanders that were presumed to be adult was $32.2 \mathrm{~mm}$. However, Chippindale et al. (1993) probably did not include the smallest reproductively mature specimens in their analysis, and no rigorous studies of reproductive biology have been conducted for this species.

M. Longevity. Unknown.

N. Feeding Behavior. Prey probably consists mainly of small aquatic invertebrates, but no detailed feeding studies of this species have been conducted. Whiteworms were accepted in the laboratory (Bogart, 1967).

O. Predators. Unknown.

P. Anti-Predator Mechanisms. Secretive.

Q. Diseases. Hunsaker and Potter (1960) documented mortality due to "redleg" disease caused by infection with bacteria (Pseudomonas hydrophila) for a population in the vicinity of the type locality.

R. Parasites. Unknown.

\section{Conservation.}

Most references to Texas salamanders in the literature involve populations that are now considered members of the E. latitans or E. troglodytes species complexes. In fact, Texas salamanders appear to be restricted to several springs in Bexar and Kendall counties. These salamanders may be common at spring outflows, but their distribution appears to be limited and patchy. Despite this, they receive no protection by either the State of Texas (www.tpwd. state.tx.us) or by the federal government.

Eurycea pterophila Burger, Smith, and Potter, 1950

FERN BANK SALAMANDER

Paul T. Chippindale

1. Historical versus Current Distribution. Fern Bank salamanders (Eurycea pterophila) were described originally from Fern Bank (Little Arkansas) Spring, Hays County, Texas, by Burger, Smith, and Potter (1950). Schmidt (1953) considered Fern Bank salamanders to be a subspecies of the supposedly widespread Texas salamanders (E. neotenes), and Sweet $(1978 \mathrm{a}, \mathrm{b})$ synonymized this taxon under $E$. neotenes without recognizing subspecies. Chippindale (1995), Chippindale (2000), and Chippindale et al. (2000) resurrected the name E. pterophila for populations of Edwards Plateau Eurycea in springs and caves of the Blanco River drainage of Blanco, Hays, and Kendall counties, Texas. Their status remains open to question, pending further studies of relationships among populations of southeastern Edwards Plateau Eurycea.

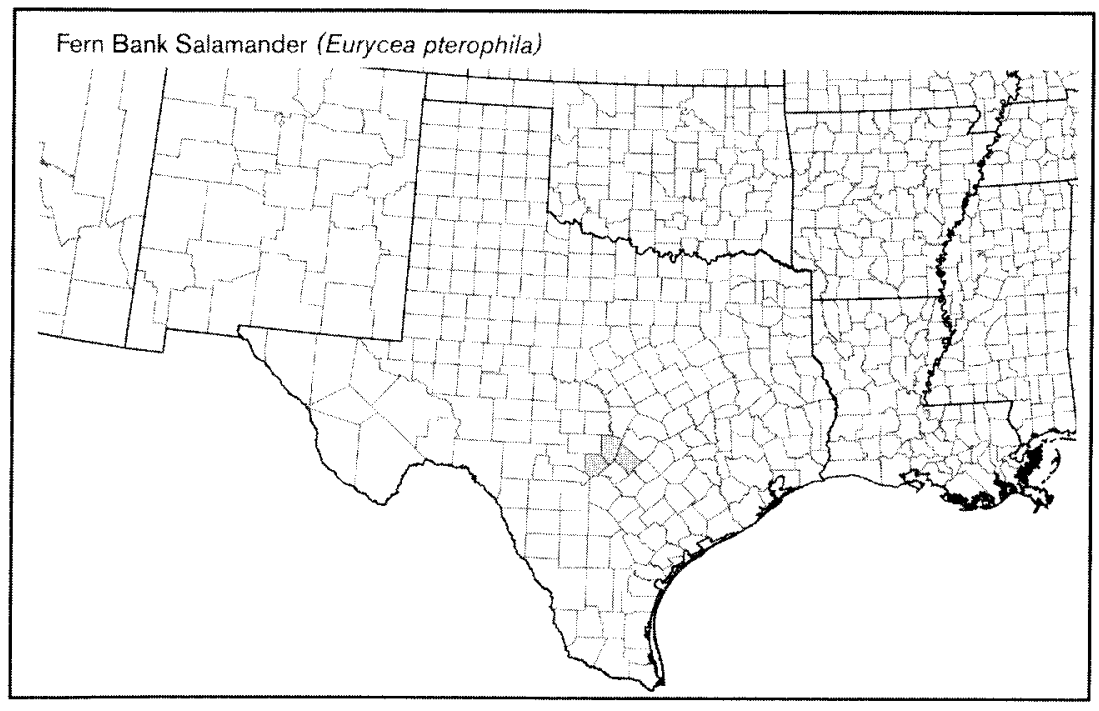

2. Historical versus Current Abundance.

Fern Bank salamanders may be common at spring outflows, but their distribution appears to be extremely limited and patchy.

\section{Life History Features. \\ A. Breeding.}

i. Breeding migrations. Unlikely to occur.

ii. Breeding habitat. Probably similar to adult habitat.

\section{B. Eggs.}

i. Egg deposition sites. Unknown; closely related species are thought to deposit eggs in gravel substrates.

ii. Clutch size. Unknown.

C. Larvae/Metamorphosis. Fern Bank salamanders are paedomorphic, and natural metamorphosis is unknown.

D. Juvenile Habitat. Probably similar to adult habitat; however, Conrads (1969) found that small juveniles often occurred in shallow $(<1 \mathrm{~cm})$ water.

E. Adult Habitat. Completely aquatic. Spring populations are known only from the immediate vicinity of spring outflows, under rocks and leaves, and in gravel substrate. This species also has been found in Grapevine Cave and $T$ Cave, Blanco County (Chippindale et al., 2000). Water temperatures in springs of the Edwards Plateau are relatively constant throughout the year and typically range from $18-20^{\circ} \mathrm{C}$ or slightly warmer near the fault zone at the Plateau's edge (Sweet, 1982). Sweet (1978a, 1982) provided a comprehensive distributional analysis of the central Texas Eurycea and discussed the hydrogeology of the region in relation to salamander distribution.

F. Home Range Size. Unknown,

G. Territories. Unknown.

H. Aestivation/Avoiding Desiccation. Hamilton (1973) reported that the population at the type locality survived an episode in which the springs ceased to flow. Although this may not constitute true aestivation, it indicates that this species can survive temporary drying of surface outflows.

I. Seasonal Migrations. Unlikely to occur.

J. Torpor (Hibernation). Probably active throughout the year.

K. Interspecific Associations/Exclusions. Unknown.

L. Age/Size at Reproductive Maturity. In a morphometric analysis of some Edwards Plateau Eurycea (Chippindale et al., 1993), the average SVL of Fern Bank salamanders that were presumed to be adults was $30.6 \mathrm{~mm}$ for specimens from the type locality and $36.6 \mathrm{~mm}$ from another site, Boardhouse Spring. However, Chippindale et al. probably did not include the smallest reproductively mature specimens in their analysis, and no rigorous studies of reproductive biology have been conducted for this species. Bogart (1967) described oviposition in the laboratory.

M. Longevity. Unknown.

N. Feeding Behavior. Prey probably consist mainly of small aquatic invertebrates, but no detailed feeding studies of this species have been conducted.

o. Predators. Unknown.

P. Anti-Predator Mechanisms. Secretive.

a. Diseases. Sweet (1978b) demonstrated that occurrence of short digits, one of the features that Burger et al. (1950) considered diagnostic in their original description of this species, was probably the result of tissue loss due to infection by bacteria (Aeromonas sp.).

R. Parasites. Unknown.

4. Conservation. The status of Fern Bank salamanders remains open to question, pending further studies of relationships among populations of southeastern Edwards Plateau Eurycea. Fern Bank salamanders may be common at spring outflows, but their distribution appears to be extremely limited and patchy. They are not listed by either the State of Texas or the federal government. 
Eurycea quadridigitata (Holbrook, 1842) DWARF SALAMANDER

Ronald M. Bonett, Paul T. Chippindale

\section{Historical versus Current Distribution.} Dwarf salamanders (Eurycea quadridigitata) were described (as Salamandra quadridigitata) by Holbrook (1842); the type locality was restricted by Schmidt (1953) to the vicinity of Charleston, South Carolina. Cope (1869) transferred this taxon to the genus Manculus (as M. quadridigitatus). Dunn (1923) considered Manculus a junior synonym of Eurycea, and Wake (1966) concurred. However, Mittleman $(1947,1967)$ supported recognition of the genus Manculis, and recognized three subspecies: M. q. quadridigitatus throughout the southeast and much of the Gulf Coastal Plain; M. q. paludicolus from Louisiana and eastern Texas; and M. q. uvidus from northeastern Texas, western Arkansas, and southwestern Missouri. Nearly all recent authors consider this taxon a single species--Eurycea quadridigitata. Molecular work supports inclusion of this taxon in Eurycea under the Linnean system of nomenclature (Chippindale et al., 2000; C. Hass and R. Highton, unpublished data; P. T. C., unpublished data). In the broad sense, dwarf salamanders have a wide range from North Carolina south into much of peninsular Florida, and west into eastern Texas and southern Arkansas; they occur primarily in the Atlantic and Gulf Coastal Plain regions (see map in Petranka, 1998). However, recent molecular work has revealed deep divergences within this "species," and also suggests that the taxon may not be monophyletic (Chippindale et al., 2000; C. Hass and R. Highton, unpublished data; P.T.C., unpublished data). Eurycea quadridigitata probably consists of at least four distinct species, some of which occur sympatrically but apparently do not interbreed (R. Highton, personal communication). In fact, Harrison and Guttman (2003) have recently described Chamberlain's dwarf salamanders (E. chamberlaini) from an isolated area in the western Piedmont of South Carolina, the lower Piedmont of North Carolina, the upper Coastal Plain of South Carolina, and the central portion of the Coastal Plain in North Carolina (see account, this volume). Even in the area of the type locality, at least two species are present and sometimes sympatric (R. Highton, personal communication). A formal taxonomic treatment of this complex is expected in the near future. Given this situation, the information for "E. quadridigitata" summarized here almost certainly represents a composite of data for several, perhaps distantly related, species.

2. Historical versus Current Abundance. Generally unknown, but numbers are undoubtedly lower in areas impacted by human activities (Petranka, 1998). Local

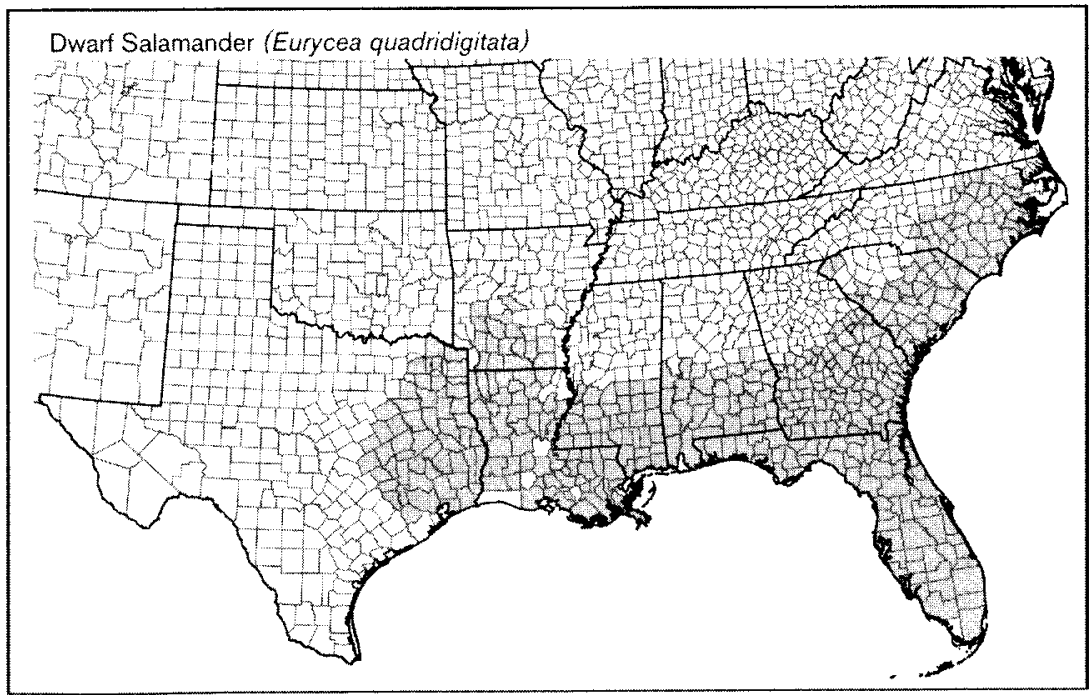

abundance of adult members of the $E$. quadridigitata complex was monitored during a 16-yr study (1979-94) of a Carolina bay in South Carolina (Semlitsch et al., 1996). Breeding adult numbers were not influenced by seasonal rainfall amounts, and recruitment of juveniles was not influenced by larval densities. Juvenile recruitment was, however, influenced by the number of breeding adults. Members of this complex appear to be common in suitable habitat (Petranka, 1998), but given the current confusion regarding species boundaries and the probable occurrence of multiple, sometimes sympatric species, estimates of distribution and abundance should be considered questionable.

\section{Life History Features.}

A. Breeding. Reproduction is aquatic.

i. Breeding migrations. In South Carolina, dwarf salamanders migrate to breeding ponds from August-October (Gibbons and Semlitsch, 1991) and have been collected during migration until late November (McMillan and Semlitsch, 1980). South Carolina breeding populations can include $\leq 10,000$ adults, with approximately equal representation of males and females (Gibbons and Semlitsch, 1991). In South Carolina, breeding migrations occur primarily at night, but individuals will also migrate crepuscularly and diurnally (Semlitsch and Pechmann, 1985; Gibbons and Semlitsch, 1991). It has been suggested that dwarf salamanders avoid predation and desiccation during diurnal migrations by traveling beneath the leaf litter (Semlitsch and Pechmann, 1985). Individuals were collected during apparent breeding migrations from late autumn to early winter in east-central Alabama (Trauth, 1983).

ii. Breeding habitat. In the Atlantic Coastal Plain of South Carolina, dwarf salamanders use lentic habitats such as
Carolina bays and ephemeral ponds (Gibbons and Semlitsch, 1991). Similarly, in Florida, dwarf salamanders were found only to be associated with ponds (Goin, 1951). In east-central North Carolina, how ever, adult dwarf salamanders and their eggs have been found along small streams (Brimley, 1923), suggesting that members of this complex will also breed in lotic habitats (Goin, 1951).

\section{B. Eggs.}

i. Egg deposition sites. Females attach their eggs singly to vegetation and other substrates such as twigs, rootlets, and debris. Eggs usually are laid so that they are associated with flowing water (Brimley, 1923; Carr, 1940a; Harrison, 1973; Trauth, 1983). Eggs may also be laid in shallow depressions beneath cover objects along wetland margins (Goin, 1951) or in dry depressions that will fill with spring rains (Taylor et al., 1988).

ii. Clutch size. Developmental data have been collected on members of the $E$. ties throughout the range. Clutches containing from 7-48 eggs are oviposited by South Carolina females from Novem(Gibbons and Semlitsch, 1991). Females from east-central Alabama populations had previtellogenic follicles within their ovaries from March-September and enlarged ovarian follicles (14-59) from October-February; oviposition probably occurs over a broad time period in this region (Trauth, 1983). Numerous eggs have been discovered in the field in east-central North Carolina during early February (Brimley, 1923). In Florida, single clutches containing 20 eggs and 62 eggs were recovered from the field in November and February, respectively (Goin, 1951). This lack of synchrony in oviposition by populations in different locations may actually reflect interspecific differences among members of this complex. In the lab, eggs quadridigitata complex from several localiber-December when breeding ponds fill 
from Florida populations took approximately 3-4 wk to hatch, with hatchlings measuring from $7.5-8.3 \mathrm{~mm}$ in total length (Goin, 1951).

C. Larvae/Metamorphosis. As with all hemidactyliines, members of the E. quadridigitata complex have an aquatic larval stage (Petranka, 1998). Goin (1951) described larvae from Florida populations to be morphologically intermediate between typical pond-type and stream-type salamander larvae, with a dorsal caudal fin that extends anteriorly to the mid dorsum (pond characteristic) and relatively few gill filaments (stream characteristic). A photograph of a larval dwarf salamander from southeastern North Carolina (R. W. VanDevender, in Petranka, 1998) matches the description of dwarf salamander larvae from Florida by Goin (1951). Larvae of members of the E. quadridigitata complex have been found to inhabit temporary ponds and Carolina bays in South Carolina (Semlitsch, 1980a; Taylor et al., 1988; Gibbons and Semlitsch, 1991). Additionally, it is likely that larvae develop in the aquatic habitats immediately adjacent to oviposition sites. This suggests that hammock ponds (Goin, 1951) and streams (Brimley, 1923) should also be included as larval habitats for members of this complex. It is unclear whether these reported differences in larval habitat reflect interspecific differences among members of this complex or the ability of larvae of these species to use a variety of aquatic habitats.

i. Length of larval stage. Most larvae metamorphose 2-6 mo after hatching (Brimley, 1923; Harrison, 1973; Semlitsch, 1980a; Petranka, 1998). Harrison (1973) and Semlitsch (1980a) found small larvae in January and February in South Carolina. Mount (1975; see also Petranka, 1998) noted small larvae in pools and ditches in March in Alabama.

\section{ii. Larval requirements.}

a. Food. According to Petranka (1998), larvae are benthic feeders. Prey include small invertebrates such as zooplankton, ostracods, and insect larvae (Taylor et al., 1988; see also Petranka, 1998).

b. Cover. Larvae are likely benthic.

iii. Larval polymorphisms. Unknown and unlikely.

iv. Features of metamorphosis. Newly metamorphosed dwarf salamanders have been found from April (Harrison, 1973) to early July (Semlitsch, 1980a; Taylor et al., 1988; see also Petranka, 1998).

v. Post-metamorphic migrations. Unknown and unlikely.

vi. Neoteny. Unknown.

D. Juvenile Habitat. Similar to adult habitat.

E. Adult Habitat. Most studies of adult members of the $E$. quadridigitata complex have involved individuals intercepted during migrations to and from breeding ponds. Therefore, aside from general notes on habitats where adult dwarf salamanders have been uncovered in the field, little is known about their terrestrial habitat characteristics outside of the breeding season. In general, members of the $E$. quadridigitata complex have been found beneath cover objects at the edges of ponds and swamps as well as in seeps and amongst leaf litter in springs (Mount, 1975; Petranka, 1998).

F. Home Range Size. Unknown. However, Carr (1940a) notes that dwarf salamanders from Florida can be found at considerable distances from aquatic habitats outside of the breeding season.

G. Territories. Unknown.

H. Aestivation/Avoiding Desiccation. Aestivation is unknown.

I. Seasonal Migrations. The only known migrations for the species of the E. quadridigitata complex are apparently for breeding purposes.

J. Torpor (Hibernation). Unknown.

K. Interspecific Associations/Exclusions. Studies in South Carolina have examined diel patterns of adult migratory activity (Semlitsch and Pechmann, 1985), and larval trophic relations of dwarf salamanders and other sympatric salamanders such as eastern newts (Notophthalmus viridescens) and various ambystomatids (Taylor et al., 1988). These studies have revealed a host of interspecific differences, but none that can be directly attributed to interactions between the species examined. Some members of the E. quadridigitata complex are known to occur sympatrically and are distinguishable based on both external morphology and molecular markers (R. Highton, personal communication). Other plethodontids that have been found syntopic with members of the E. quadridigitata complex in southern Mississippi and southeastern Louisiana include threelined salamanders (E. guttolineata), southern red salamanders (Pseudotriton ruber vioscai), and spotted dusky salamanders (Desmognathus conanti; R. M. B., personal observation).

L. Age/Size at Reproductive Maturity. In east-central North Carolina, dwarf salamanders are reported to hatch in March and transform 2-3 mo later (Brimley, 1923). Larval periods of approximately 5-6.5 mo are reported for South Carolina populations (Harrison, 1973; Semlitsch, 1980a), and both males and females reach sexual maturity about 8-9 mo after hatching (Semlitsch, 1980a). Semlitsch (1980a) proposes that males are likely to reproduce during their first year, while females likely take an additional year for ova to develop. There has been considerable variation in size at maturity reported among populations of this complex, and the different species that currently are considered E. quadridigitata may mature at different sizes. Monitoring natural populations in South Carolina, Semlitsch (1980a) found larval periods to last from
5-6 mo when individuals attain lengths of 20.7-25.6 mm SVL. Other measurements of newly metamorphosed individuals from South Carolina showed a smaller size at metamorphosis (17-20 $\mathrm{mm}$ SVL; Harrison, 1973).

M. Longevity. Unknown.

N. Feeding Behavior. In South Carolina, dwarf salamander larvae feed diurnally, with small individuals taking primarily zooplankton and large larvae consuming small invertebrates (Taylor et al., 1988). Metamorphosed individuals in South Carolina were found to feed upon acarinans, arachnids, coleopterans, collembolans, diplopods, dipterans, hemipterans, homopterans, hymenopterans, and pseudoscorpionids (McMillan and Semlitsch, 1980). Acarinans, arachnids, coleopterans, collembolans, hymenopterans, and larval insects were recovered from the stomachs of terrestrial individuals from southern Georgia (Powders and Cate, 1980). The individuals examined by Powders and Cate (1980) were from two distinct size classes, but showed no differences in preferred prey items. Individuals from Florida populations were found to feed upon coleopterans (larval and adult), annelids, and amphipods (Carr, 1940a).

O. Predators. Examination of stomach contents of 122 pig frogs (Rana grylio) from southwest Georgia revealed four dwarf salamanders (Lamb, 1984). This is the only evidence of predation on dwarf salamanders, although it has been speculated that birds, snakes, and large invertebrates are likely predators (Petranka, 1998).

P. Anti-Predator Mechanisms. Unknown.

a. Diseases. Unknown.

R. Parasites. Unknown.

\section{Conservation.}

Members of the E. quadridigitata complex currently are given no special protective status. Given the existence of several putative, currently undescribed species in the group, their conservation status should be re-examined after species boundaries and geographic ranges have been accurately delineated.

Eurycea rathbuni Stejneger, 1896 TEXAS BLIND SALAMANDER

Paul T. Chippindale

\section{Historical versus Current Distribution.}

Texas blind salamanders (Eurycea rathbuni) were first described by Stejneger (1896; as Typhlomolge rathbuni) from a $58 \mathrm{~m}$-deep artesian well drilled in 1895 in the city of San Marcos, Hays County, Texas, on what is now the campus of Southwest Texas State University. These salamanders are known from several caves, wells, and pipes that intersect the San Marcos Pool of the Edwards Aquifer in San Marcos and are unlikely to range beyond this region 
(for more detailed discussions of this species with respect to hydrogeology of the region, see also Uhlenhuth, 1919; Russell, 1976; Longley, 1978; Potter and Sweet, 1981; Chippindale et al., 2000). Status of the genus Typhlomolge as distinct from Eurycea has been controversial (e.g., Mitchell and Reddell, 1965; Wake, 1966; Mitchell and Smith, 1972; Potter and Sweet, 1981), but it is now clear that " $T$." rathbuni and its presumed sister species " $T$." robusta are phylogenetically nested within the central Texas Eurycea and should be considered species of Eurycea (Chippindale, 1995, 2000; Chippindale et al., 2000). Petranka (1998) recently followed this taxonomic approach. Eurycea rathbuni plus $E$. robusta, and a newly described species from Austin (Hillis et al., 2001) appear to represent the sister group to other central Texas Eurycea from south of the Colorado River.

netting two wells that provide outflow from the Edwards Aquifer (J. Fries, personal communication). Individuals of this species can reliably be observed at a tiny cave opening into the Edwards Aquifer in San Marcos (Russell, 1976; personal observations, early 1990s). When the cave floods, Texas blind salamanders are active on the surface in broad daylight (personal observations).

\section{Life History Features.}

A. Breeding. Reproduction is aquatic. i. Breeding migrations. Unknown.

ii. Breeding habitat. Unknown in nature. However, this species has laid eggs on numerous occasions in captivity at the Dallas Aquarium at Fair Park, the Cincinnati Zoo, the Aquarena Center (San Marcos), and the San Marcos National Fish Hatchery and Technology Center (L. Ables, Dal-

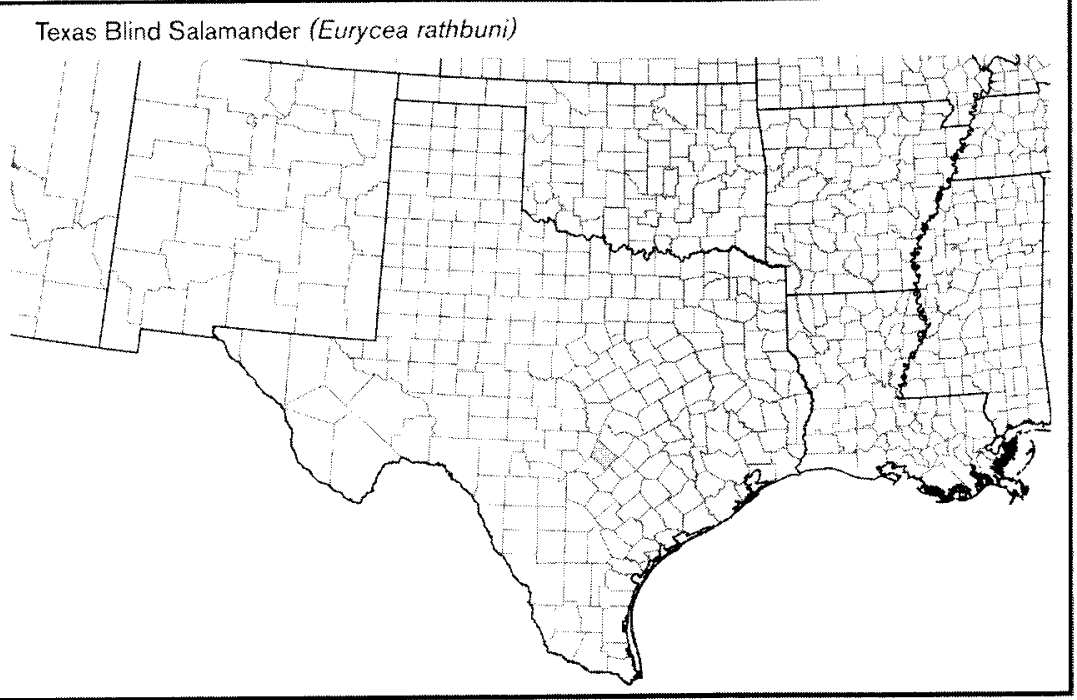

\section{Historical versus Current Abundance.}

Densities of cave-dwelling populations of the central Texas Eurycea are difficult to assess. For several years after drilling of the artesian well at San Marcos (in the late 1800 s), over 100 individuals emerged annually; this number soon dropped to a few per year (Uhlenhuth, 1921). Individuals of this species still appear common in outflows of Diversion Spring, a pipe that carries outflows from the Edwards Aquifer at San Marcos (Aquarena) Springs; most individuals that emerge probably are eaten by fishes, but salamanders can be captured if a net is placed over the pipe's outflow. However, numbers collected vary widely from year to year; currently, most individuals recovered are juveniles ( $\mathrm{J}$. Fries, personal communication). The National Fish Hatchery at San Marcos, Texas, currently maintains approximately 180 individuals, almost all obtained as juveniles, captured over a 4 -yr period by las Aquarium at Fair Park, personal communication).

B. Eggs.

i. Egg deposition sites. In nature, unknown.

ii. Clutch size. Unknown

C. Larvae/Metamorphosis. Texas blind salamanders are paedomorphic, and natural metamorphosis is unknown. Attempts to artificially induce transformation through use of thyroid hormone resulted in only partial metamorphosis (Dundee, 1957). Captive-hatched individuals at the Dallas Aquarium at Fair Park grew from approximately $10 \mathrm{~mm}$ to $80-90 \mathrm{~mm} \mathrm{TL}$, in about 14-16 mo (L. Ables, personal communication). Grobman (1957) investigated the thyroid gland of this species, and Sever (1985) provided information of sexual dimorphism of the cloacal glands of this species.

D. Juvenile Habitat. Probably similar to adult habitat.
E. Adult Habitat. Completely aquatic. Found in caverns of the San Marcos Pool of the Edwards Aquifer, where they have been observed climbing rock surfaces or swimming in open water. Water temperature of the spring outflows of this region of the Edwards Aquifer is relatively constant at approximately $21-21.5^{\circ} \mathrm{C}$ throughout the year (Berkhouse and Fries, 1995).

F. Home Range Size. Unknown.

G. Territories. Unknown.

H. Aestivation/Avoiding Desiccation. Unknown.

I. Seasonal Migrations. Unknown.

J. Torpor (Hibernation). Probably active throughout the year.

K. Interspecific Associations/Exclusions. No other salamanders are known from the subterranean habitat of this species, although San Marcos salamanders ( $E$. nana) are abundant in springs directly above the caves occupied by this species.

L. Age/Size at Reproductive Maturity. Petranka (1998) listed the size of adults as 90-135 $\mathrm{mm}$ in total length. Brandon (1971b) found that males mature at about $40 \mathrm{~mm} \mathrm{SVL}$, and females at about 40-50 mm SVL. Captive-raised females at the Dallas Aquarium at Fair Park displayed visible eggs (and deposited infertile eggs) at approximately $35 \mathrm{~mm}$ SVL (L. Ables, personal communication). Courtship and reproduction was documented by Belcher (1988), and captive reproduction has occurred at the Dallas Aquarium at Fair park, the Cincinnati Zoo, the Aquarena Center (San Marcos), and the San Marcos National Fish Hatchery and Technology Center (L. Ables, personal communication). Reproduction in the wild probably occurs throughout the year (Longley, 1978).

M. Longevity. The longest officially recorded period in captivity was $10 \mathrm{yr}$, $4 \mathrm{mo}$, with this individual still living at the time of the report (Snider and Bowler, 1992).

N. Feeding Behavior. Prey probably consists primarily of subterranean invertebrates; Longley (1978) reported amphipods, snails, and cave shrimp (Palaemonetes antrorum) as food items. One individual was seen skimming the water surface in a cave, perhaps seeking insects on the water's surface (personal observations). An individual outside a flooded cave was seen feeding on an earthworm (personal observation), and captive specimens will eat meat (Norman, 1900). This species will readily enter traps baited with potato peels; this may be due to the bait's attraction for aquatic invertebrates (Russell, 1976; personal observations).

O. Predators. Unknown.

P. Anti-Predator Mechanisms. Unknown.

Q. Diseases. Unknown.

R. Parasites. Unknown. 
4. Conservation

Texas blind salamanders are known from several caves, wells, and pipes that intersect the San Marcos Pool of the Edwards Aquifer in San Marcos and are unlikely to range beyond this region. Populations have been lost, and they are listed as Endangered by both the State of Texas (www.tpwd.state.tx.us) and the federal government (http://ecos.fws.gov).

Eurycea robusta Longley, 1978

BLANCO BLIND SALAMANDER

Paul T. Chippindale

1. Historical versus Current Distribution.

Blanco blind salamanders (Eurycea robusta) were described based on a single specimen collected in 1951, when workers drilled a hole for water in the bed of the then-dry Blanco River just east of San Marcos, Hays County, Texas (additional specimens were lost; apparently some were eaten by a heron shortly after capture). Authorship of the name is problematic. Potter (1963) described the species as Typhlomolge robusta in a Master's thesis, but this description is invalid under current rules of zoological nomenclature. Longley (1978) must be credited with description of the species, although he did so unintentionally in a government report. Potter and Sweet (1981) redescribed this taxon and discussed biogeographic history of salamanders in the Edwards Plateau region and status of the genus Typhlomolge (note that Dixon [1987] argued that Potter and Sweet should be credited with description of this species). Potter and Sweet (1981) and Russell (1976) provided evidence that the geological formation in which this species occurs is hydrologically isolated from that in which the geographically proximal species $E$. (formerly T.) rathbuni is found, supporting recognition of this population as a distinct species. Based on molecular data, Chippindale (1995, 2000) and Chippindale et al. (2000) agreed with Mitchell and Reddell (1965) and Mitchell and Smith (1972), who recommended synonymy of the genus $T y$ phlomolge under Eurycea. Because "T." robusta appears to be closely related to " $T$." rathbuni based on morphology (no molecular data are available for " $T$." robusta), this renders the species $E$. robusta. Petranka (1998) followed this designation. No further specimens have been collected.

\section{Historical versus Current Abundance.}

Nothing is known; a 1995 petition to list this species as Federally Endangered was rejected due to lack of information on its status and distribution (O'Donnell, 1998).

\section{Life History Features.}

A. Breeding. Reproduction is aquatic.

i. Breeding migrations. Unknown.

ii. Breeding habitat. Unknown.

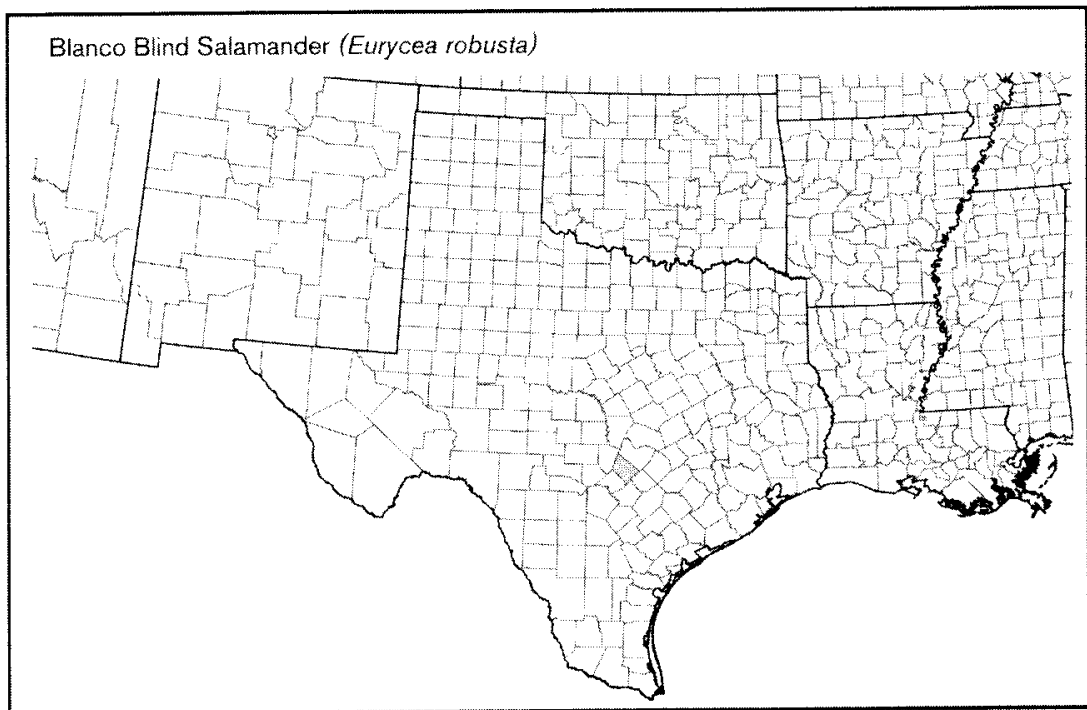

B. Eggs.

i. Egg deposition sites. Unknown.

ii. Clutch size. Unknown.

C. Larvae/Metamorphosis. Unknown.

D. Juvenile Habitat. Unknown.

E. Adult Habitat. Completely aquatic and subterranean; nothing else is known.

F. Home Range Size. Unknown.

G. Territories. Unknown.

H. Aestivation/Avoiding Desiccation. Unknown.

I. Seasonal Migrations. Unknown.

J. Torpor (Hibernation). Unknown

K. Interspecific Associations/Exclusions. Unknown.

L. Age/Size at Reproductive Maturity. Unknown; the type specimen is a reproductively mature female, $57.1 \mathrm{~mm} \mathrm{SVL}$, $100.8 \mathrm{~mm}$ total length.

M. Longevity. Unknown.

N. Feeding Behavior. Unknown.

O. Predators. Unknown (excluding the heron mentioned above, certainly not a natural predator).

P. Anti-Predator Mechanisms. Unknown.

Q. Diseases. Unknown.

R. Parasites. Unknown.

\section{Conservation}

Little is known about the conservation status of Blanco blind salamanders. A 1995 petition to list this species as Federally Endangered was rejected due to lack of information on its status and distribution. However, the State of Texas lists them as Threatened (www.tpwd.state.tx.us).

Eurycea sosorum Chippindale, Price, and Hillis, 1993

BARTON SPRINGS SALAMANDER

Paul T. Chippindale, Robert Hansen

1. Historical versus Current Distribution.

Barton Springs salamanders (Eurycea sosorum) were described by Chippindale, Price, and Hillis (1993); the type locality is Barton Springs pool, a spring-fed swimming hole in the city of Austin, Travis County, Texas. This species is known only from the pool and three other springs that are immediately adjacent (Chippindale et al., 1993; City of Austin, 1997; Hansen et al., 1998). The spring outflows inhabited by this species are fed by the Barton Springs segment of the Edwards Aquifer. Eurycea sosorum was first recognized as a distinct, undescribed species by Sweet (1978a 1984), based on its morphological differentiation from other surface and subterranean species of central Texas Eurycea Chippindale et al. (1993) also demonstrated that this species is distinct based on morphology and allozymes. Chippindale et al. (2.000) support recognition of this species and determined its relationships to other central Texas Eurycea using allozyme and mitochondrial DNA sequence data. Hillis et al. (2001) confirmed the phylogenetic position of this species using additional sequence data. Eurycea sosorum is a member of the "southeast ern" subset of the "southern group" of Chippindale $(1995,2000)$ and Chippindale et al. (2000); this monophyletic group occurs south of the Colorado River in the Edwards Plateau region of central Texas.

\section{Historical versus Current Abundance.}

Little is known of the historical abundance of this species. The first known specimens were collected in 1946 by B.C. Brown from among plants in Barton Springs Pool (Chippindale et al., 1993). Observations by others (summarized by Chippindale et al., 1993) indicate that this species was abundant in the $1960 \mathrm{~s}$ and 1970s. Considerable evidence (summarized by Chippindale et al., 1993; O'Donnell, 1994, 1997; Hansen et al., 1998: Hillis et al., 2001) indicates that the population underwent a major decline in the 1980s-90s, probably due in part to cleaning procedures used by the 


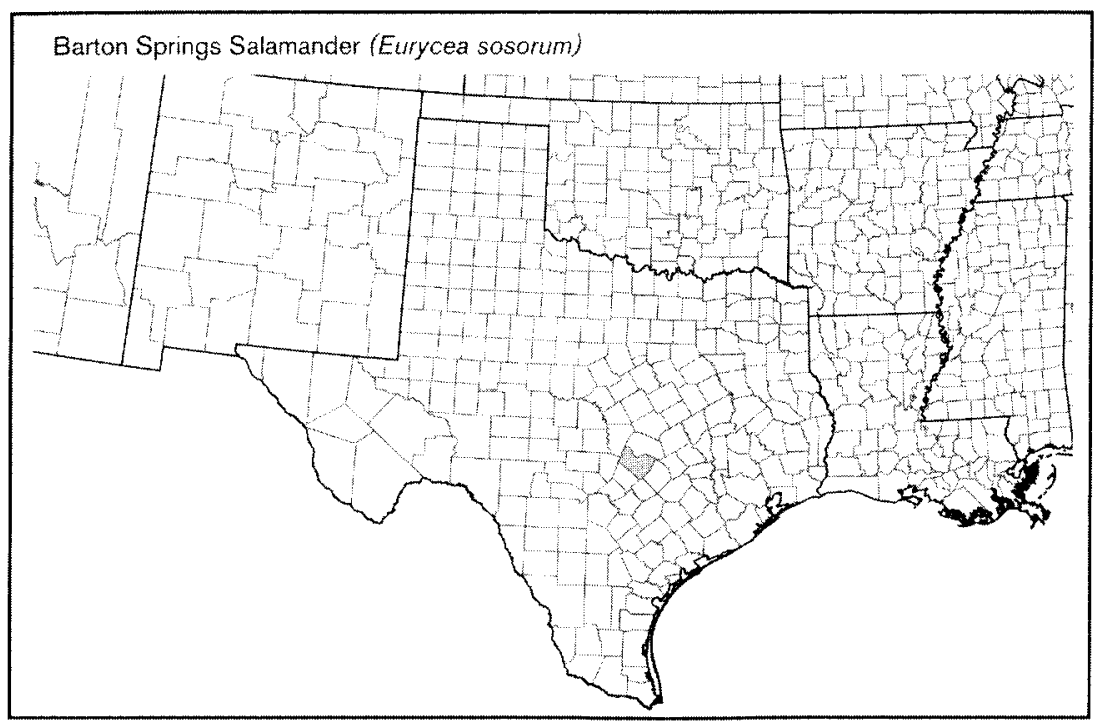

City of Austin at Barton Springs Pool. The City was made aware of the problems in the early 1990 s and has since cooperated closely with biologists and conservation agencies to balance the need for pool maintenance with protection of Barton Springs salamanders. Details of the City's actions and the conservation history of this species are provided by Chippindale and Price (this volume, Part One). Abundance of salamanders appeared to increase substantially following modification of pool maintenance procedures, but the number of individuals located have been highly variable from year to year and the most recent data suggest a decline in numbers in 2000 . Considerable concern remains regarding the impacts of human activities on water quality in the Barton Springs Aquifer, summarized by Chippindale and Price (this volume, Part One)

\section{Life History Features.}

A. Breeding. Reproduction is aquatic.

i. Breeding migrations. Unlikely to occur.

ii. Breeding habitat. Unknown; a subset of adult habitat.

\section{B. Eggs.}

i. Egg deposition sites. Unknown in the wild; some other spring-dwelling species of central Texas Eurycea are thought to deposit eggs in gravel substrate. In captivity, oviposition has been observed at the Dallas Aquarium and the city of Austin facility. Females appear to deposit the eggs randomly on cobble, gravel, aquatic macrophytes, and even the glass sides and bottom of the aquaria. Gravid females may retain the eggs for periods longer than 12 mo (L. Ables, D. Chamberlain, personal communication). With some gravid females, oviposition does not occur and the eggs are resorbed by the female.

ii. Clutch size. Twenty-nine ovipositions have been reported in captivity as of August 2000. The Dallas Aquarium has re- ported 24 egg-laying events. Of these, 20 have occurred in one particular tank containing one male and four females. In captivity, eggs hatch in approximately $25-35$ d (L. Ables, personal communication). The high mortality rate of small juveniles at the Dallas Aquarium has limited the number of surviving young Barton Springs salamanders to about 50 juveniles (L. Ables, personal communication). The City of Austin has recorded three ovipositions of 29,26 , and 28 eggs with hatch rates of $0 \%, 27 \%$, and $7 \%$, respectively. Survival rates for the three ovipositions are $0 \%, 11 \%$, and $4 \%$ (City of Austin, unpublished data). The San Antonio Zoo reported one oviposition of 18 eggs and a $0 \%$ hatch rate $(G$. Stettner, personal communication). The USGS's Midwest Science Center reported one oviposition of 29 eggs with a $10 \%$ hatch rate (J. Dwyer, personal communication). Clearly, further study is necessary to determine what cues (if any) trigger breeding and what conditions are optimal for development of eggs and young. The City of Austin is currently expanding their captive breeding program, and the facility has been relocated to the University of Texas at Austin campus.

C. Larvae/Metamorphosis. Barton Springs salamanders are paedomorphic, and natural metamorphosis is unknown.

D. Juvenile Habitat. Probably similar to those of adults. City of Austin field studies (unpublished data) indicate that larvae, juveniles, and adults utilize similar substrate types (cobble, gravel, aquatic macrophytes).

E. Adult Habitat. Completely aquatic. Barton Springs salamanders are known only from the vicinity of spring outflows, under rocks and leaves, and in gravel substrate at depths ranging from a few $\mathrm{cm}$ to about $5 \mathrm{~m}$. The first known specimens were collected in 1946 among aquatic plants. Water temperature of the spring outflows remains relatively constant at about $20-22{ }^{\circ} \mathrm{C}$ throughout the year.

A recent study conducted by Alan Plummer Associates, Incorporated (2000), for the City of Austin summarizes water quality conditions at Barton Springs Pool. The analysis was based on City of Austin and U.S. Geological Survey data and concluded the following: (1) no trends of increasing concentration were found for several of the parameters commonly associated with nonpoint source pollutionnutrients, total suspended solids, and pesticides/herbicides; (2) trends of increasing concentrations were found for conductivity, sulfate, turbidity, and total organic carbon; (3) a trend of decreasing dissolved oxygen concentration was identified; and (4) the ratio of total nitrogento-total phosphorus was found to vary widely over time (from $\leq 20$ to $\geq 100$ ) and no observable trend was identified.

The City of Austin has also conducted contaminated sediment studies and analysis at Barton Springs Pool and sites in Barton Creek above and below the pool. Polycyclic aromatic hydrocarbons (PAHs) were detected in sediment in or near Barton Springs at levels that may have biological effects. High levels of several pesticides were also detected in sediment directly upstream of Barton Springs Pool. These pesticides include aldrin, DDD, DDE, DDT, BHC, endosulfan, endrin, heptachlor epoxide, heptachlor, and lindane. Heavy metals also were detected in sediment at sites in and near Barton Springs. These metals include arsenic, cadmium, chromium, copper, lead, and zinc (City of Austin, 1997).

Barton Springs salamanders appear to be primarily surface dwelling, but may also use subterranean habitat; the extent of their occurrence underground is uncertain (Chippindale et al., 1993). Sweet (1982) provided a comprehensive distributional analysis of the central Texas Eurycea and discussed hydrogeology of the region in relation to salamander distribution.

F. Home Range Size. Unknown.

G. Territories. Unknown.

H. Aestivation/Avoiding Desiccation. Unknown.

I. Seasonal Migrations. Very unlikely to occur; recent field studies by City of Austin staff indicate that no seasonal variation occurs for habitat use.

J. Torpor (Hibernation). Individuals have been found active throughout the year.

K. Interspecific Associations/Exclusions. Partially sympatric with the recently discovered Austin blind salamander (E. waterlooensis), which inhabits the subterranean portion of the Barton Springs Aquifer (Hillis et al., 2001). Individuals of this new species occasionally wash out of the spring outflows where $E$. sosorum occur. Specimens of Eurycea have been 
collected at Barton Springs Pool, Eliza Spring, and Old Mill Spring. No specimens have been observed at the Upper Barton Springs site (City of Austin, unpublished data). Eurycea waterlooensis is much more closely related to Texas and Blanco blind salamanders ( $E$. rathbuni and E. robusta) than to E. sosorum (Hillis et al., 2001).

L. Age/Size at Reproductive Maturity. Unknown. Average SVL of specimens measured by Chippindale et al. (1993) was $29.2 \mathrm{~mm}$; all animals measured were thought to be sexually mature, but this was only verified for some of the specimens. Maximum size of specimens examined by Chippindale et al. (1993) was $36.5 \mathrm{~mm} \mathrm{SVL}$ (62.6 mm TL).

M. Longevity. Individuals (still living) have been maintained for over $6 \mathrm{yr}$ in captivity.

N. Feeding Behavior. Prey probably consists mainly of small aquatic invertebrates, especially amphipods (Hyallela azteca), which are abundant in the habitat of this species. Gut analyses have revealed the following prey items: mayfly larvae, midge larvae, ostracods, copepods, physid snails, planorbid snails, and leeches (City of Austin, unpublished data). Captive specimens have accepted amphipods, earthworms, brine shrimp, bloodworms, blackworms, mosquito larvae, and commercial fishfood pellets (Chippindale et al., 1993; L. Ables, D. Chamberlain, personal communication; personal observations). Small larvae have disappeared when kept in aquaria with large juveniles and adults, so cannibalism may occur (L. Ables, personal communication).

O. Predators. Bass and sunfish are known predators (City of Austin, unpublished data; D. Hillis, personal communication). Crayfish have been suggested as potential predators, but most local experts think that they are not major predators.

P. Anti-Predator Mechanisms. Secretive.

Q. Diseases. Unknown.

R. Parasites. Unknown.

\section{Conservation.}

While Barton Springs salamanders were abundant in the 1960s-70s, they underwent a major decline in the $1980 \mathrm{~s}-90 \mathrm{~s}$, probably due in part to cleaning procedures used by the City of Austin at Barton Springs Pool. Abundance of salamanders appeared to increase substantially following modification of pool maintenance procedures, but the number of individuals located have been highly variable from year to year. The City of Austin has established a captive breeding program for this species, and considerable concern remains regarding the impacts of human activities on water quality in the Barton Springs Aquifer. Barton Springs salamanders have been listed as a Federally Endangered species since 1997 (O'Donnell, 1997).
Eurycea tonkawae Chippindale, Price, Wiens, and Hillis, 2000

JOLLYVILLE PLATEAU SALAMANDER

Paul T. Chippindale

\section{Historical versus Current Distribution.}

Jollyville Plateau salamanders (Eurycea tonkawae) were described by Chippindale, Price, Wiens, and Hillis (2000); the type locality is a spring at the margin of the Jollyville Plateau in the city of Austin, Travis County, Texas. Other spring populations of this species are known from the Jollyville Plateau and Brushy Creek areas of Travis and Williamson counties (Chippindale et al., 2000; Davis et al., 2001). Chippindale et al. (2000) provisionally considered populations from several caves in the area, including the recently discovered Buttercup Creek Cave system in the Cedar Park area of Williamson County, to represent this species. However, they emphasized that some of these cave forms may prove to be distinct species. Most of the known populations were discovered recently; the few populations known prior to the work of Chippindale (1995) and Chippindale et al. (2000) had been considered peripheral isolates of E. neotenes (Baker, 1961; B.C. Brown, 1967a,c; Sweet, 1978a, 1982). Eurycea tonkawae is a member of the "northern group" of Chippindale $(1995,2000)$ and Chippindale et al. (2000); this monophyletic group occurs northeast of the Colorado River in the Edwards Plateau region of central Texas. Based on molecular markers, this and other northern species are extremely divergent from $E$. neotenes and other Eurycea from the southern Edwards Plateau region (Chippindale et al., 2000).

\section{Historical versus Current Abundance.}

Little is known of the historical abundance of this species. Individuals may be common at some spring outflows. Krienke Spring, a site in the Brushy Creek drainage of Williamson County from which a large series was collected (preserved at the Texas Memorial Museum, Austin, Texas), apparently was destroyed by quarrying operations in the 1960s (Sweet, 1978a). An office building recently was built directly above the one other known Brushy Creek locality (Chippindale et al., 2000). A morphologically unusual cave population on the Jollyville Plateau, which may represent this species (Salamander Cave; Sweet, 1978a), now lies beneath an apartment complex (J. Reddell, personal communication). Chippindale et al. (2000) briefly addressed some aspects of the conservation biology of this species; Price et al. (1995) provided a more detailed discussion. Currently, the City of Austin is conducting comprehensive studies of spring populations in the Jollyville Plateau region and formulating policies for protection of this species (Davis et al., 2001; unpublished data). This work involves detailed analyses of habitat and water quality parameters and their relationship to salamander distribution and abundance. Preliminary results indicate an inverse correlation between the degree of urbanization and salamander abundance at spring outflows.

\section{Life History Features.}

A. Breeding. Reproduction is aquatic.

i. Breeding migrations. Unlikely to occur.

ii. Breeding habitat. Unknown; a subset of the adult habitat.

\section{B. Eggs.}

i. Egg deposition sites. Unknown; some other spring-dwelling species of central Texas Eurycea are thought to deposit eggs in gravel substrate. The highest ratios of small juveniles to large juveniles and adults have been observed in March-August (City of Austin, 2000).

ii. Clutch size. Unknown.

C. Larvae/Metamorphosis. This species is paedomorphic, and natural metamorphosis is unknown.

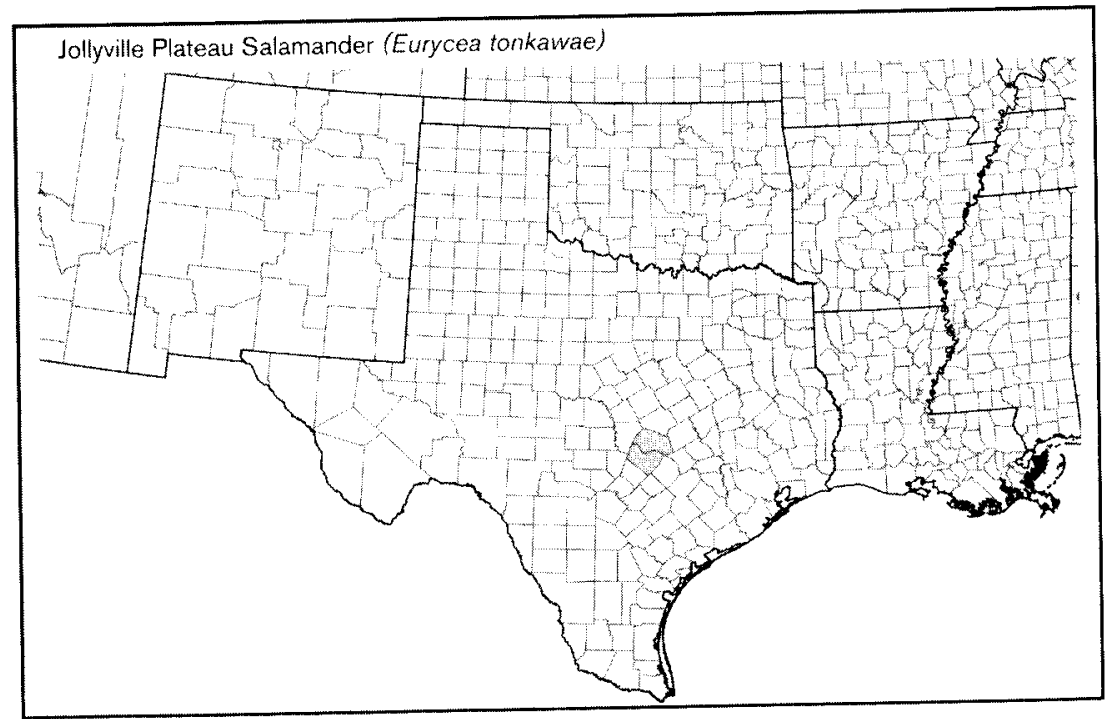


D. Juvenile Habitat. City of Austin personnel found that juveniles are more likely than adults to occur in shallow water near stream edges; they appear to prefer substrates with smaller particles than do large juveniles or adults (Davis et al., 2001).

E. Adult Habitat. Completely aquatic. Jollyville Plateau salamanders are known only from the vicinity of spring outflows, under rocks and leaves, and in gravel substrate. City of Austin personnel have found a positive correlation between abundance of large juvenile and adult salamanders and area of cobble available (Davis et al., 2001). Individuals in spring populations of the Jollyville Plateau region were found behaving (apparently) normally at water temperatures that ranged from 10.6-30.0 ${ }^{\circ} \mathrm{C}$, and no correlation was found between water temperature and salamander abundance (Davis et al., 2001). Preliminary results indicate that salamander abundance decreases as the degree of urbanization increases (Davis et al., 2001). Nitrate levels are a particular concern; during a 2-yr study, the highest observed incidences of dead individuals and animals with spinal deformities occurred at one site (the type locality) for which nitrate levels were particularly high (Davis et al., 2001). Sweet (1982) provided a comprehensive distributional analysis of the central Texas Eurycea and discussed hydrogeology of the region in relation to salamander distribution.

F. Home Range Size. Unknown.

G. Territories. Unknown.

H. Aestivation/Avoiding Desiccation. Unknown. However, available evidence suggests that this species makes extensive use of subterranean aquatic habitat, especially when surface spring flows decrease (Davis et al., 2001). On several occasions, City of Austin personnel found apparently healthy adult salamanders with the return of spring flow at sites that had been dry for months.

I. Seasonal Migrations. Unlikely to occur, although there may be seasonal variation in surface versus subsurface habitat use (Davis et al., 2001).

J. Torpor (Hibernation). Animals are probably active throughout the year.

K. Interspecific Associations/Exclusions. Other species of salamanders are not known from the habitat of this species.

L. Age/Size at Reproductive Maturity. Unknown. Average length of specimens measured by Chippindale et al. (2000) was $30.5 \mathrm{~mm} \mathrm{SVL}$; all measured were thought to be sexually mature, but this was only verified for some of the specimens.

M. Longevity. Unknown.

N. Feeding Behavior. Prey probably consist mainly of small aquatic invertebrates, but no detailed studies of feeding in this species have been conducted. City of Austin personnel analyzed gut contents of individuals that were found dead and found a wide range of invertebrate prey items representative of the diversity found in salamander habitats (Davis et al., 2001).
Particularly common prey items included chironomid larvae, physid snails, copepods, and ostracods.

o. Predators. Circumstantial evidence suggests that centrarchid fishes may substantially reduce numbers of salamanders at some sites (Davis et al., 2001).

P. Anti-Predator Mechanisms. Secretive.

a. Diseases. Unknown.

R. Parasites. Analyses of specimens found dead revealed encysted metazoan parasites (species unknown) in ova, pancreas, gut, and skeletal muscle. One individual had nematode parasites in the intestine (Davis et al., 2001).

\section{Conservation.}

Because Jollyville Plateau salamanders were described only recently and most of the known populations were discovered recently, little is known of the historical abundance of this species. Individuals may be common at some spring outflows, although development is known to have affected some populations and may be affecting others. Currently, the City of Austin is conducting comprehensive studies of spring populations in the Jollyville Plateau region and formulating policies for protection of this species. This work involves detailed analyses of habitat and water-quality parameters and their relationship to salamander distribution and abundance. Not surprisingly, preliminary results indicate an inverse correlation between the degree of urbanization and salamander abundance at spring outflows.

\section{Eurycea tridentifera Mitchell and Reddell, 1965}

COMAL BLIND SALAMANDER

Paul T. Chippindale

1. Historical versus Current Distribution.

Comal blind salamanders (Eurycea tridentifera) were described by Mitchell and Reddell
(1965) from Honey Creek Cave, Comal County, Texas. Sweet (1977b, 1978a, 1984) extended the distribution of this species to include several other caves in the Cibolo Sinkhole Plain of the southeastern Edwards Plateau region (Comal and Bexar counties). Chippindale et al. (2000) listed additional cave localities for this species in the same area and suggested that this species probably extends into Kendall County. Sweet (1978a, 1984) demonstrated that populations assigned to this species cluster together based on morphometric analyses. Some authors (Mitchell and Reddell, 1965; Bogart, 1967; Mitchell and Smith, 1972) have suggested that additional species may be present within what is considered $E$. tridentifera. There has been some difference of opinion regarding the generic allocation of this species. Wake (1966) considered it a member of the genus Typhlomolge, but despite some external and osteological similarity to the two species that were once included in this genus, it is not as closely related to either "T." (now Eurycea) rathbuni or robusta as it is to other southeastern Edwards Plateau Eurycea. Bogart (1967), Mitchell and Smith (1972), and Sweet (1978a, 1984) discuss the placement of this species; Chippindale $(1995,2000)$, Chippindale et al. (2000), and Wiens et al. (2003) address relationships of $E$. tridentifera in an explicitly phylogenetic context. Generic boundaries in the central Texas hemidactyliine plethodontid salamanders have been controversial, but all species now are considered members of the genus Eurycea (see Chippindale, 1995, 2000; Chippindale et al., 2000; Chippindale and Price, this volume, Part One). All recent authors have considered this species a member of the genus Eurycea.

\section{Historical versus Current Abundance.}

Assessment of abundance of Texas cave Eurycea is difficult, so no reliable assessments of past versus current abundance

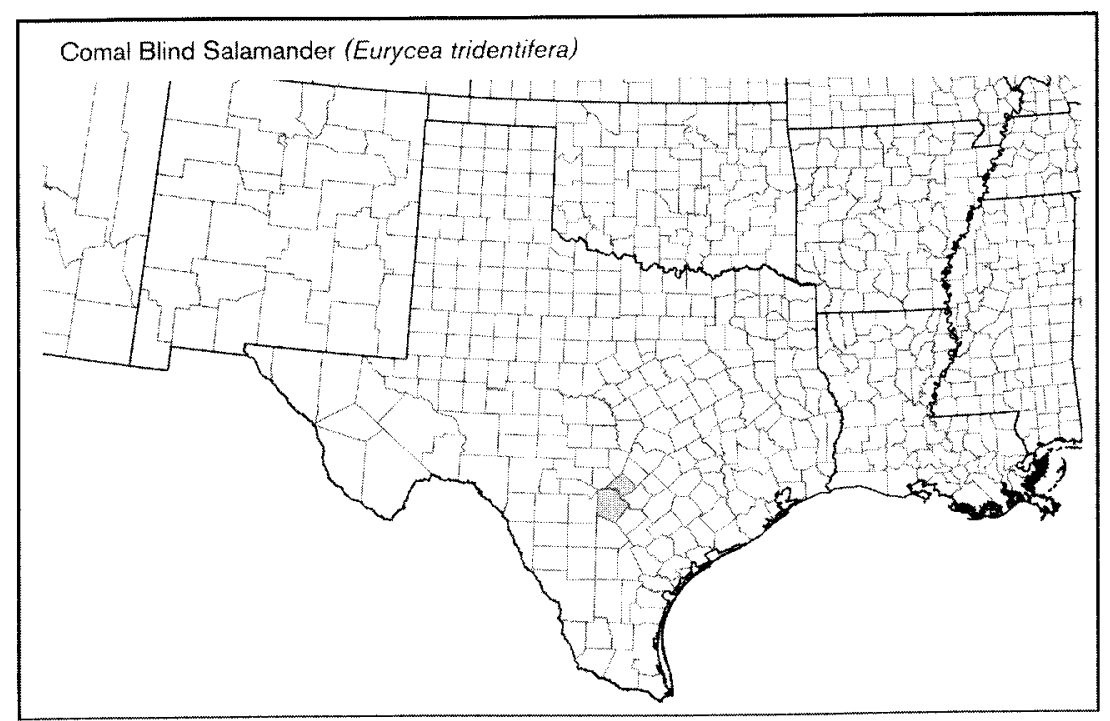


can be made. Individuals of this species appeared scarce during visits to the type locality in the early 1990 s (personal observations), although Mitchell and Reddell (1965), Bogart (1967), and Sweet (1978a, 1984) were able to collect fairly large series at this site.

\section{Life History Features.}

A. Breeding. Reproduction is aquatic.

i. Breeding migrations. Unlikely to occur.

ii. Breeding habitat. Likely the same as adult habitat.

B. Eggs.

i. Egg deposition sites. Unknown; closely related species are thought to deposit eggs in gravel substrates.

ii. Clutch size. Bogart (1967) artificially induced hybridization between this species and Valdina Farms salamanders (E. troglodytes), and the resulting eggs developed and hatched. Approximately 7-18 mature ova are produced/clutch, and eggs hatch when embryos are about $7 \mathrm{~mm} \mathrm{SVL}$ (Sweet, 1977b).

C. Larvae/Metamorphosis. Comal blind salamanders are paedomorphic, and natural metamorphosis is unknown. Bogart (1967) reported that Comal blind salamanders fail to metamorphose when treated with either thyroid hormone or pituitary implantation.

D. Juvenile Habitat. Probably same as adult habitat.

E. Adult Habitat. Comal blind salamanders are found on rock and mud substrates in caves. Water temperature in waters of the Edwards Plateau is relatively constant throughout the year and typically ranges from $18-20^{\circ} \mathrm{C}$ (Sweet, 1982).

F. Home Range Size. Unknown.

G. Territories. Unknown.

H. Aestivation/Avoiding Desiccation. Unknown.

I. Seasonal Migrations. Unlikely to occur. J. Torpor (Hibernation). Probably active throughout the year.

K. Interspecific Associations/Exclusions. At the outflow of the type locality, where Honey Creek Cave becomes a spring, surface Eurycea occur (Mitchell and Reddell, 1965; Bogart, 1967; Sweet, 1978a, 1984). Sweet (1978a, 1982, 1984) considered these to be Texas salamanders ( $E$. neotenes). Chippindale (1995) and Chippindale et al. (2000) considered these a member of the E. latitans complex. At the cave entrance, individuals intermediate in morphology between $E$. tridentifera and the surface species have been found and hybridization between the two species seems likely (Sweet, 1978a, 1984).

L. Age/Size at Reproductive Maturity. Brandon (1971b) found that males are mature at $22 \mathrm{~mm}$ SVL and females at 25 $\mathrm{mm}$; Sweet $(1977 \mathrm{~b})$ reported maturity at $25-27 \mathrm{~mm}$ for males and $28-32 \mathrm{~mm}$ for females.

M. Longevity. Unknown.
N. Feeding Behavior. Prey probably consists mainly of small aquatic invertebrates, but no detailed feeding studies of this species have been conducted. Individuals often have large amounts of detritus in their stomachs, suggesting they may graze the substrate for tiny invertebrates (personal observations). Bogart (1967) found remains of insects in fecal matter and suggested that this species may eat bat guano. Specimens maintained by Bogart (1967) accepted liver as food.

O. Predators. Sweet $(1978 a, 1984)$ noted that Eurycea usually are absent from caves where fishes are present in the general area of the Edwards Plateau inhabited by Comal blind salamanders. Bogart (1967) observed crayfish at the type locality, Honey Creek Cave, and suggested these as possible predators.

P. Anti-Predator Mechanisms. Sweet (1978a, 1984) reported that Comal blind salamanders usually swim upward when disturbed. This contrasts with behavior of most other members of the group that swim toward the substrate or to cover when frightened. Sweet suggested that this may reflect the absence of fish predators in caves inhabited by Comal blind salamanders.

Q. Diseases. Unknown.

R. Parasites. Unknown.

\section{Conservation}

Assessment of abundance of Texas cave Eurycea, including Comal blind salamanders, is difficult, so no reliable assessments of past versus current abundance can be made. While historical collectors were able to collect fairly large series of individuals (Mitchell and Reddell, 1965;, Bogart, 1967; and Sweet, 1978a, 1984), Comal blind salamanders appeared scarce during visits to the type locality in the early 1990s. This species is listed as Threatened by the State of Texas, although it has not attracted federal attention.

\section{Eurycea troglodytes Baker, 1957}

VALDINA FARMS SALAMANDER

\section{Paul T. Chippindale}

\section{Historical versus Current Distribution.}

Valdina Farms salamanders (Eurycea troglodytes) were described by Baker (1957) from Valdina Farms Sinkhole, Medina County, Texas. Sweet $(1978 a, 1984)$ demonstrated that this population includes individuals with a spectrum of morphological features, ranging from highly caveassociated morphologies most similar to those of Comal blind salamanders ( $E$. tridentifera) to surface-like morphologies most similar to those of what he considered Texas salamanders (E. neotenes). He hypothesized that this range of morphologies was the result of hybridization between surface Texas salamanders and a cave-dwelling species, perhaps Comal blind salamanders (note that the known range of Comal blind salamanders is far to the east of the type locality for Valdina Farms salamanders; Sweet suggested that Comal blind salamanders might have a more extensive subterranean range than was recognized). Most recent authors have not recognized $E$. troglodytes as a distinct species. However, Chippindale et al. (2000) found that salamanders from the Valdina Farms Sinkhole system were phylogenetically nested (based on mitochondrial DNA analysis) within a group of spring and cave populations of Eurycea in the southwestern Edwards Plateau region, where Valdina Farms Sinkhole is located. Combined analyses of allozyme and mitochondrial sequence data support monophyly of this group and reveal deep divergences among many populations. Chippindale (2000) and Chippindale et al. (2000) included all these southwestern populations in the $E$. troglodytes complex, but noted that additional undescribed species may exist. At present, the E. troglodytes complex encompasses a large and wide-ranging array of spring and cave populations in Bandera, Edwards, Gillespie, western Kerr, Medina, Real, and Uvalde counties. Populations from Val Verde County probably represent the E. troglodytes complex as well, but have not yet been examined for molecular markers. It is likely that salamanders from the E. troglodytes complex occur in Kinney County, but no populations have yet been discovered.

\section{Historical versus Current Abundance.}

Salamanders of the E. troglodytes complex are often abundant at spring outflows, especially in canyons of Bandera, Kerr, and Real counties. It is difficult to assess densities for cave populations. Construction of a diversion dam in the 1980 s temporarily submerged Valdina Farms Sinkhole, the type locality of Valdina Farms salamanders, and introduced catfish and other predators. Subsequent surveys (Veni and Associates, 1987; G. Veni, personal communication) have failed to reveal any Valdina Farms salamanders, even in areas of the cave where they once were common.

\section{Life History Features.}

A. Breeding. Reproduction is aquatic.

i. Breeding migrations. Unlikely to occur.

ii. Breeding habitat. Likely the same as adult habitat.

\section{B. Eggs.}

i. Egg deposition sites. Unknown; closely related species are thought to deposit eggs in gravel substrate.

\section{ii. Clutch size. Unknown.}

C. Larvae/Metamorphosis. Most populations in this species complex are paedomorphic, and metamorphosis is unknown for these. However, natural metamorphosis has been observed in populations from several springs in the Sabinal River drainage of Bandera County (Bogart, 1967; Sweet, 


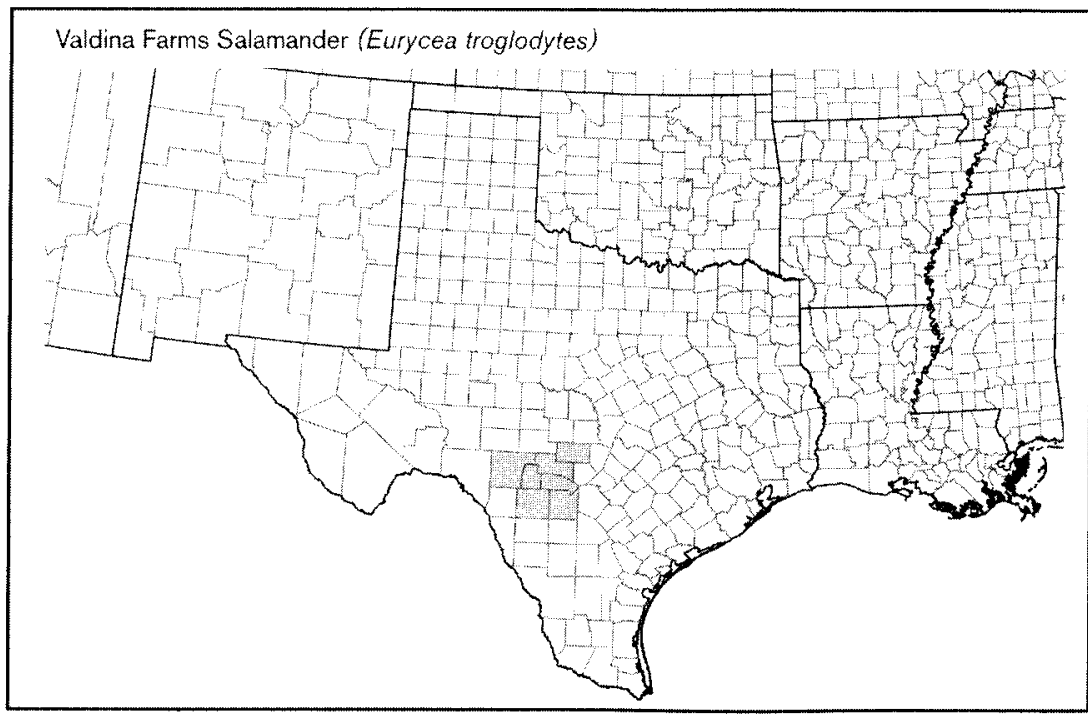

1977a). Sweet (1978a) observed a transformed individual in a Uvalde County cave and reported on a transformed individual observed by B.C. Brown in another cave in Uvalde County. Bogart (1967) induced transformation in animals from the type locality through implantation of frog pituitary glands.

D. Juvenile Habitat. Probably the same as adult habitat.

E. Adult Habitat. Individuals in most populations are completely aquatic, but Sweet (1977a, 1978b) found remains of terrestrial invertebrates in stomachs of some transformed individuals that were captured in water; this suggests that transformed animals may venture short distances onto land. Members of the $E$. troglodytes complex are known only from caves that contain water and the immediate vicinity of spring outflows; individuals in caves are often seen in the open on submerged rock or mud substrate, whereas individuals from spring populations are found under rocks and leaves and in gravel substrate. Water temperature in springs and caves of the Edwards Plateau is relatively constant throughout the year and typically ranges from $18-20^{\circ} \mathrm{C}$ in the areas inhabited by this species (Sweet, 1982). Sweet (1982) provided a comprehensive distributional analysis of the central Texas Eurycea and discussed hydrogeology of the region in relation to salamander distribution.

F. Home Range Size. Unknown.

G. Territories. Unknown.

H. Aestivation/Avoiding Desiccation. Unknown.

I. Seasonal Migrations. Unlikely to occur.

J. Torpor (Hibernation). Probably active throughout the year.

K. Interspecific Associations/Exclusions As described above, Sweet (1978a, 1984) considered the population at the type locality to be hybrids between $E$. neotenes and E. tridentifera. Chippindale (1995) and Chippindale et al. (2000) regarded this as unlikely, based on molecular data and geographical considerations, and continued to recognize E. troglodytes as a distinct species.

L. Age/Size at Reproductive Maturity. Sweet $(1977 a, 1978$ a) found that in transforming populations (which he considered to be $E$. neotenes), sexual maturity is concurrent with transformation at 30-32 mm SVL. Bruce (1976) studied Kerr County populations, which almost certainly are part of this species complex (he also considered them $E$. neotenes). He found that individuals under $25 \mathrm{~mm}$ were invariably immature and concluded that males become reproductively active early in their second year, while females mature at the same time but first oviposit at $2 \mathrm{yr}$ of age. Bogart (1967) artificially induced hybridization between $E$. troglodytes from the type locality and $E$. tridentifera.

\section{Longevity. Unknown.}

N. Feeding Behavior. Prey probably consists mainly of small aquatic invertebrates, but no detailed feeding studies of this species have been conducted. Sweet (1977a, 1978a) found remains of terrestrial collembolans and isopods in stomachs of transformed specimens. Transformed individuals maintained on wet moss by Bogart (1967) accepted Drosophila as food.

O. Predators. Unknown.

P. Anti-Predator Mechanisms. Springdwellers are secretive.

Q. Diseases. Sweet $(1978 \mathrm{a}, \mathrm{b})$ found evidence of "red-leg" disease, thought to be caused by bacteria of the genus Aeromonas, in some populations (note that Sweet considered these populations to be E. neotenes).

R. Parasites. Unknown

Valdina Farms salamanders were described from Valdina Farms Sinkhole, Medina

\section{Conservation.}

County, Texas. While it is difficult to assess densities for cave populations, salamanders of the E. troglodytes complex often are abundant at spring outflows, especially in canyons of Bandera, Kerr, and Real counties. Construction of a diversion dam in the 1980s temporarily submerged the type locality of Valdina Farms salamanders and introduced catfish and other predators. Subsequent surveys have failed to reveal any Valdina Farms salamanders, even in areas of the cave where they once were common. This species has not been given special conservation status by either the State of Texas or the federal government.

Eurycea tynerensis Moore and Hughes, 1939

OKLAHOMA SALAMANDER

Ronald M. Bonett

1. Historical versus Current Distribution.

Oklahoma salamanders (Eurycea tynerensis) were discovered in 1939 by ichthyologists seining in Tyner Creek, Adair County, Oklahoma (Moore and Hughes, 1939). The geographic distribution of Oklahoma salamanders currently is uncertain. They have been considered to range throughout the Springfield Plateau of northwestern Arkansas, northeastern Oklahoma, and southwestern Missouri (Dundee, 1965b; Conant and Collins, 1998; Petranka, 1998). Due to the subterranean tendencies of this neotenic species, the putative distribution described above includes drainage systems and physiographic regions that may potentially harbor populations of Oklahoma salamanders (Dundee, 1965b). The distribution of known localities, however, appears to be considerably smaller than their proposed range. The entire distribution of Oklahoma salamanders is nested within that of the extremely similar gray-bellied salamanders (E. multiplicata griseogaster), which have transforming adults (Petranka, 1998). Multivariate morphological analyses by Tumlison et al. (1990a) attempted to provide a mechanism for discerning Oklahoma salamanders from larval graybellied salamanders. However, it is possible that the morphometric differences that they found are associated with life history mode (paedomorphosis versus transformation), and do not represent species-specific differences. Furthermore, unpublished data show some populations of Oklahoma salamanders and gray-bellied salamanders to be indistinguishable based on allozymes (R. Wilkinson, personal communication). For this reason, all populations in Missouri formerly considered E. tynerensis are now considered to be E. m. griseogaster (Johnson, 2000). I am currently undertaking a study that includes delineating the species boundaries and revising the taxonomic status of the 


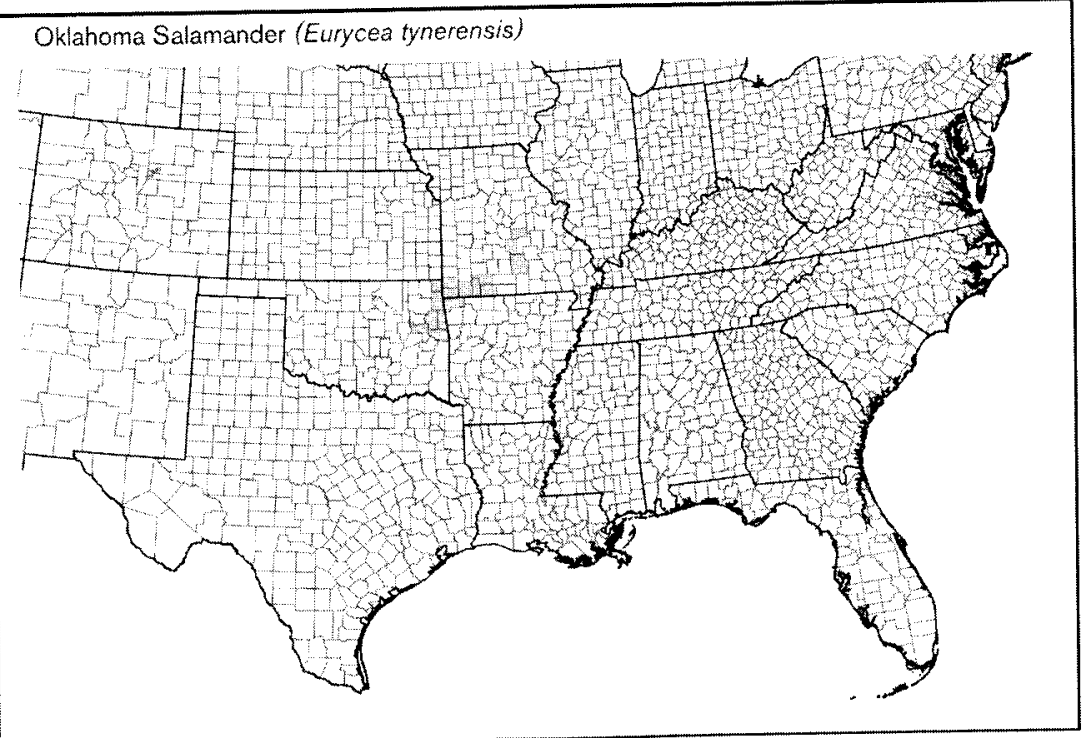

members of this complex using molecular and morphological data.

2. Historical versus Current Abundance.

No extirpations of populations or range extensions in previously uninhabited regions have been reported for Oklahoma salamanders.

\section{Life History Features.}

A. Breeding. Reproduction is aquatic.

i. Breeding migrations. Natural populations of Oklahoma salamanders currently are thought to include only permanently aquatic, non-transforming individuals (Petranka, 1998). As explained in other sections, Oklahoma salamanders exhibit considerable movement within their aquatic habitat, but the degree of migration for breeding purposes is unknown.

ii. Breeding habitat. Presumably the same as adult habitat.

\section{B. Eggs.}

i. Egg deposition sites. Egg clutches of Oklahoma salamanders have yet to be recovered in the field.

ii. Clutch size. In mid-May and midNovember, 1-11 eggs were harvested from three gravid females collected in Arkansas (Trauth et al., 1990), and gravid females collected in Oklahoma in late May contained as many as seven eggs measuring $1.8 \times 1.5 \mathrm{~mm}$ (Moore and Hughes, 1939).

C. Larvae/Metamorphosis. Hatchlings measure from 9-13 $\mathrm{mm}$ TL (Dundee, 1965b). Morphological differences between larvae and adults are slight, with larvae having fewer ampullary (electroreceptor) organs and larger tail fins and gills (Moore and Hughes, 1939). Four Oklahoma salamanders were induced to metamorphose (undergoing a loss of gills and tail fin, alterations in the morphology of the skull and eyes, and exhibiting an affinity for terrestriality) when treated with thyroxin (Kezer, 1952a).
D. Juvenile Habitat. Probably are the same as for adults, although studies that examine micohabitat usage by Oklahoma been conducted.

E. Adult Habitat. Traditionally, Oklahoma salamanders were thought to inhabit only cool, clear, swift streams that contain coarse gravel, where this species hides (Moore and Hughes, 1939; Dundee, 1958). Tumlison et al. (1990c) conducted thorough examinations of surface habitat parameters that are most preferable to $\mathrm{Ok}$ lahoma salamanders. Abiotically, they found shallow, slowly moving streams only partially embedded to reliably contain Oklahoma salamanders. Oklahoma salamanders also were found to be most abundant in areas where aquatic invertebrate densities are high. However, it is unclear if this biotic factor results from high prey density or a mutual response of both the aquatic invertebrates and Oklahoma salamanders to water conditions or predator avoidance. Additional observations on the habitat of Oklahoma salamanders reveal that they also occur in small springs and seeps amongst moist leaf litter over a mud-and-detritus substrate (Tumlison and Cline, 1997).

F. Home Range Size. Unknown.

G. Territories. Unknown.

H. Aestivation/Avoiding Desiccation. Dundee (1958) reported drought conditions to cause mass migrations of $\mathrm{Ok}$ lahoma salamanders to more hospitable subsurface environments. A persistent drought dried Tyner Creek, Adair County, Oklahoma (the type locality for E. tynerensis), from 1951-55, but excavation of the stream bed revealed water $2.4 \mathrm{~m}(8 \mathrm{ft})$ below the surface, where Oklahoma salamanders apparently sought refuge (Dowling, 1956). salamanders at various life stages have not containing medium-sized rocks that are Oklahoma salamanders preferring areas of
I. Seasonal Migrations. The discovery of subterranean isopods (Caecidotea sp.) in the stomachs of two specimens and the location of many individuals in small, isolated springs distant from a main stream course led Tumlison and Cline (1997) to propose that Oklahoma salamanders may be migrating along subterranean corridors to reach resource-rich habitats on the surface. However, high densities of Oklahoma salamanders in rather atypical habitats might also be interpreted as a sequestering of all individuals into the last remaining moist habitats to survive drought conditions.

J. Torpor (Hibernation). Unknown and unstudied.

K. Interspecific Associations/Exclusions. Rudolph (1978) reported that $\leq 4$ additional species of plethodontids with stream-dwelling larval stages are sympatric with Oklahoma salamanders. Among those are cave salamanders ( $E$. lucifuga), dark-sided salamanders (E. longicauda melanopleura), gray-bellied salamanders; and grotto salamanders (Typhlotriton [Eurycea] spelaeus). Rudolph (1978) found substantial differences between Oklahoma salamanders and other species in their ability to survive flood conditions, probably by seeking refuge within the gravel. He also noted that Oklahoma salamanders were the only species that are able to coexist with grotto salamanders at the heads of springs.

L. Age/Size at Reproductive Maturity. Oklahoma salamanders reach sexual maturity in 2-3 yr (Dundee, 1958) at approximately $26 \mathrm{~mm}$ SVL (Dundee, 1965b). Sexual size dimorphism has not been noted.

\section{Longevity. Unknown.}

N. Feeding Behavior. A wide array of prey items has been identified from the digestive tracts of Oklahoma salamanders, including dipterans, ephemeropterans, plecopterans, coleopterans, trichopterans, hymenopterans, thysanopterans, odonates, ostracods, isopods, amphipods, decapods, hydracarians, and pulmonates (Tumlison et al., 1990b). In addition, pulmonates, copepods, and homopterans were identified from the feces of Oklahoma salamanders (Rudolph, 1978).

Specimens used in an attempt to observe feeding postures of Oklahoma salamanders (Dodd, 1980) were later reidentified as grotto salamanders (Dodd, 1982).

o. Predators. Oklahoma salamander larvae were consumed by fishes, including banded sculpins (Cottus carolinae), black bullheads (Ameiurus melas), and green sunfish (Lepomis cyanellus) under laboratory conditions (Rudolph, 1978), but predation by fish in the wild has not been reported. of the Oklahoma salamanders collected by Tumlison et al. (1990c), 22\% had autotomized tails, which was suggested might be a result of predation by crayfish that occupy the same rocky substrate. 
P. Anti-Predator Mechanisms. In laboratory trials, fish predation was substantially less on larval Oklahoma salamanders than on grotto salamander, cave salamander, and long-tailed salamander larvae. This was attributed to the tendency of Oklahoma salamanders to seek refuge beneath the gravel substrate (Rudolph, 1978). In additional trials using leafy substrates, Oklahoma salamanders still evaded fish predation best, but there were more individuals consumed than in the trials on gravel substrate (Rudolph, 1978). Tumlison et al. (1990c) hypothesized that the shallow water preference of Oklahoma salamanders may reflect the exclusion of some fish (i.e., Cottus sp.) from such shallow depths.

Q. Diseases. Have not been reported or systematically studied.

R. Parasites. Two parasites have been described from Oklahoma salamanders: an echinorynchid worm, Acanthocephalus van cleavi (Hughes and Moore, 1943a), and a polystomatid fluke, Sphyranura ellryceae (Hughes and Moore, 1943b).

\section{Conservation.}

Eurycea tynerensis, once listed as Rare on Missouri's Rare and Endangered Species List (Johnson, 1987), is no longer recognized as a valid taxon in Missouri (Johnson, 2000). The name E. tynerensis is still used in Oklahoma, but it is provided with no special protected status there. In Arkansas, E. tynerensis is considered to be a Species of Special Concern, and collecting permit requests are closely monitored (K. Irwin, personal communication).

Being permanently aquatic leaves this species particularly vulnerable to alterations in water quality and pollutants. Much needed studies using molecular techniques to determine the differences between E. tynerensis and E. multiplicata, and to define their distributions, are currently in progress. The seasonal movements of Oklahoma salamanders, in particular their tendency to follow stream levels to subsurface habitats, may complicate monitoring studies of this species (Dowling, 1956). An understanding of the subterranean abundance and activity of Oklahoma salamanders will provide valuable insights into their status and conservation requirements.

Eurycea waterlooensis Hillis, Chamberlain, Wilcox, and Chippindale, 2001

AUSTIN BLIND SALAMANDER

Paul T. Chippindale

\section{Historical versus Current Distribution}

Austin blind salamanders (Eurycea waterlooensis) are a newly discovered species known only from the outflows of Barton Springs in the city of Austin, Travis County, Texas. A formal description is given in

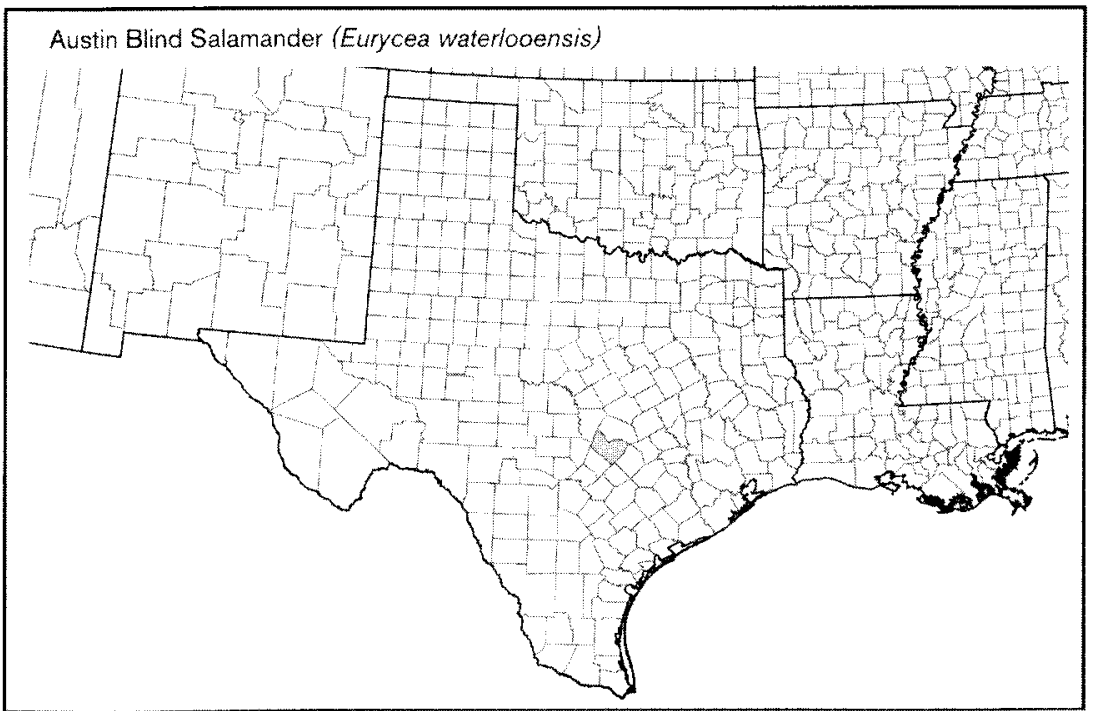

Hillis et al. (2001). This subterranean species is most closely related to Texas blind salamanders ( $E$. [formerly Typhlomolge] rathbuni) and Blanco blind salamanders ( $E$. [formerly Typhlomolge] robusta); both species occur in or near San Marcos, Hays County, Texas (Hillis et al., 2001). Only a few specimens are available, and Austin blind salamanders are much more rarely encountered than Barton Springs salamanders (E. sosorum), which occur on the surface at Barton Springs.

\section{Historical versus Current Abundance.} Unknown.

\section{Life History Features. \\ A. Breeding.}

i. Breeding migrations. Unknown. ii. Breeding habitat. Unknown.

B. Eggs.

i. Egg deposition sites. Unknown. ii. Clutch size. Unknown.

C. Larvae/Metamorphosis. This species is paedomorphic, and natural metamorphosis is unknown. Several specimens obtained as juveniles grew in captivity from about 15-60 mm TL in $8 \mathrm{mo}$, at which time they were presumed to be sexually mature (Hillis et al., 2001).

D. Juvenile Habitat. Probably similar to those of adults.

E. Adult Habitat. Completely aquatic. Austin blind salamanders are known only from spring outflows (juveniles that probably washed out accidentally); this species almost certainly is a cave dweller. Water temperature in the Barton Springs Aquifer is relatively constant at about $20^{\circ} \mathrm{C}$. Sweet (1982) provided a comprehensive distributional analysis of the central Texas Eurycea and discussed hydrogeology of the region in relation to salamander distribution.
F. Home Range Size. Unknown.

G. Territories. Unknown.

H. Aestivation/Avoiding Desiccation. Unknown.

I. Seasonal Migrations. Unlikely to occur.

J. Torpor (Hibernation). Probably active throughout the year.

K. Interspecific Associations/Exclusions. Partially sympatric with Barton Springs salamanders.

L. Age/Size at Reproductive Maturity. Unknown, but based on growth patterns for captive specimens, this species probably matures at about $60 \mathrm{~mm}$ total length. The largest known specimen (maintained alive by the City of Austin) had a total length of about $79 \mathrm{~mm}$ in July 2000. The largest known preserved specimen is $35.6 \mathrm{~mm}$ SVL with a total

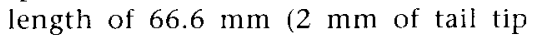
missing).

M. Longevity. Unknown.

N. Feeding Behavior. Prey probably consists mainly of aquatic invertebrates, but no feeding studies of this species have been conducted.

O. Predators. Unknown.

P. Anti-Predator Mechanisms. Unknown.

Q. Diseases. Unknown.

R. Parasites. Unknown.

\section{Conservation}

Austin blind salamanders are a newly discovered species known only from the outflows of Barton Springs in the city of Austin, Travis County, Texas. Only a few specimens are available, and Austin blind salamanders are much more rarely encountered than syntopic Barton Springs salamanders, which occur on the surface at Barton Springs. Austin blind salamanders are currently listed by the federal government as a Candidate species; they receive no special protection in Texas. 
Eurycea wilderae Dunn, 1920 BLUE RIDGE TWO-LINED SALAMANDER

David M. Sever

1. Historical versus Current Distribution. Until raised to full species status by Jacobs (1987), Blue Ridge two-lined salamanders (Eurycea wilderae) were considered a subspecies of northern two-lined salamanders (E. bislineata) as described by Dunn (1920). Dunn (1920) stated that the range of his new taxon is the "southern division of the Blue Ridge," and Dunn (1926) reported that the distribution is "from White Top Mountain, Virginia; south in mountains to Clayton, Rabun County, Georgia, and Cherry Log, Gilmer County, Georgia. They inhabit the whole Southern Blue Ridge region." The range is sometimes loosely given as "the southern Appalachian Mountains" (Jacobs, 1987; Conant and Collins, 1998), but essentially the range as defined by Dunn (1926) is restricted to the Southern Blue Ridge Mountain physiographic province. Blue Ridge two-lined salamanders occur from baselevel streams to the tops of the highest peaks (about $1,900 \mathrm{~m}$ ). The most remarkable characteristic of this species is the presence of two male morphs that differ dramatically in morphology, especially in regards to the male secondary sexual characters (Sever, 1979, 1999c). One of these is considered the typical "wilderae" morph because it possesses labial cirri, which also characterize males in the type series (Dunn, 1920). This gracile form also possesses a mental gland, seasonally enlarged premaxillary teeth, and $0-2$ costal grooves between toes of the adpressed limbs. Males of the other morph, called "morph A" by Sever (1979), lack cirri, mental glands, and seasonally enlarged premaxillary teeth, and they possess $2-3$ costal grooves between toes of the adpressed limbs. During the breeding season, the muscles comprising the jaw adductors hypertrophy, making morph A the "bigheaded" form in the Southern Blue Ridge. Hypertrophy of the jaw adductors is also known in populations of northern twolined salamanders and Junaluska salamanders ( $E$. junaluska), but these species all possess mental glands and enlarged premaxillary teeth, and cirri also occur in Junaluska salamanders (Sever, 1979). Females associated with the two male morphs of Blue Ridge two-lined salamanders are indistinguishable but generally have 2-4 costal grooves between adpressed limbs. Morph A has been reported from Blount, Monroe, and Sevier counties, Tennessee, and Graham, Haywood, Macon, and Watuga counties, North Carolina (Sever, 1989), and probably occurs throughout the Southern Blue Ridge. Whether the morphs represent separate species or a polymorphism in Blue Ridge two-lined salamanders still is unresolved, but morph A also occurs in populations in the Piedmont and Coastal Plain of North Carolina within the defined range of southern two-lined salamanders (E. cirrigera; Sever, 1999b). Note that in some other populations of southern two-lined salamanders, such as in northern Alabama and the Cumberland Plateau of southeastern Tennessee, "big-headed" males occur (Mount, 1975; Sever, 1999b), but these individuals possess mental glands and cirri and therefore are not identifiable as morph A. Specimens resembling the male wilderae morph also have been found outside of the Southern Blue Ridge. Individuals morphologically similar to the wilderae morph have been reported by Chermock (1952) from Mount Cheaha in Alabama (which Chermock, as well as Mount, 1975, considers an extension of the Blue Ridge) and by Rossman (1965b) from Wilcox County in the Coastal Plain of Alabama. Allozyme analysis of specimens from these localities, however, align them with $E$. cirrigera (Jacobs, 1987). I have seen specimens that resemble the male wilderae morph from Cloudland Canyon State Park, Dade County, Georgia, and Kings Mountain State Park, York County, South Carolina. Howell and Switzer (1953) reported "integrades" between E. cirrigera and E. wilderae in the Piedmont of Georgia. An allozyme analysis of the contact zone between $E$. wilderae and $E$. cirrigera in northwestern South Carolina revealed the presence of populations of $E$. wilderae in the Piedmont of Anderson, Oconee, and Pickens counties (Kozak, 1999). The limits of the range of $E$. wilderae and interactions with E. bislineata and E. cirrigera in areas of contact or sympatry need much more study (Sever, 1999a,b,c). Finally, Jacob's (1987) group E of E. wilderae included samples from the type locality (Grayson County, Virginia) and two samples from Watuga County, North Carolina, whereas his group $\mathrm{F}$ contains all other samples of
E. wilderae from more southern areas of the Blue Ridge. Mean $D=0.30$ between the $\mathrm{E}$ and $\mathrm{F}$ groups, far exceeding levels (as low as $D>0.15$ ) commonly used to denote species level differences (Highton, 1998; Thorpe, 1982). Thus, E. wilderae is likely polyspecific; the northern taxon (group $\mathrm{E}$ ) is referable to $E$. wilderae, but the southern taxon (group $F$ ) requires a new name.

\section{Historical versus Current Abundance.}

Early reports indicate that Blue Ridge two-lined salamanders were frequently encountered during fieldwork. Dunn (1917a) reported on collections of the species near Brevard, Transylvania County, and Linville, Avery County, North Carolina. He stated,

We found the larvae of this species common in every small stream examined, and even in those as large as the Linville River. Adults were found rarely at Brevard. Only 1 adult and 1 transforming specimen were taken near there. At Linville both adults and larvae were common, but adults were found only on land under logs in situations similar to those chosen by various Plethodons and by Desmognathus o. carolinensis (D. carolinensis), in fact often in company with these species.

In Rutherford County, North Carolina, Weller (1930) found Blue Ridge two-lined salamanders to be "very common, both at camp and in the surrounding mountains." King (1939) stated, "This is one of the common salamanders in the Great Smokies. It may be found in nearly every spring, seep and permanently damp place at suitable elevations." In another account on Blue Ridge two-lined salamanders in the Smokies, Huheey and Stupka (1967) reported, "This common salamander ranges throughout the Park, occurring at all altitudes." I have been collecting the species for over $35 \mathrm{yr}$. I believe that historically the species probably occurred in

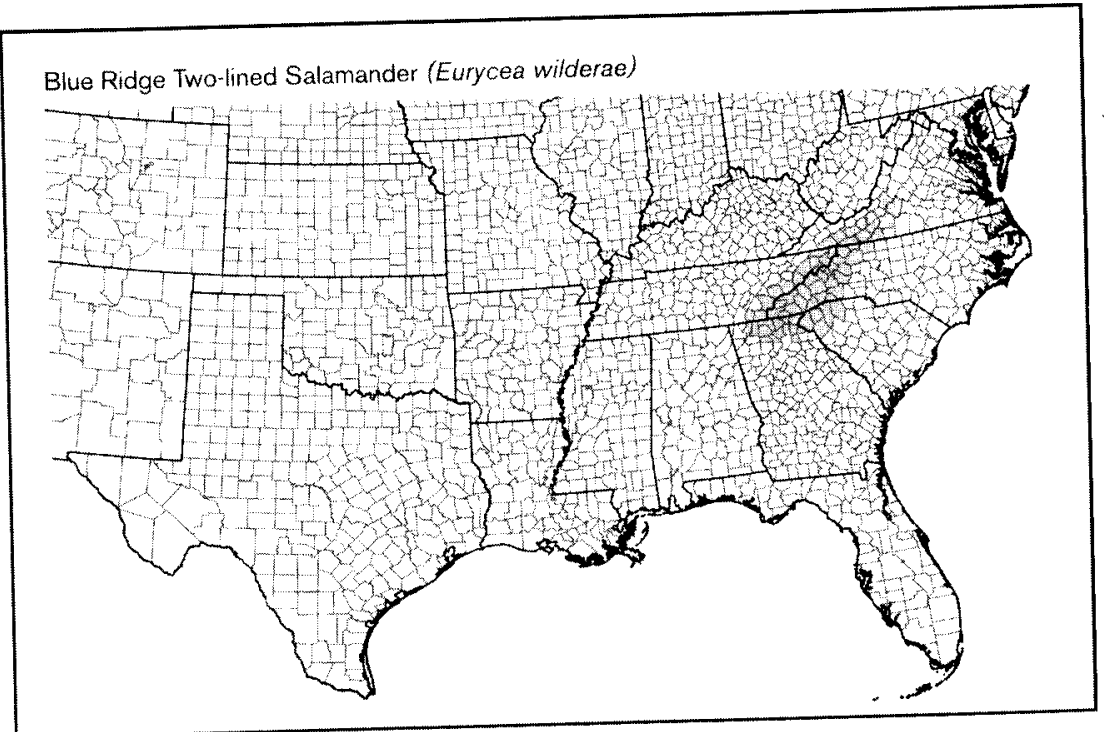


every rocky mountain stream in the Southern Blue Ridge. Today, Blue Ridge two-lined salamanders are still likely to be found in every stream that has not been damaged by pollution, siltation, deforestation, channeling, and other factors. The species, however, appears rather resilient, and one should not be surprised to find it almost anywhere in the Southern Blue Ridge, even in seemingly inhospitable habitats. For example, Tullulah Creek in Graham County, North Carolina, is historically a clear-flowing rocky, baselevel stream. Large samples of Blue Ridge two-lined salamanders could be collected in the 1970s where Tullulah Creek runs through Robbinsville. In the past $15 \mathrm{yr}$, the stretch through Robbinsville has become increasingly murky and exposed as businesses and homes along the creek have flourished. Other formerly common salamanders, such as three-lined salamanders (E. guttolineata), Junaluska salamanders, and black-bellied salamanders $(D$. quadramaculatus), are now rare along Tullulah Creek in Robbinsville, but Blue Ridge two-lined salamanders are still common. Adults aggregate at mating/nesting sites from October-April and may be abundant in streams where few adults can be found in mid summer. However, mass metamorphosis of larvae can again make the species seem incredibly abundant along rocky mountain streams in summer but these individuals are mostly juveniles.

\section{Life History Features.}

Consult Sever (1999a) for additional references on Blue Ridge two-lined salamanders.

A. Breeding. Reproduction is aquatic.

i. Breeding migrations. Many authors have noted that adults can be found considerable distances from water (e.g., King, 1939; Huheey and Stupka, 1967). In midsummer on Wayah Bald, Macon County, North Carolina, I have found dozens under single strips of bark on fallen trees hundreds of meters from the nearest streams. Because the eggs are laid in water and the larvae are aquatic, however, migration must occur to suitable nesting sites. Also, because both males and females migrate, nesting sites constitute mating areas as well. Aggregations start in the fall, and at higher elevations, the mating/nesting areas also serve as hibernation sites. The peak concentration of adults in mating/nesting areas is in spring. Courtship and mating occur on the banks of streams adjacent to nesting areas. The projecting premaxillary teeth of males of the wilderae morph scrape the female's skin during courtship, allowing secretions of the male's mental gland to enter the superficial circulation of the female (Arnold, 1977).

ii. Breeding habitat. Usually the eggs are attached to the underside of rocks in flowing water. I have not noticed any consistency in the size of the rock (large or small) or shape (flat or round). Females remain with the eggs. The gelatinous matrix of the eggs is naturally adhesive; eggs may be in one rather discreet cluster or more scattered. A large, favorable rock may have nests of several females. I occasionally have found eggs (with attendant females) by digging through gravelly spring heads; an individual egg in these situations may adhere to several small pieces of gravel.

\section{B. Eggs.}

i. Egg deposition sites. As reported above, nests most frequently have been found under rocks in streams. A considerable amount of variation, however, occurs in the timing of oviposition in this species. Dunn (1920) reported: "At Linville a batch of eggs was found hatching on July 19 They were attached to the under side of a stone in a brook just as are the eggs of bislineata." Wood (1949) stated that late summer deposition occurs at elevations of $1,525 \mathrm{~m}$, and egg laying occurs earlier at lower elevations. At $1,220 \mathrm{~m}$ on Mount Mitchell on 4 May, Wood (1949) found a batch of 87 eggs suspended from the lower surface of a flat stone in a small seepage spring. Bruce (1982a) reported numerous egg clusters in late winter and early spring in streams in the Tuckasegee River basin (695-1,050 m) in Jackson County, North Carolina. At Santeetlah Creek $(650 \mathrm{~m})$, Graham County, North Carolina. Bruce (1982b) reported finding nests on 13 and 15 May; at the same site, however, I have found nests in mid-March.

ii. Clutch size. The batch of 87 eggs reported by Mitchell from the lower surface of a rock in a small spring on Mount Mitchell probably represents the clutches of more than one female. Clutch sizes in various populations have been reported to range from 8-34 and 28-56 (Ryan and Bruce, 2000).

C. Larvae/Metamorphosis. Ryan (1997) provides an excellent drawing of the larva. The larvae of Blue Ridge two-lined salamanders are a pale yellow to yellow-green dorsally with a thin, broken dorsolateral stripe, ventral to which is fine mottling and three rows of unpigmented lateral line spots (Eaton, 1956; Ryan, 1997). The tail is flattened and mottled while the venter is clear and a light cream color Bruce (1986) reported on drift movements of Blue Ridge two-lined salamanders in a stream at $1,170 \mathrm{~m}$ in Macon County, North Carolina. He found that downstream movements are dominated by firstyear larvae. Upstream movements are not sufficient to compensate for downstream drift, so drift may represent a density-dependent means of population regulation.

i. Length of larval stage. Bruce (1982a, 1985b) reported metamorphosis usually occurs in late spring and early summer after $1-2 \mathrm{yr}$ at a mean $18.5-23.9 \mathrm{~mm}$ SVL in stream populations, and at $26.4 \mathrm{~mm}$ SVL in a pond. Although a tendency exists for growth rates to be lower at higher elevations, no corresponding tendency occurs for the larval period to be prolonged (Bruce, 1985b). At Santeetlah Creek, Graham County, North Carolina, the larval period typically is $2 \mathrm{yr}$ with mean $31.8 \mathrm{~mm}$ SVL in the oldest cohort to metamorphose (Bruce, 1982b). Voss (1993b) found that larvae metamorphose after $1 \mathrm{yr}$ in firstorder streams, whereas in higher-order streams metamorphosis may be delayed for an additional year. This variation is due to warmer temperatures in first-order streams (Voss, 1993b). Beachy (1994) found that survival and growth of Blue Ridge twolined salamander larvae raised in the laboratory together were independent of density, suggesting a lack of competition.

ii. Larval requirements.

a. Food. I am unaware of any study specifically dealing with food habits of larval Blue Ridge two-lined salamanders, although such studies do exist for the sibling species E. bislineata (Smallwood, 1928; Burton, 1976) and E. cirrigera (Petranka, 1984b).

b. Cover. As Petranka (1984b) reported for the sibling species E. cirrigera, larval Blue Ridge two-lined salamanders are found under rock cover during the day and move about stream beds feeding continuously at night (Wiltenmuth, 1997a).

iii. Larval polymorphisms. None are known.

iv. Features of metamorphosis. As reported in "Length of larval stage" above, metamorphosis occurs after 1-2 yr of larval development. Newly metamorphosed juveniles are often abundant around breeding areas in late spring and summer, indicating some synchrony in metamorphosis within a population.

v. Post-metamorphic migrations. Individuals that metamorphose in the late spring or summer may participate in breeding activities the following spring, at the beginning of their third or fourth year (Bruce, 1988b). Thus, the juvenile stage is short, and juveniles may not move far from streamside habitats along the natal area. I have found mature gonads in dissected individuals that are only $25-28 \mathrm{~mm} \mathrm{SVL}$, within the range of body sizes characterizing newly metamorphosed animals in some populations (Bruce, 1982a,b, 1985b).

vi. Neoteny. Not known to exist.

D. Juvenile Habitat As mentioned above, juveniles often are found in streamside habitats. They may be found under rocks and logs, by scraping through leaves and other detritus. Bruce (1986) did not find significant differences between upstream and downstream movements in second-year larvae and metamorphosed individuals.

E. Adult Habitat. Males frequently are found with females under rocks in streams during the spring mating period. Females subsequently stay in the water with their nests, whereas the males move into terrestrial habitats. After eggs hatch, females 
must follow males into more terrestrial habitats because adults of either sex are usually uncommon along streams in midsummer.

F. Home Range Size. I am unaware of any literature on whether individuals of Blue Ridge two-lined salamanders establish home ranges during any period of the year or stage of life. The study done by Bruce (1986) on upstream and downstream movements suggests that adults and second-year larvae move upstream and downstream in equal frequencies, which no doubt contributes to maintaining a certain density at a locale. First-year larvae, however, move downstream more frequently, resulting in a density dependent mechanism of regulation of excess production (Bruce, 1986).

G. Territories. Wiltenmuth (1997a) reported aggression in larval Blue Ridge two-lined salamanders, but whether this behavior is due to territorial or nonterritorial interference competition requires further investigation.

H. Aestivation/Avoiding Desiccation. Not known to occur. Hutchison (1961) reported on critical thermal maxima in a number of salamanders, including three juvenile Blue Ridge two-lined salamanders. He found a CTM of $32.1^{\circ} \mathrm{C}$, the lowest of any salamander tested (Hutchison, 1961).

I. Seasonal Migrations. Movements between terrestrial and stream habitats associated with mating/nesting activities are discussed in "Breeding migrations" above.

J. Torpor (Hibernation). Numerous individuals can be found by digging through gravelly spring heads in mid-winter, even at high elevations where harsh winter weather surely precludes much surface activity. At lower elevations, however, activity may occur through mid-winter.

K. Interspecific Associations/Exclusions. The Southern Blue Ridge physiographic province is a center of salamander diversity in North America (Bruce et al., 2000). Blue Ridge two-lined salamanders commonly are found in association with a dozen or more other species. Brodie (1981) reported that yellow-striped Ocoee salamanders (Desmognathus ocoee; called $D$. ochrophacus by Brodie) from several North Carolina localities are mimics of Blue Ridge two-lined salamanders. However, this model-mimic relationship is not as prevalent as in New York between Allegheny Mountain dusky salamanders $(D$. ochrophaeus) and northern two-lined salamanders, which are relatively more common in association with Allegheny Mountain dusky salamanders than Blue Ridge two-lined salamanders are with Ocoee salamanders in North Carolina.

L. Age/Size at Reproductive Maturity. The smallest individuals I have dissected that definitely possess mature gonads are $25 \mathrm{~mm} \mathrm{SVL}$ for a female and $28 \mathrm{~mm}$ SVL for a male. However, some individuals as small as $23 \mathrm{~mm} \mathrm{SVL}$ may be mature, and many are still immature at $30 \mathrm{~mm}$ SVL. Bruce (1988b) reported that individuals spend $\geq 1$ yr as juveniles after $1-2$ yr as larvae. Age at first reproduction in both sexes is estimated to be 3-4 yr, but usually the latter, since most individuals metamorphose at $2 \mathrm{yr}$ (Bruce, 1988b). Mean SVL of adults from various populations ranges from 30.3-49.0 mm (Sever, 1999a), with total lengths of $60-90 \mathrm{~mm}$ (Bishop, 1943). The record specimen came from Indian Gap in the Great Smoky Mountains and is $120 \mathrm{~mm}$ TL (King, 1939).

M. Longevity. Bruce (1988b) constructed a life table for a population of Blue Ridge two-lined salamanders from $1,100 \mathrm{~m}$ in Macon County, North Carolina. He found that $\mathrm{RO}=0.821$, indicating a declining population and an unstable age distribution. Bruce believed that this $\mathrm{R}$ value was a result of procedural errors and used alternative methods (that do not rely upon any assumptions concerning $\mathrm{R}$ ) to calculate an estimate mean generation time of $4.4 \mathrm{yr}$; an annual survivorship of 0.408 was calculated for females. Few animals survive beyond $5 \mathrm{yr}$ and none beyond $10 \mathrm{yr}$.

N. Feeding Behavior. I am not aware of any studies that specifically address feeding behavior of Blue Ridge two-lined salamanders.

o. Predators. Huheey and Stupka (1967) mention that spring salamanders (Gyrinophilus porphyriticus; see also Bruce, 1979; Beachy, 1994) and common garter snakes (Thamnophis sirtalis) are predators. Larval (Beachy, 1994, 1997) and metamorphosed (Davic, 1991) black-bellied salamanders are known predators, and it is likely that several other larger plethodontids (including red salamanders, [Psetudotriton ruberj and shovel-nosed salamanders, [D. marmoratus /) eat Blue Ridge two-lined salamander larvae or adults as well (Bruce, 1982a). Beachy (1994) raised larval Blue Ridge two-lined salamanders in the laboratory for $30 \mathrm{~d}$ with larvae of spring salamanders and/or black-bellied salamanders. He found that both predators significantly reduced survivorship of Blue Ridge two-lined salamanders, but that spring salamanders were more effective. Larvae of spring salamanders exposed to high prey densities grew more than those exposed to low prey densities, but prey density had no effect on prey survival. When grouped together with Blue Ridge two-lined salamanders, predator effects on prey survival were additive, indicating neither a mutualistic nor a competitive interaction between spring salamanders and black-bellied salamanders. Beachy (1997a) conducted additional experiments in which he exposed larval Blue Ridge two-lined salamanders to larval black-bellied salamanders. Risk of predation caused significant variation in growth rate, with larvae under highest predation risk growing faster during certain periods. However, larvae metamorphosed at the same time regardless of different growth rates and predation risks. Beachy (1997a) hypothesized that no advantage exists in varying time or size at metamorphosis due to the permanency and low productivity of mountain streams.

P. Anti-Predator Mechanisms. Wiltenmuth (1997a) conducted experiments to determine whether differences in body size among age classes of Blue Ridge twolined salamander larvae affect intraspecific agonistic behavior, and whether cover availability in the presence of a predator species (larval black-bellied salamanders) affects spacing behavior of larvae. She found that larvae of Blue Ridge two-lined salamanders prefer the vicinity of rock cover and that larger larvae are dominant to smaller larvae. However, Blue Ridge two-lined salamanders did not increase use of rock cover in the presence of visual or chemical cues from black-bellied salamanders. She concluded that either black-bellied salamanders do not pose a substantial threat to Blue Ridge two-lined salamanders or that Blue Ridge two-lined salamanders do not hide under cover to avoid black-bellied salamanders (Wiltenmuth, 1997a).

a. Diseases. None are known.

R. Parasites. I am not aware of any reports on parasites of Blue Ridge two-lined salamanders.

\section{Conservation.}

There are no current conservation concerns associated with Blue Ridge two-lined salamanders. They are not state or federally listed (Levell, 1997). Habitat remains plentiful throughout their range, and they remain abundant in suitable streams.

\section{Eurycea sp. 1}

COMAL SPRINGS SALAMANDER

\section{Paul T. Chippindale, Joe N. Fries}

\section{Historical versus Current Distribution.}

This putative species is known only from Comal Springs in the city of New Braunfels, Comal County, Texas. Some authors (Sweet, 1978a; Dixon, 1987) have considered this population conspecific with $E$. nara from San Marcos Springs, Hays County, but morphological and molecular evidence strongly supports a rejection of this hypothesis (Chippindale, 1995, 2000; Chippindale et al., 1998, 2000). This taxon appears to be most closely related to the southeastern Edwards Plateau clade of Eurycea recognized by Chippindale (1995, 2000) and Chippindale et al. (2000). Systematic studies are in progress.

\section{Historical versus Current Abundance.}

Unknown. Currently common at and near spring outflows.

\section{Life History Features.}

A. Breeding. Reproduction is aquatic. 


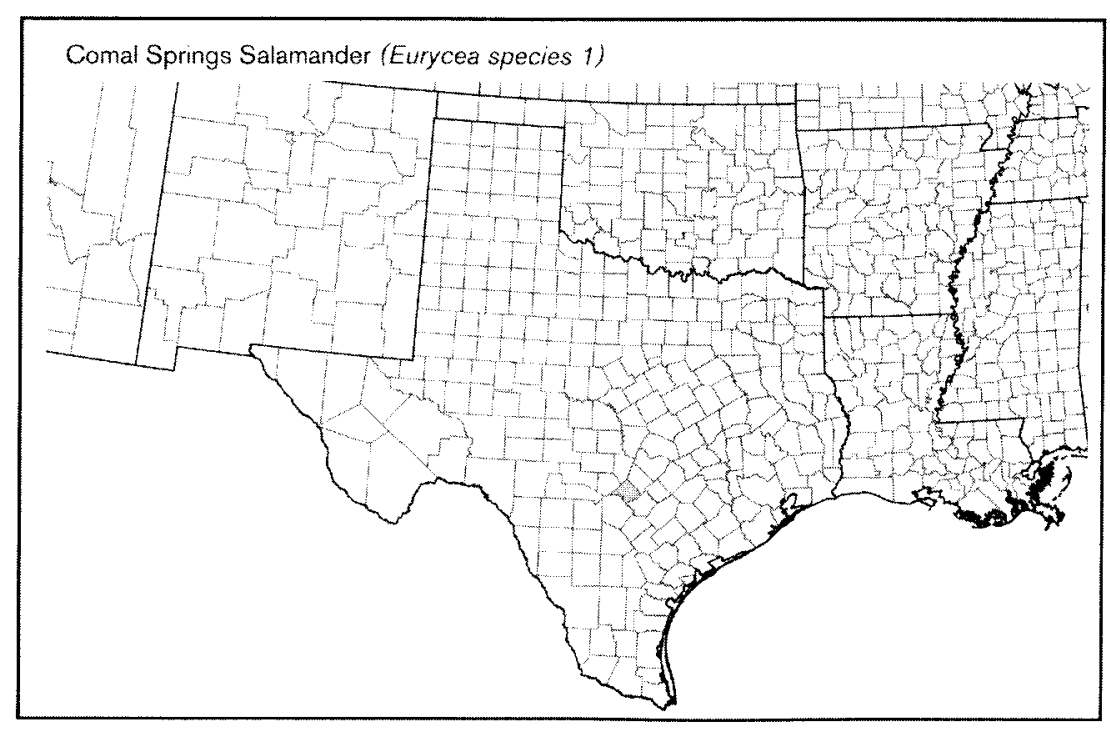

i. Breeding migrations. Unlikely to occur. ii. Breeding habitat. Roberts et al. (1995) successfully bred this species in acrylic columns filled with large gravel through which artesian water was pumped.

B. Eggs.

i. Egg deposition sites. Roberts et al. (1995) provided detailed information on egg laying. Based on their observations, they suggested that individuals travel downward into spring upwellings to deposit eggs.

ii. Clutch size. From 19 to $>50$ eggs (Roberts et al., 1995).

C. Larvae/Metamorphosis. This species is paedomorphic, and natural metamorphosis is unknown. Captive-hatched individuals at the Dallas Aquarium at Fair Park reached total lengths of $26 \mathrm{~mm}$ by 2 mo of age; by $6 \mathrm{mo}$ of age they were $60 \mathrm{~mm}$, and females showed signs of ova development; at $1 \mathrm{yr}$, two individuals were gravid (Roberts et al., 1995). Roberts et al. (1995) described development of eggs and larvae.

D. Juvenile Habitat. Probably the same as adult habitat.

E. Adult Habitat. Completely aquatic. This species is known only from the vicinity of spring outflows, under rocks, and in gravel substrate. Water temperature in Comal Springs typically is $23{ }^{\circ} \mathrm{C}$ (George et al., 1952; USFWS, 1996b). Roberts et al. (1995) provided detailed information on water chemistry for captive specimens. Sweet (1982) provided a comprehensive distributional analysis of the central Texas Eurycea and discussed hydrogeology of the region in relation to salamander distribution.

F. Home Range Size. Unknown.

G. Territories. Unknown.

H. Aestivation/Avoiding Desiccation. Unknown. However, Comal Springs is known to have ceased flowing during a drought in the 1950s; therefore, some members of this species are able to retreat underground when necessary.
I. Seasonal Migrations. Unlikely to occur, although there may be seasonal variation in surface versus subsurface habitat use.

J. Torpor (Hibernation). Probably active throughout the year.

K. Interspecific Associations/Exclusions. Fountain darters (Etheostoma fonticola) are common in the same areas where salamanders are found.

L. Age/Size at Reproductive Maturity. In morphometric analyses of some Edwards Plateau Eurycea (Chippindale et al., 1993, 1998), the average SVL of individuals that were presumed to be adults was $27.8 \mathrm{~mm}$ (in their 1993 paper, Chippindale et al. tentatively assigned this population to $E$. neotenes). Roberts et al. (1995) reported that 6-mo-old, captive-hatched individuals were approaching maturity at about $60 \mathrm{~mm} \mathrm{TL}$; at $1 \mathrm{yr}$, some were gravid. Breeding animals at the Dallas Zoo Aquarium were $91 \mathrm{~mm} \mathrm{TL}$ (male) and $74 \mathrm{~mm}$ (female) for a wild-caught pair, and $76 \mathrm{~mm}$ (male) and $65 \mathrm{~mm}$ (female) for an $\mathrm{F} 1$ pair (Roberts et al., 1995).

M. Longevity. At least $3 \mathrm{yr}$ in captivity.

N. Feeding Behavior. Prey probably consists mainly of small aquatic invertebrates. Captive individuals fed on brine shrimp, amphipods, oligochaete worms, snails, and zooplankton.

O. Predators. Unknown.

P. Anti-Predator Mechanisms. Secretive.

Q. Diseases. Unknown.

R. Parasites. Unknown.

\section{Conservation.}

This putative species is known only from Comal Springs in the city of New Braunfels, Comal County, Texas. Their conservation status is unknown; they currently are considered common at and near spring outflows.

\section{Eurycea sp. 2}

PEDERNALES SPRINGS SALAMANDER

Paul T. Chippindale

\section{Historical versus Current Distribution.}

Pedernales Springs salamanders (unnamed Eurycea [Eurycea sp.]) are a putative species first found in 1989 by D. Hillis and P. Chippindale in a spring along the Pedernales River in extreme western Travis County, Texas; the only other known locality is a second nearby spring. These animals have never been formally assigned to any species, but appear to be distinct based on molecular markers, and are well separated geographically, geologically, and hydrologically from other members of the group (Chippindale, 1995, 2000; Chippindale et al., 2000). This taxon appears to be most closely related to the southeastern Edwards Plateau clade of Eurycea recognized by Chippindale (1995, 2000 ) and Chippindale et al. (2000). Systematic studies are in progress.

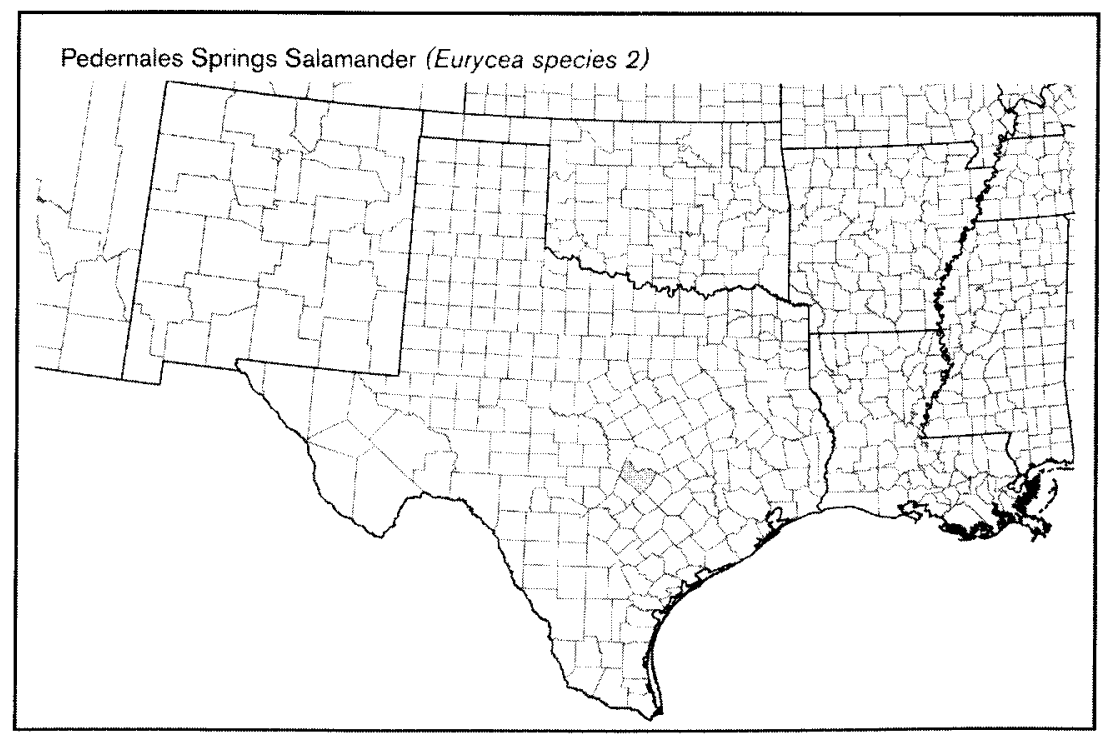


2. Historical versus Current Abundance.

May be common at spring outflows, but their distribution appears to be extremely limited and patchy.

\section{Life History Features.}

A. Breeding. Reproduction is aquatic.

i. Breeding migrations. Unlikely to occur.

ii. Breeding habitat. Probably the same as adult habitat.

B. Eggs.

i. Egg deposition sites. Unknown; some other central Texas Eurycea are thought to deposit eggs in gravel substrate.

ii. Clutch size. Unknown.

C. Larvae/Metamorphosis. This species is paedomorphic, and natural metamorphosis is unknown.

D. Juvenile Habitat. Probably the same as adult habitat.

E. Adult Habitat. Completely aquatic. These animals are known only from the immediate vicinity of spring outflows, under rocks and leaves and in gravel substrate. Water temperature in springs of the Edwards Plateau is relatively constant throughout the year and typically ranges from $18-20^{\circ} \mathrm{C}$ or slightly warmer near the fault zone at the Plateau's edge (Sweet, 1982). Sweet (1982) provided a comprehensive distributional analysis of the central Texas Eurycea and discussed hydrogeology of the region in relation to salamander distribution.

F. Home Range Size. Unknown.

G. Territories. Unknown.

H. Aestivation/Avoiding Desiccation. Unknown.

I. Seasonal Migrations. Unlikely to occur.

J. Torpor (Hibernation). Probably active throughout the year.

K. Interspecific Associations/Exclusions. Unknown.

L. Age/Size at Reproductive Maturity. Unknown, but Chippindale et al. (2000) noted that this species may mature at a slightly smaller size compared with other spring-dwelling central Texas Eurycea.

M. Longevity. Unknown.

N. Feeding Behavior. Prey probably consists mainly of small aquatic invertebrates, but no feeding studies of this species have been conducted.

O. Predators. Unknown.

P. Anti-Predator Mechanisms. Secretive.

Q. Diseases. Unknown.

R. Parasites. Unknown.

\section{Conservation.}

Pedernales Springs salamanders are a putative species first found in two springs near the Pedernales River in extreme western Travis County, Texas. They may be common at spring outflows, but their distribution appears to be extremely limited and patchy.
Gyrinophilus gulolineatus Brandon,

1965(a)

BERRY CAVE SALAMANDER

Christopher K. Beachy

1. Historical versus Current Distribution.

Berry Cave salamanders (Gyrinophilus gulolineatus) were originally a subspecies of Tennessee cave salamanders (G. palleucus). Collins (1991) suggested their elevation to species status based on allopatry and substantial morphometric differentiation (e.g., unique throat stripe, large size, and fewer trunk vertebrae in G. gulolineatus [Brandon, 1965a]) compared to other members of the G. palleucus complex. ii. Breeding habitat. Berry Cave salamanders most likely breed in the caverns and passages they occupy.

B. Eggs.

i. Egg deposition sites. Microhabitat characteristics of egg deposition sites are unknown. Extending what is known about egg deposition sites in spring salamanders (G. porphyriticus), clutches will be attached as a single mass to the undersides of large stones.

ii. Clutch size. Unknown. However, a large clutch size (compared to other species of Gyrinophilus) is predicted, based on well-established relationships between salamander body size and clutch size (Kaplan and Salthe, 1979).

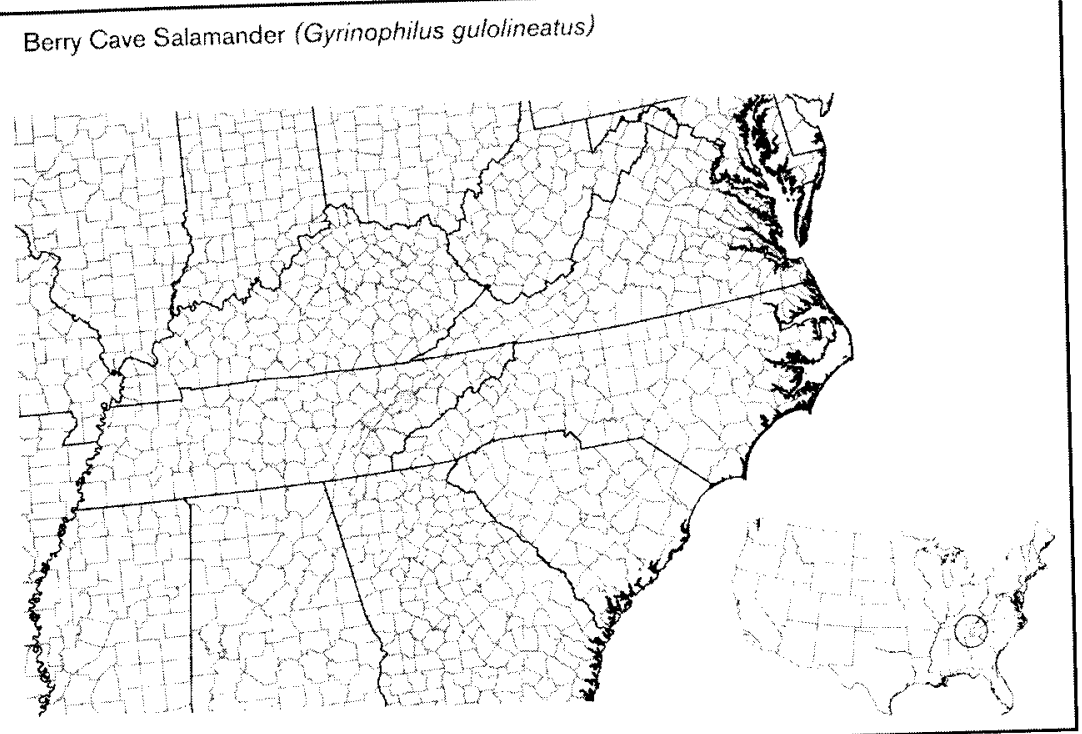

Berry Cave salamanders are known only from sites in the Ridge and Valley Province in Knox, McMinn, and Roane counties, Tennessee (Brandon, 1965a, 1966c, 1967a; Petranka, 1998). The data necessary to compare current versus historical distributions have not been collected.

\section{Historical versus Current Abundance.}

Berry Cave salamander populations are declining (Caldwell and Copeland, 1992), likely due to above-ground habitat destruction and subsequent effects on water quality; and Caldwell and Copeland (1992) have suggested that Berry Cave salamanders should be given Endangered status.

\section{Life History Features.}

A. Breeding. No aspect of breeding has been observed. However, reproduction is undoubtedly aquatic, because Berry Cave salamanders are neotenic.

i. Breeding migrations. Unlikely. Given that Berry Cave salamanders are neotenic, breeding habitat is likely to be the same as, or a subset of, adult habitat.
C. Larvae/Metamorphosis.

i. Length of larval stage. Unknown. Berry transition from larvae to reproductive adults has not been documented.

ii. Larval requirements.

a. Food. Unknown, although presumably larvae feed on aquatic, primarily benthic, invertebrates that are small enough to ingest whole (see Brandon, 1967b).

$b$. Cover. Unknown.

iii. Larval polymorphisms. Unknown.

iv. Features of metamorphosis. Unknown.

v. Post-metamorphic migrations. Unlikely in these neotenic animals.

vi. Neoteny. Berry Cave salamanders are obligate neotenes (Brandon, 1965a, 1966c; Simmons, 1975)

D. Juvenile Habitat. Juveniles live in the same cave systems occupied by adults and are therefore likely to have similar habitat characteristics.

E. Adult Habitat. Berry Cave salamanders either inhabit, or are associated with, caves. Caldwell and Copeland (1992) suggest that inflow (sinkhole) caves versus outflow caves may provide the best Cave salamanders are neotenic and the 
habitat. Inflow caves provide a detritus base that appears to be necessary for Berry Cave salamanders.

F. Home Range Size. Unknown, but possibly extremely small. In mark-recapture studies, animals are found in exactly the same location (e.g., Simmons, 1975).

G. Territories. Unknown.

H. Aestivation/Avoiding Desiccation. Aestivation is unknown and unlikely.

I. Seasonal Migrations. Unknown but unlikely. Unstudied, but if they occur, migrations occur either within their cave system or from caves to the immediate vicinity of cave openings (where animals were first collected; Brandon, 1965a).

J. Torpor (Hibernation). Unknown and unlikely.

K. Interspecific Associations/Exclusions. Berry Cave salamanders are not syntopic with any other amphibian species.

L. Age/Size at Reproductive Maturity. Berry Cave Salamanders are extremely large plethodontids. The holotype is an apparently reproductively mature female measuring $122 \mathrm{~mm}$ SVL (preserved; Brandon, 1965a).

M. Longevity. Unknown.

N. Feeding Behavior. Berry Cave salamanders likely feed on isopods, annelids, and aquatic invertebrates, similar to other troglobitic Gyrinophilus (see Brandon, 1967b; Simmons, 1975, 1976). Individuals have larger heads than Tennessee cave salamanders. Brandon (1965a) suggests that this is a feeding specialization, noting that among salamanders the most highly modified snouts are found on the most highly specialized cave salamanders, and speculates that because cavedwelling salamanders tend to feed on bottom-dwelling invertebrates, a broad, spatulate snout may be effective in detecting and capturing food under dark conditions.

O. Predators. Unknown.

P. Anti-Predator Mechanisms. Unknown.

a. Diseases. Unknown.

R. Parasites. Brandon (1967b) noted intestinal parasites (e.g., nematodes, cestodes, and acanthocephalans) in closely related Tennessee cave salamanders.

\section{Conservation.}

Berry Cave salamanders are known only from sites in the Ridge and Valley Province in Knox, McMinn, and Roane counties, Tennessee. These populations are declining due to above-ground habitat destruction and subsequent effects on water quality. The Tennessee Wildlife Resources Agency (1994) has listed G. palleucus as Threatened; because $G$. gulolineatus was recognized as a subspecies of Tennessee cave salamanders at the time of listing and only occurs in Tennessee, the arguments for listing $G$. gulolineatus are equally valid. Caldwell and Copeland (1992) have suggested that Berry Cave salamanders should be given Endangered status.
Gyrinophilus palleucus McCrady, 1954 TENNESSEE CAVE SALAMANDER

Christopher K. Beachy

1. Historical versus Current Distribution. Tennessee cave salamanders (Gyrinophilus palleucus) exhibit a spotty distribution associated with cave systems throughout central Tennessee, northern Alabama, and northwestern Kentucky (Brandon, 1967a,b; Cooper, 1968; Cooper and Cooper, 1968; Redmond and Scott, 1996). Two subspecies of Tennessee Cave salamanders are recognized: Sinking Cove Cave salamanders (G. p. palleucus) and Big Mouth Cave salamanders ( $G$. p. necturoides). The current distribution of Tennessee cave salamanders is probably similar to the historical distribution-there is no evidence that populations have been lost.

winter (Simmons, 1975; see also Petranka, 1998).

ii. Breeding habitat. The sinkhole-type caves characteristic of adult habitats.

\section{B. Eggs.}

i. Egg deposition sites. Unknown. It is expected that eggs will be deposited in a manner similar to that of spring salamanders ( $G$. porphyriticus), that is attached to the undersides of large rocks. Ova (from one female) averaged $3.2 \mathrm{~mm}$ in diameter.

ii. Clutch size. Unknown. Clutch size/ SVL relationships for spring salamanders provide a basis for estimating clutch size in Tennessee cave salamanders (Bruce, 1972).

\section{Larvae/Metamorphosis}

Length of larval stage. Unusually long, which led to their genus name, which in Greek means "tadpole loving" (Brandon, 1967a). Naturally metamorphosed ani-

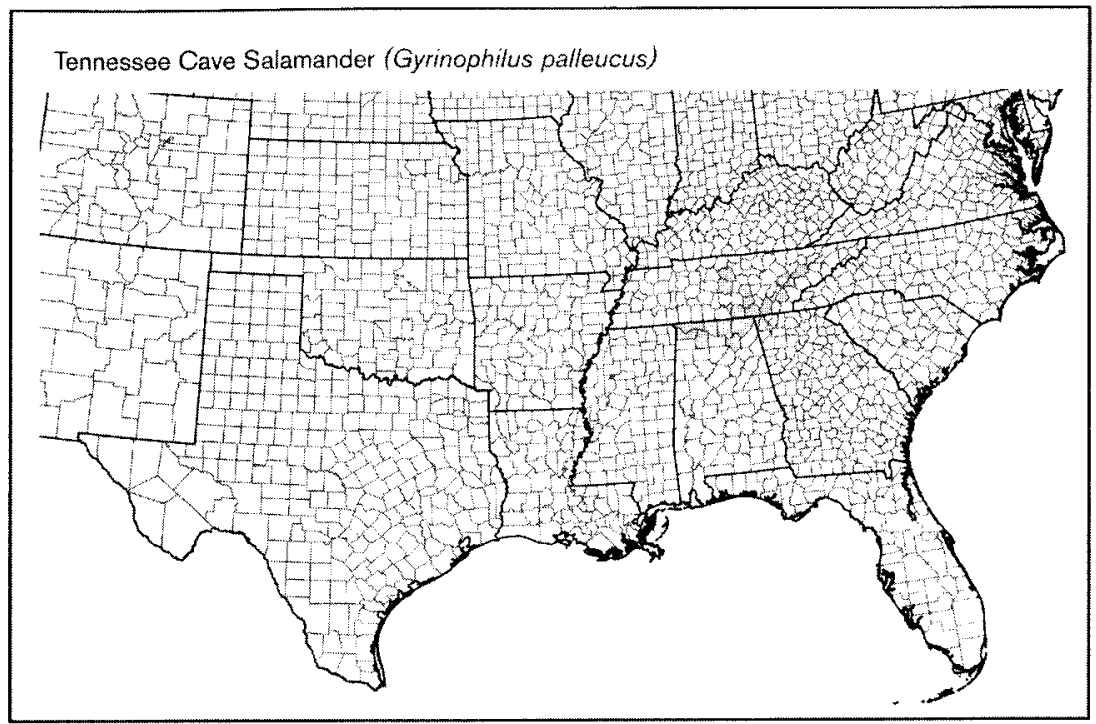

2. Historical versus Current Abundance. Petranka (1998) notes that population surveys rarely reveal $>10-20$ animals/ cave visit, suggesting that populations are small. Population estimates from various caves reveal sizes of $25,32,48$, and 88 animals, with densities ranging from $0.06-0.15$ animals $/ \mathrm{m}^{2}$. The abundance of animals in some populations has been affected by siltation and increased water flows associated with deforestation (see Petranka, 1998). Most populations appear to be declining (Simmons, 1975; Caldwell and Copeland, 1992; Redmond and Scott, 1996).

\section{Life History Features.}

A. Breeding.

i. Breeding migrations. Do not occur. The presence of males with spermatophores in August (Lazell and Brandon, 1962) and the occurrence of small hatchlings in caves in December-February suggest that females lay eggs in autumn or early mals have only rarely been found (e.g., Simmons, 1975, 1976; Yeatman and Miller, 1985); populations typically consist of only neotenic forms (Lazell and Brandon, 1962; Brandon, 1966c, 1967a; Simmons, 1975, 1976; Caldwell and Copeland, 1992).

ii. Larval requirements.

a. Food. Tennessee cave salamanders consume benthic invertebrates and are constrained primarily by gape limitations (Brandon, 1966c; Simmons, 1975).

b. Cover. Animals can be found under rocks. However, most animals are found by direct observation without removal of cover objects (see Simmons, 1975). It is likely that cover is not used. Simmons (1975) describes the "disconcerting" habit of Tennessee cave salamanders to be found in exactly the same spot as months earlier.

iii. Larval polymorphisms. Unknown.

iv. Features of metamorphosis. Metamorphosis does not occur in Tennessee cave 
salamanders. Animals can be stimulated to metamorphose with thyroxin treatment (Dent and Kirby-Smith, 1963), and animals occasionally will metamorphose after collection and transport to the laboratory.

v. Post-metamorphic migrations. Unlikely.

vi. Neoteny. Most populations of Tennessee cave salamanders consist of only neotenic animals. Naturally metamorphosed specimens are found occasionally (e.g., Simmons, 1975, 1976; Yeatman and Miller, 1985).

D. Juvenile Habitat. Juvenile habitats are the same as adults.

E. Adult Habitat. Tennessee cave salamanders are found in sinkhole-type caves or phreatic cave systems in the vicinity of sinkholes. This association is due to the nutrients that flow into these systems and the prey base they support. Caldwell and Copeland (1992) suggest that inflow (sinkhole) caves versus outflow caves may provide the best habitat. Animals are found under rocks in rocky and sandy substrates in quiet, shallow pools (McCrady, 1954; Simmons, 1975; see also Petranka, 1998).

F. Home Range Size. Petranka (1998) notes that individuals are highly sedentary, rarely moving $>3-4 \mathrm{~m}$ between surveys, with many individuals repeatedly found in the same locations (Simmons, 1975).

G. Territories. Unknown.

H. Aestivation/Avoiding Desiccation. Unknown and unlikely.

I. Seasonal Migrations. Unknown and unlikely.

J. Torpor (Hibernation). Unknown.

K. Interspecific Associations/Exclusions. There are no other amphibian species in habitats where Tennessee cave salamanders are found.

L. Age/Size at Reproductive Maturity. Growth rates are slow, and animals may be larvae for many years (Brandon, 1967a,b; Petranka, 1998). Males reach sexual maturity at $66 \mathrm{~mm}$ SVL (Petranka, 1998); in Sinking Cove cave salamanders, size at sexual maturity is $70-100 \mathrm{~mm}$ SVI (Brandon, 1967b). The inner contour of the vent is sexually dimorphic (Brandon, 1967a).

M. Longevity. Unknown.

N. Feeding Behavior. Tennessee cave salamanders feed on invertebrates and conspecifics. Invertebrates include amphipods, annelids (oligochaetes and earthworms), cladoceran zooplankton, crayfish, and insects such as coleopterans, plecopterans, ephemeropterans, trichopterans, dipterans (chironomid larvae), and thrips. The invertebrate (potential prey) fauna associated with caves has been described by Cooper and Cooper (1968).

o. Predators. Known predators include conspecifics (Lazell and Brandon, 1962; Simmons, 1975) and American bullfrogs (Rana catesbeiana), which can inhabit the mouths of cave entrances (Lee, 1969b). Petranka (1998) suspects that crayfish feed on small larvae.

P. Anti-Predator Mechanisms. Being troglobytic assists in the avoidance of most amphibian predators.

Q. Diseases. Unknown.

R. Parasites. Unknown.

\section{Conservation.}

The current distribution of Tennessee cave salamanders probably is similar to the historical distribution, although populations have been affected by the indirect effects of deforestation and most appear to be declining. Petranka (1998) makes a plea for conservation through water quality and protective land management initiatives. The Tennessee Wildlife Resources Agency (1994; see also www.state.tn.us) has listed Tennessee cave salamanders as Threatened. Although the U.S. Fish and Wildlife Service (1994c) listed Tennessee cave salamanders as a Category 2 candidate for federal listing, they were not included in a more recent federal list (USFWS, 1996a).

Gyrinophilus porphyriticus (Green, 1827) SPRING SALAMANDER

Christopher K. Beachy

1. Historical versus Current Distribution. Spring salamanders (Gyrinophilus porphyriticus) range from the middle of Maine southwest along the Appalachian spine (Dunn, 1926; Brandon, 1967c; French, 1976; Petranka, 1998). Brandon (1966c) recognized four subspecies. Northern spring salamanders ( $G$.p. porphyriticus) are found throughout most of New Eng land, New York, and Pennsylvania, and in portions of Ohio, West Virginia, Virginia, Tennessee, North Carolina, Georgia, Alabama, and extreme northwestern Mississippi (Engelhardt, 1919; Warfel, 1937; Fowler and Sutcliffe, 1952; Thurow, 1954;
Brandon, 1966c; Graham, 1981; Graham and Stevens, 1982; Lazell and Raithel, 1986; Petranka, 1998). A disjunct population occurs near Cincinnati in southwestern Ohio. Kentucky spring salamanders (G. p. duryi) are found in western West Virginia, northeastern Kentucky, and southcentral Ohio (Brandon, 1967c; Petranka, 1998), with a single record documented in Tazewell County, Virginia (Newman, 1954a). Carolina spring salamanders ( $G$. $p$. dunni) are found in southwestern North Carolina, northwestern South Carolina, northern Georgia, and northeastern Alabama (Brandon, 1966c, 1967c). Blue Ridge spring salamanders ( $G$. p. danielsi) occur in extreme western North Carolina (Brandon, 1966c, 1967c).

The range of the species apparently is the same currently (Petranka, 1998) as when Dunn (1926) first summarized the range of spring salamanders. It is probable that $G$. porphyriticus consists of several cryptic species. Southern Appalachian populations exhibit significant life history variation, morphometric differentiation, and ethological isolation among parapatric populations (Bruce, 1972, 1978; Beachy, 1996; Adams and Beachy, 2001).

Petranka (1998) notes that deforestation is a threat to many populations of spring salamanders.

2. Historical versus Current Abundance.

Spring salamanders are well known for being difficult to find. Repeated trips to classic salamander localities usually results in finding one or two spring salamanders, but often none at all (Bruce, 1972a, 1978a; Beachy, 1996). The habitat (see "Adult Habitat" below) simply proves difficult to penetrate, and the salamanders that are obtained seem to be the occasional animals that are active on the surface. Current densities seem in line with historical densities. This means that in most of their range, spring salamanders have always been difficult to obtain.

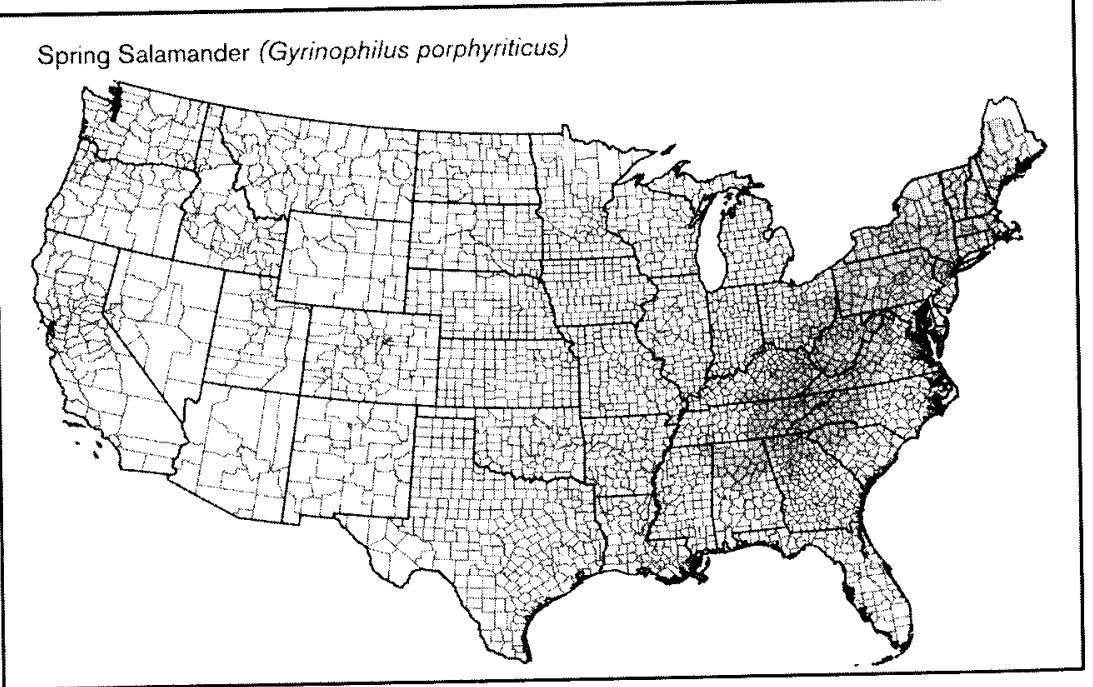

